\author{
Universidade de São Paulo \\ Escola Superior de Agricultura "Luiz de Queiroz" \\ Centro de Energia Nuclear na Agricultura
}

\title{
Distribuição e abundância de anfíbios e répteis neotropicais em paisagem silvicultural em São Paulo, Brasil
}

\author{
Paula Caroline Lopes
}

Dissertação apresentada para obtenção do título de Mestre em Ciências. Área de concentração: Ecologia Aplicada

Piracicaba 


\title{
Paula Caroline Lopes \\ Bióloga
}

\section{Distribuição e abundância de anfíbios e répteis neotropicais em paisagem silvicultural em} São Paulo, Brasil

\author{
Orientador: \\ Prof. Dr. LUCIANO MARTINS VERDADE \\ Co-orientador: \\ Prof. Dr. CÉLIO FERNANDO BAPTISTA HADDAD
}

Dissertação apresentada para obtenção do título de Mestre em Ciências. Área de concentração: Ecologia Aplicada

\section{Piracicaba}


Dados Internacionais de Catalogação na Publicação DIVISÃO DE BIBLIOTECA E DOCUMENTAÇÃO - ESALQ/USP

Lopes, Paula Caroline

Distribuição e abundância de anfíbios e répteis neotropicais em paisagem silvicultural em São Paulo, Brasil / Paula Caroline Lopes. - - Piracicaba, 2010.

76 p. : il.

Dissertação (Mestrado) - - Escola Superior de Agricultura "Luiz de Queiroz", 2010.

Bibliografia.

1. Anfíbios 2. Biodiversidade 3. Eucalipto 4. Répteis 5. Silvicultura I. Título

CDD 634.9734

L864d

"Permitida a cópia total ou parcial deste documento, desde que citada a fonte - O autor" 
Dedico este trabalho a minha família, especialmente às minhas avós, que sempre me apoiaram em todas as minhas escolhas. 


\section{AGRADECIMENTOS}

Este trabalho só foi possível com a ajuda de diversas pessoas. Assim, espero agradecer a todos que colaboraram para sua realização.

Ao Luciano Martins Verdade, pela orientação em todas as fases do projeto, pela experiência a mim transmitida e pela sua amizade;

Aos funcionários da Fazenda Três Lagoas (Ilson, Bete, Nê, Sonia e Tiririca), pelo apoio durante todo o trabalho de campo;

À minha querida amiga Paula Sanches Martin, pela companhia e amizade durante todo o campo e também fora dele nas mais diversas situações do nosso convívio, inclusive pelas estadias em São Paulo;

À Carla Gheler-Costa, pela enorme ajuda ao trabalho em campo e às análises dos dados;

Ao pessoal do Projeto Temático que acompanhou direta e indiretamente as campanhas de coleta em Angatuba (Thiago, Sabrina, Marina, Jaime, Ana Paula, Cristiane, Stefania, Bruno, Adriane, Thaís e Fabrício);

Aos amigos José Wagner Ribeiro Júnior e Ricardo A. Brassaloti, que me mostraram os caminhos da herpetologia e me ajudaram com discussões e análises, fazendo-me entender um pouco mais sobre esses lindos animaizinhos;

Ao Eduardo A. Athayde, pelas informações sobre a flora local;

Ao Célio Haddad, pela co-orientação e pela ajuda com os anfíbios;

À Giovanna G. Montingelli, pelo apoio na identificação das serpentes;

À FAPESP, pelo financiamento do Projeto Temático de que este estudo fez parte e pela bolsa de mestrado a mim concedida;

Ao pessoal do Laboratório de Ecologia Animal, pela intensa convivência e discussões sobre os mais diversos assuntos;

Ao IPEF, Conpacel S/A, Fazenda Três Lagoas, Eucatex S/A, Fazenda Arca e Soma Agropecuária, pelo apoio logístico e operacional ao projeto;

Ao Programa de Pesquisa em Biodiversidade do Ministério de Ciência e Tecnologia, pela iniciativa em propor a sistematização amostral em levantamentos multi-taxa;

A todos que, como mencionei acima, de uma forma ou de outra, ajudaram-me a conduzir este estudo e, principalmente, pelo conhecimento por ele gerado. 


\section{SUMÁRIO}

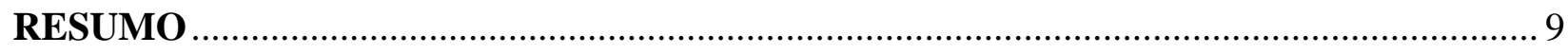

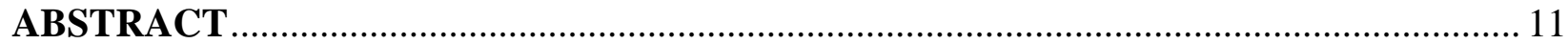

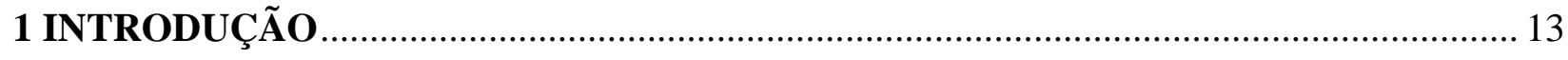

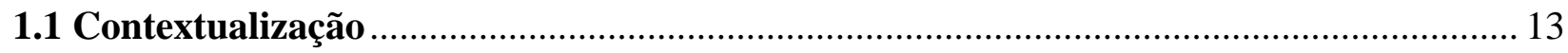

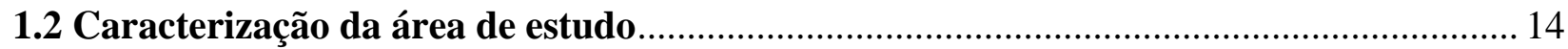

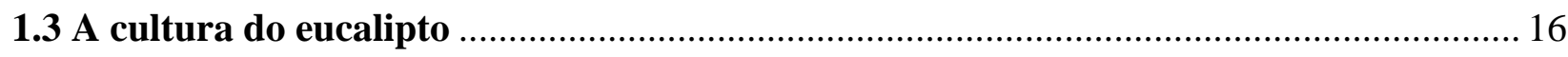

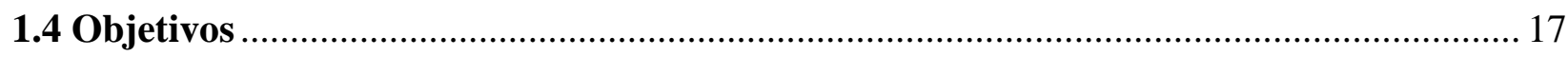

2 PADRÃO ESPAÇO-TEMPORAL DE DISTRIBUIÇÃo E ABUNDÂNCIA DE ANFÍBIOS E RÉPTEIS NEOTROPICAIS EM PAISAGEM SILVICULTURAL ............. 21

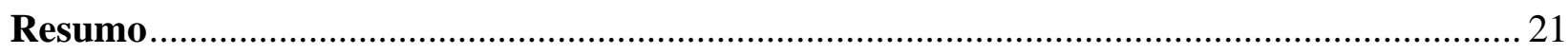

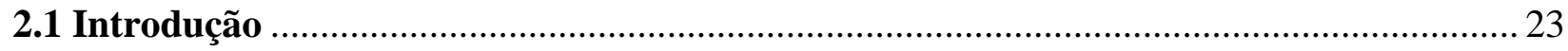

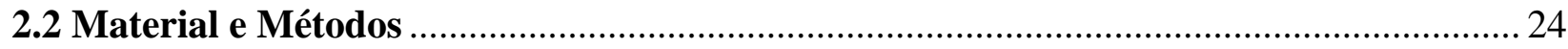

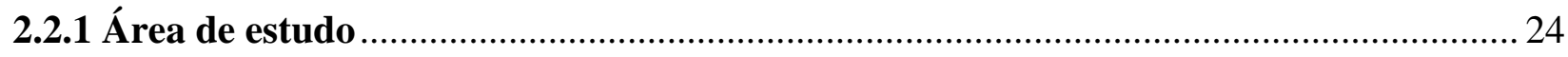

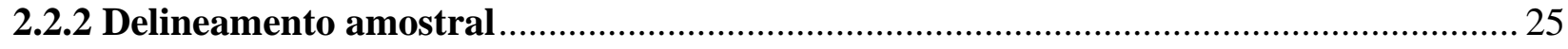

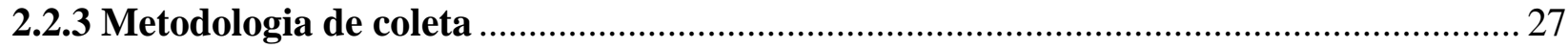

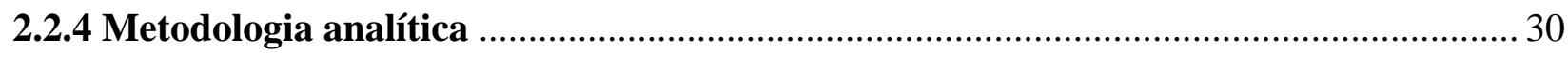

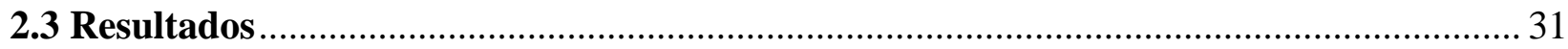

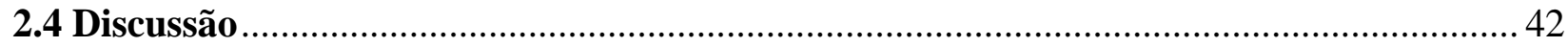

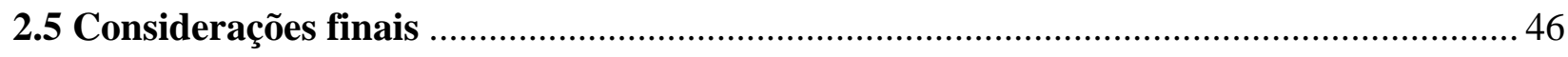

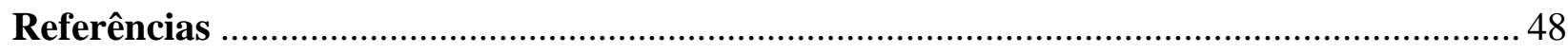

3 PADRÃO ESPAÇO-TEMPORAL DE DISTRIBUIÇÃO E ABUNDÂNCIA DE ANFÍBIOS NEOTROPICAIS EM PLANTAÇÕES DE EUCALIPTO (Eucalyptus spp.) .... 57

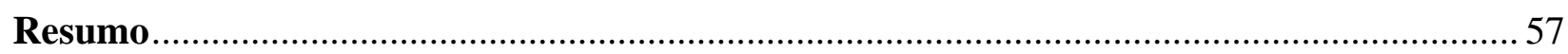

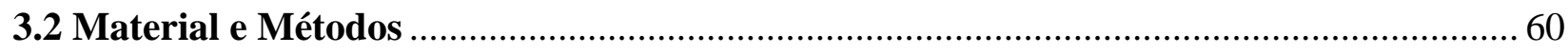

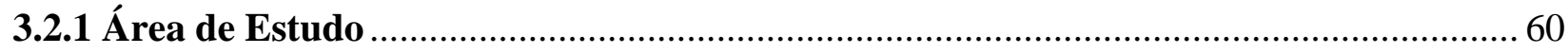

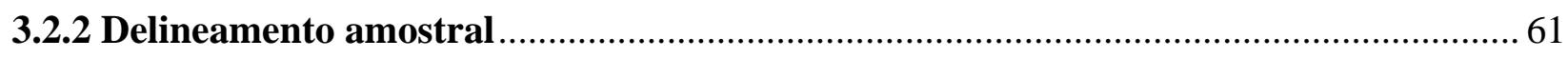

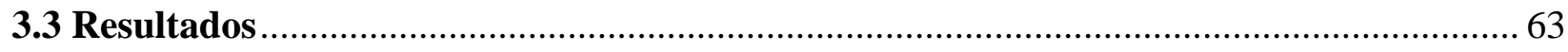

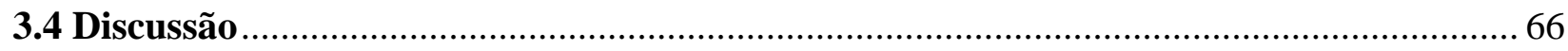

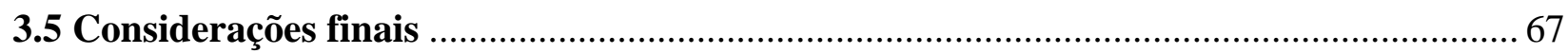




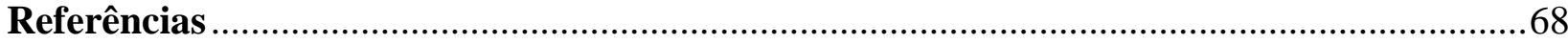

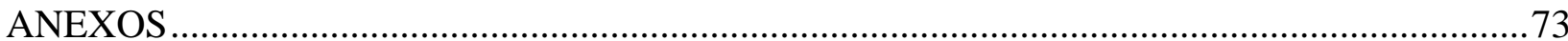




\section{RESUMO \\ Distribuição e abundância de anfíbios e répteis neotropicais em paisagem silvicultural em São Paulo, Brasil}

A maioria dos estudos sobre biodiversidade realizados no Brasil é desenvolvida em remanescentes de vegetação nativa. Entretanto, estudos recentes sugerem que paisagens agrícolas suportam uma considerável biodiversidade. O estado de São Paulo, região sudeste do Brasil, apresenta extensas áreas de pastagens, ainda sendo este o seu principal uso de solo, seguido por canaviais e eucaliptais. Este estudo foi desenvolvido nas Fazendas Três Lagoas e Arca, localizadas na bacia do Alto Paranapanema. A área inicialmente utilizada como pastagem (Brachiaria spp.) foi parcialmente substituída por plantações de eucalipto durante o período de agosto de 2006 a fevereiro de 2008. Neste estudo foram levantados anfíbios e répteis em 30 unidades amostrais contendo armadilhas de interceptação e queda distando um quilômetro uma das outras. Foram amostrados três ambientes distintos: eucaliptal (18 unidades amostrais), vegetação nativa (7 unidades amostrais) e pastos abandonados (5 unidades amostrais), resultando num esforço total de 4.977 armadilhas dia em 23 campanhas mensais, entre agosto de 2007 e julho de 2009. Para análises dos dados foram consideradas como variável independente os ambientes (eucaliptais, pastos abandonados e vegetação nativa) e como variáveis dependentes a riqueza e abundância de anfíbios coletados nas armadilhas. Foram detectadas nas armadilhas 23 espécies, sendo 18 de anfíbios anuros (13 nos eucaliptais, 11 nos pastos abandonados e 10 na vegetação nativa) e cinco de répteis (três nos eucaliptais, três nos pastos abandonados e três na vegetação nativa). Surpreendentemente, a vegetação nativa apresentou menor riqueza de espécies que o eucaliptal e o pasto abandonado, possivelmente em função de seu precário estado de conservação. Esta relação foi marginalmente significativa para abundância. A distribuição temporal das espécies foi heterogênea, concentrando os encontros na época quente e chuvosa. Adicionalmente, foram complementadas as listas de espécies por meio de busca ativa e encontros ocasionais, totalizando assim 49 espécies para a área de estudo, sendo 31 de anfíbios e 18 de répteis. Nos eucaliptais, a distância em relação ao corpo d'água e vegetação nativa mais próximos não tiveram influência na distribuição das espécies. Os resultados obtidos, aliados ao atual contexto alteração do uso da terra, demonstram que as paisagens silviculturais, cuja matriz são eucaliptais, podem ter um razoável valor conservacionista.

Palavras-chave: Anfíbios; Répteis; Eucalipto; Paisagem silvicultural; Herpetofauna 


\title{
ABSTRACT \\ Distribution and abundance of neotropical amphibians and reptiles in silvicultural landscape in Sao Paulo, Brazil
}

\begin{abstract}
Most studies on biodiversity conducted in Brazil are accomplished in remnants of native vegetation. However, recent studies suggest that agricultural landscapes support a considerable biodiversity. The state of São Paulo, southeastern Brazil, has extensive grassland areas which is still its primary land use, followed by sugar cane crops and eucalyptus forests. The present study was conducted in Três Lagoas and Arca farms, located in the Upper Paranapanema basin. The area originally used as pasture (Brachiaria spp.) was partially replaced by eucalyptus plantations from August 2006 to February 2008. During the present study amphibians and reptiles were surveyed in 30 sampling units containing pitfall traps one kilometer apart from each other. Three different environments were sampled: eucalyptus forest (18 sampling units), native vegetation (seven sampling units) and abandoned pastures (five sampling units), resulting in a total effort of 4977 trap-days in 23 monthly campaigns between August 2007 and July 2009. Concerning data analysis the environments (eucalyptus, abandoned pastures and native vegetation) were considered as independent variable and as dependent variables richness and abundance of trapped amphibians and reptiles. 23 species were detected in traps, 18 amphibians (13 in eucalyptus, 11 in abandoned pastures and 10 in native vegetation) and five reptiles (three in eucalyptus, three in abandoned pastures and three in native vegetation). Surprisingly, native vegetation environment presented lower species richness than plantation and abandoned pasture environments, possibly due to its precarious conservation condition. This relationship was marginally significant for abundance. The temporal distribution of species was heterogeneous, concentrating the encounters during the hot and rainy season. Additionally, the lists of species were supplemented through active search and occasional encounters, totaling 49 species for the study area (31 amphibians and 18 reptiles). In eucalypt plantations, the distance from water body and closest native vegetation did not influence the distribution of species. The results coupled with the current context of land use change, demonstrate that silvicultural landscapes, whose matrix are eucalyptus forests may have a reasonable conservation value.
\end{abstract}

Keywords: Amphibians; Reptiles; Eucalyptus; Silvicultural landscape; Herpetofauna 


\section{INTRODUÇÃO}

\subsection{Contextualização}

O desenvolvimento do Estado de São Paulo ocasionou profundas alterações em sua vegetação. A agropecuária e a agroindústria são as atividades antrópicas que mais impactaram os ambientes naturais, causando desequilíbrio nos diversos ecossistemas existentes (CHIARELLO, 2000). A modernização da agricultura, aliada ao processo de expansão da fronteira agrícola e da pecuária sobre a Mata Atlântica e o Cerrado tiveram como fator característico a efetiva participação do Estado (SILVA, 2001). A pecuária brasileira desenvolveu-se por expansão da fronteira agrícola, incorporando ao sistema extensivo de produção novas áreas, em regiões desprovidas de infra-estrutura, e pela utilização de terras esgotadas pela produção de grãos (VEIGA et al., 2004). No entanto, áreas originalmente ocupadas por pecuária extensiva têm sido na ultima década substituídas por cana-de-açúcar e silvicultura de eucalipto, mais rentáveis, ocupando principalmente áreas de baixa produtividade da região centro sul e leste do estado (KRONKA et al., 2003).

O Estado de São Paulo apresenta uma extensa área de plantios de Eucalyptus spp. em áreas anteriormente ocupadas por florestas nativas e agropecuária (OLIVEIRA, 2004; PEREIRASILVA et al., 2004). O plantio de eucalipto cresceu cerca de $120 \%$ nos últimos quatro anos, sendo no município de Angatuba cultivados 1,5\% do eucalipto de todo o estado, chegando atualmente a mais de 12 mil hectares (SÃO PAULO, 2008). As florestas plantadas com Eucalyptus spp. representam cerca de $65,4 \%$ dos reflorestamentos brasileiros. É comum que estes plantios estejam em contato direto com remanescentes florestais ou envolvendo fragmentos (OLIVEIRA, 2004).

Fatores resultantes da fragmentação de habitats apresentam relações com fenômenos biológicos que afetam a natalidade e a mortalidade de plantas como, por exemplo, o efeito de borda, a deriva genética e as interações entre plantas e animais (CHIARELLO, 2000). Viana e Pinheiro (1998) concluíram que áreas vizinhas a pastagens estavam sujeitas a um efeito de borda mais intenso e que atividades de reflorestamento e/ou o uso de sistemas agroflorestais são favoráveis para atenuar este efeito. Os efeitos das modificações nos ambientes originais das espécies e sua adaptabilidade a ambientes alterados são ainda pouco conhecidos para a maioria das espécies da herpetofauna. É importante compreender que diferentes espécies apresentam diferentes respostas às modificações no ambiente. 
A conservação da vida silvestre baseia-se no conhecimento dos processos (ou interações) e mecanismos que afetem a distribuição e abundância das espécies. Entretanto, a atual importância sócio-econômica (e cultural) da agricultura no mínimo se equipara à da conservação dos recursos naturais. Por esta razão, os atuais inventários de fauna e programas de conservação deveriam considerar não apenas os ecossistemas primitivos ou pouco alterados, mas também ambientes urbanos e agroecossistemas.

A riqueza de espécies e os padrões de distribuição e abundância encontrados para outros grupos de vertebrados sugerem que áreas de silvicultura podem suportar uma razoável diversidade (OLIVEIRA, 2004). Os esforços devem incluir o combate à monocultura e a preservação de fragmentos florestais nativos entremeados às áreas de plantio de eucalipto, incluindo estudos sobre a minimização do impacto das diversas técnicas de manejo silvicultural (OLIVEIRA, 2004). Em áreas de silvicultura, os estudos são apresentados em forma de consultorias ambientais para empreendimentos (Estudos de Impacto Ambiental - EIA) ou manuscritos acadêmicos (dissertações de mestrado e teses de doutorado), não sendo de conhecimento de toda comunidade acadêmica devido a não publicação destes resultados em periódicos de razoável circulação (OLIVEIRA, 2004; ARAÚJO; CONDEZ; SAWAYA, 2009).

Os anfíbios são considerados bons indicadores biológicos por serem particularmente sensíveis a algumas alterações ambientais, pois derivam de uma combinação de atributos morfológicos, fisiológicos e comportamentais, adaptados a certas condições ambientais (DUELLMAN; TRUEB, 1986). Estes fatores colaboram para demonstrar a sensibilidade dos anfíbios às mudanças ambientais. Entre os répteis, as espécies florestais são mais vulneráveis por serem incapazes de suportar as altas temperaturas das formações abertas (RODRIGUES, 2005). Assim, espécies de savana e de formações abertas tendem a ser mais persistentes a alterações ambientais, mas mesmo assim muitas desaparecerão se seus habitats forem destruídos.

\subsection{Caracterização da área de estudo}

As Fazendas Três Lagoas e Arca estão localizadas na região centro-sul do Estado de São Paulo, município de Angatuba. Cerca de 3.000 ha das fazendas foram desmatados para implantação de pastagens exóticas para criação de gado no início da década de 1970. Nesse processo milhares de árvores foram deixadas no pasto para sombreamento do gado. No entanto, desde então houve extração seletiva de madeira nas áreas remanescentes de vegetação nativa. A 
área total da primeira é de 3.209,93 ha. A matriz original, predominantemente constituída de 2.590 ha de pastagem exótica (Brachiaria spp.), foi substituída parcialmente por plantações de eucalipto (2.223,9 ha) entre agosto de 2006 e dezembro de 2007, ampliando a Reserva Legal (RL) da fazenda para 586,52 ha e a Área de Preservação Permanente (APP) para 269,23 ha. A área total da segunda é de 1.122,77 ha, sendo 721,9 ha de plantio de eucalipto, 66,6 ha de Área de Preservação Permanente e 293,98 ha de Reserva Legal. Entre agosto de 2006 e fevereiro de 2008, parte das áreas de pastagem foram substituídas por plantações de eucalipto, e o restante da área de pastagem foi abandonada para revegetação, compondo assim as Áreas de Preservação Permanente e Reserva Legal.

As áreas de vegetação nativa são compostas de cerrado, sendo o cerradão a fitofisionomia predominante, sucedida por áreas de vegetação aberta de cerrado sensu stricto. Neste encontramos espécies vegetais típicas como Anadenanthera falcata, Caryocar brasiliensis, Dimorphandra mollis, Stryphynodendron adstringens e Roupala brasiliensis, sendo estas espécies paulatinamente substituídas nas áreas de cerradão por espécies da família Melastomataceae, Rubiaceae, Annonaceae e Myrtaceae. No cerradão aparecem espécies como Xylopia brasiliensis, Miconia chatacea, Tapirira guianensis, Amaioua guianensis, Siparuna guianensis, Persea pyrifolia, sendo as espécies vegetais dominantes. Associadas a essas espécies, estão a Copaifera langsdorffii, Pera obovata, Machaerium villosum e Miconia spp. que são espécies vegetais abundantes em toda a área da fazenda.

Seguindo os cursos d'água da fazenda encontram-se as matas ciliares ou matas de galeria. Nesta fitofisionomia aparecem espécies resistentes à inundação como Calophyllum brasiliense, e espécies abundantes neste tipo vegetacional como Nectandra megapotamica, Sorocea bonplandii, Gymnanthes concolor, Bauhinia sp., Croton floribundus e Piptocarpha gonoacantha, sendo as espécies dominantes nessas áreas. Ainda aparecem pequenas manchas de áreas permanentemente alagadas com uma rica vegetação aquática com espécies das famílias Pontederiaceae, Juncaceae, Araceae, Ranunculaceae e outras.

Nas áreas de vegetação em regeneração recente, consideradas como Áreas de Preservação Permanente e Reserva Legal, os pastos abandonados transformaram-se em capoeiras. Nestas áreas de regeneração podemos observar diferentes fases de sucessão, desde áreas dominadas por gramíneas e Pteridium aquilinum até áreas em fase de sucessão mais avançada com plantas 
lenhosas e/ou sublenhosas espaçadas, predominando espécies das famílias Fabaceae, Solanaceae, Verbenaceae, Asteraceae e Melastomataceae.

Poucos esforços visando identificar possíveis influências das plantações de eucalipto na distribuição de anfíbios e répteis foram realizados, principalmente no processo de implantação desta cultura. Acredita-se que para um manejo adequado destas novas plantações seja necessário conhecer a distribuição espaço-temporal das espécies. O conhecimento sobre os impactos que tal mudança no uso da terra tem sobre a fauna local é praticamente inexistente. O presente estudo situa-se nesse contexto.

\subsection{A cultura do eucalipto}

O eucalipto é uma espécie arbórea pertencente à família das Mirtáceas, nativa da Austrália e de outras ilhas da Oceania. O eucalipto é plantado, atualmente, em quase todo o mundo, por possuir mais de 670 espécies adaptáveis a várias condições de clima $\left(-15\right.$ a $\left.35^{\circ} \mathrm{C}\right)$ e solo. A maioria das espécies plantadas no Brasil apresenta um crescimento rápido e produz grande quantidade de madeira, papel e celulose, podendo algumas espécies ser utilizadas como mourões para cerca, pontaletes para construção civil, postes, lenha e carvão.

Inicialmente é necessária a produção de mudas em viveiros. As sementes são plantadas em sacos plásticos ou tubetes, adubadas e irrigadas, sendo as mudas transportadas até o local de plantio após atingirem cerca de $30 \mathrm{~cm}$ de altura. Antes do plantio, é necessário remover os ninhos de formigas com iscas a fim de evitar a perda de mudas. O cultivo do eucalipto é racionalizado, com o emprego de máquinas para preparação dos solos, controle de ervas invasoras e insetos predadores (EMBRAPA, 2003).

Os locais de aceiros e carreadores internos são planejados antecipadamente. Os aceiros devem ter no mínimo $6 \mathrm{~m}$ de largura em todo o perímetro da área de plantio, facilitando a prevenção e combate a incêndios. Os carreadores internos em áreas inclinadas deverão ser traçados em sentido suave, cortando as águas, de modo a não serem prejudicados pela erosão. $\mathrm{O}$ espaçamento recomendado é de $3 \mathrm{~m} \mathrm{x} 2 \mathrm{~m}$, totalizando $6 \mathrm{~m}^{2}$ por árvore, e 1.666 plantas por hectare (EMBRAPA, 2003). O corte do eucalipto é feito de forma mecanizada na operação de baldeio, retirada da madeira da área de corte e empilhamento em locais mais abertos para que sejam transportadas para caminhões. 
A produtividade florestal das plantações cresceu de cerca de $14 \mathrm{~m}^{3} /$ hectare/ano em 1990 a $30 \mathrm{~m}^{3} / \mathrm{ha} /$ ano atualmente. As projeções feitas para os plantios atuais são de cerca de $38 \mathrm{~m}^{3} / \mathrm{h} / \mathrm{ano}$ (SBS, 2007). A atividade florestal exige rotações mais longas que as demais atividades agropecuárias. $\mathrm{O}$ corte do eucalipto para industrialização ocorre normalmente aos 7 anos de idade, num regime que permite até 3 rotações sucessivas e econômicas, com ciclo final de até 21 anos (EMBRAPA, 2003).

\subsection{Objetivos}

Poucos estudos enfocam a distribuição, os padrões ecológicos e a utilização pela fauna de ambientes alterados por ação antrópica. Avaliar o impacto dessas mudanças em relação a processos de sucessão ecológica e/ou sazonalidade na abundância da herpetofauna são relevantes para conhecer as mudanças ocasionadas quando há mudança no uso da terra. Nesse contexto, este estudo apresentou como objetivos gerais:

a) Detectar a variação temporal dos padrões de distribuição e abundância de anfíbios e répteis em paisagem silvicultural;

b) Identificar a distribuição e abundância espaço-temporal de anfíbios e répteis em uma plantação de eucalipto recente ( 0 a 3 anos) e,

c) Detectar a possível influência da proximidade de corpos d'água e remanescentes de vegetação nativa na distribuição e abundância de anfíbios nas plantações recentes de eucalipto (0 a 3 anos) que substituíram uma área de pastagem.

Os objetivos específicos e os resultados obtidos são apresentados nos dois capítulos, a seguir:

a) Padrão espaço-temporal de distribuição e abundância de anfíbios e répteis neotropicais em paisagem silvicultural;

b) Padrão espaço-temporal de distribuição e abundância de anfíbios neotropicais em plantações de eucalipto (Eucalyptus spp.). 
Estes estudos estão inseridos no projeto temático "Mudanças Socioambientais no Estado de São Paulo e Perspectivas para a Conservação" (FAPESP Proc. N 2006/60954-4). Visando a área de extensão acadêmica, esta sendo elaborado um guia de anfíbios e répteis para a área de estudo, sendo apresentada neste documento uma versão preliminar com as imagens das espécies que constarão nesse guia (ANEXO A). 


\section{Referências}

ARAÚJO, C.O.; CONDEZ, T.H.; SAWAYA, R.J.S. Anfíbios Anuros do Parque Estadual das Furnas do Bom Jesus, sudeste do Brasil, e suas relações com outras taxocenoses no Brasil. Biota Neotropica, São Paulo, v. 9, n. 2. jan.-mar. 2009. Disponível em: 〈htttp://Www.biotaneotropica. org.br/v9n2/pt/abstract? article+bn01309022009>. Acesso em: 05 maio 2009.

CHIARELLO, A.G.. Conservation value of a native forest fragment in a region of extensive agriculture. Brazilian Journal of Biology, São Carlos, v. 60, n. 2, p. 237-247, maio 2000.

DUELLMAN, W.E.; TRUEB, L. Biology of amphibians. New York, McGraw-Hill, 1986. 670p.

EMBRAPA. Florestas - Sistemas de Produção. Cultivo do eucalipto - Nutrição, adubação e calagem. 2003. Disponível em: $\langle$ http://sistemasdeproducao.cnptia.embrapa.br/FontesHTMLj Eucalipto/ CultivodoEucalipto/index.htm>. Acesso em: 10 abril 2010.

KRONKA, F.J.N.; NALON, M.A.; MATSUKUMA, C.K.; KANASHIRO, M.M.; YWANE, M.S.S.; LIMA, L.M.P.R.; GUILLAUMON, J.R.; BARRADAS, A.M.F.; PAVÃO, M.; MANETTI, L.A.; BORGO, S.C. 2003. Mapeamento e quantificação do reflorestamento no Estado de São Paulo. Disponível em: 〈htttp://www.sp.br.emb-japan.go.jp/1 portugues/img/simp_kronka.pdf>. Acesso em: 05 maio 2006.

OLIVEIRA, S.H. Diversidade de anuros de serapilheira em fragmentos de Floresta Atlântica e plantios de Eucaliptus saligna no Município de Pilar do Sul, SP. 2004. 60p. Dissertação (Mestrado em Ecologia Aplicada) - Escola Superior de Agricultura "Luiz de Queiroz", Universidade de São Paulo, Piracicaba, 2004. Disponível em: 〈http://www.saber.usp.bì >. Acesso em: 29 maio 2007.

PEREIRA-SILVA, E.F.L.; SANTOS, J.E.; KAGEYAMA, P.Y.; HARDT, E. Florística e fitossociologia dos estratos arbustivo e arbóreo de um remanescente de Cerradão em uma Unidade de Conservação do Estado de São Paulo. Revista Brasileira de Botânica, São Paulo, v. 27, n. 3, p. 533-544, jul.-set. 2004.

SÃO PAULO (Estado). Secretaria de Agricultura e Abastecimento. Coordenadoria de Assistência Técnica Integral. Instituto de Economia Agrícola. Levantamento censitário de unidades de produção agrícola do Estado de São Paulo - LUPA 2007/2008. São Paulo: SAA/CATI/IEA, 2008. Acesso em: 12 ago. 2009.

RODRIGUES, M.T. Conservação dos répteis brasileiros: os desafios para um país megadiverso. Megadiversidade, Belo Horizonte, v.1, n. 1, p. 87-94, jul. 2005. 
SBS. Sociedade Brasileira de Silvicultura. 2007. Disponível em: $\langle$ http:///www.sbs.org.brỳ. Acesso em: 28 mar.2010.

SILVA, L.L. O papel do Estado no processo de ocupação das áreas de cerrado entre as décadas de 60 e 80. 2001. Caminhos de Geografia, Uberlândia, v. 2, n. 2, p. 24-36, fev. 2001.

VIANA, V.M.; PINHEIRO, L.A.F.V. Conservação da biodiversidade em fragmentos florestais. Série Técnica IPEF, Piracicaba, v. 12, n. 32, p. 25-42, dez. 1998. 


\section{PADRÃO ESPAÇO-TEMPORAL DE DISTRIBUIÇÃO E ABUNDÂNCIA DE ANFÍBIOS E RÉPTEIS NEOTROPICAIS EM PAISAGEM SILVICULTURAL}

\section{Resumo}

A maioria dos estudos sobre biodiversidade realizados no Brasil é desenvolvida em remanescentes de vegetação nativa. Entretanto, estudos recentes sugerem que paisagens agrícolas suportam uma considerável biodiversidade. O estado de São Paulo, região sudeste do Brasil, apresenta extensas áreas de pastagens, sendo este ainda seu principal uso de solo, seguido por canaviais e eucaliptais. Este estudo foi desenvolvido nas Fazendas Três Lagoas e Arca, localizadas na bacia do Alto Paranapanema. As áreas inicialmente utilizadas como pastagem (Brachiaria spp.) foram substituídas por plantações de eucalipto entre agosto de 2006 e fevereiro de 2008, restando a partir disso cerca de 350 ha de pastos abandonados, incorporados à Reserva Legal e Áreas de Proteção Permanente. Neste estudo foram levantados anfíbios e répteis em 30 unidades amostrais contendo armadilhas de interceptação e queda distando um quilômetro uma das outras. Foram amostrados três ambientes distintos: eucaliptal (18 unidades amostrais), vegetação nativa ( 7 unidades amostrais) e pastos abandonados (5 unidades amostrais), resultando num esforço total de 4.977 armadilhas dia em 23 campanhas mensais, entre agosto de 2007 e julho de 2009. Para análises dos dados foram consideradas como variáveis independentes os ambientes (eucaliptais, pastos abandonados e vegetação nativa) e como variáveis dependentes a riqueza e abundância de anfíbios coletados nas armadilhas. Foram detectadas 23 espécies, sendo 18 de anfíbios anuros e cinco de répteis. Dentre os répteis, apenas uma serpente foi amostrada pelas armadilhas. Surpreendentemente, a vegetação nativa apresentou menor riqueza de espécies que o eucaliptal e o pasto abandonado, possivelmente em função de seu precário estado de conservação. Para abundância, a relação entre os ambientes foi marginalmente significativa. A distribuição temporal das espécies foi heterogênea, concentrando-se os encontros na época quente e chuvosa. Adicionalmente, foram complementadas as listas de espécies por meio de busca ativa e encontros ocasionais, totalizando assim 49 espécies para a área de estudo, sendo 31 de anfíbios e 18 de répteis. Os resultados obtidos, aliados ao atual contexto alteração do uso da terra, demonstram que as paisagens silviculturais, cuja matriz são eucaliptais, podem ter um razoável valor conservacionista.

Palavras-chave: Anura; Répteis; Eucalipto; Silvicultura 


\title{
SPACIAL-TEMPORAL PATTERN OF DISTRIBUTION AND ABUNDANCE OF NEOTROPICAL AMPHIBIANS AND REPTILES IN SILVICULTURAL LANDSCAPE
}

\begin{abstract}
Most studies on biodiversity conducted in Brazil are accomplished in remnants of native vegetation. However, recent studies suggest that agricultural landscapes support a considerable biodiversity. The state of São Paulo, southeastern Brazil, has extensive grassland areas which is still its primary land use, followed by sugar cane crops and eucalyptus forests. The present study was conducted in Três Lagoas and Arca farms, located in the Upper Paranapanema basin. The area originally used as pasture (Brachiaria spp.) was partially replaced by eucalyptus plantations from August 2006 to February 2008, leaving from that about 350 ha of abandoned pastures, incorporated to Legal Reserve and Permanent Protection Areas. During the present study amphibians and reptiles were surveyed in 30 sampling units containing pitfall traps one kilometer apart from each other. Three different environments were sampled: eucalyptus forest (18 sampling units), native vegetation (seven sampling units) and abandoned pastures (five sampling units), resulting in a total effort of 4.977 trap-days in 23 monthly campaigns between August 2007 and July 2009. Most studies on biodiversity conducted in Brazil are accomplished in remnants of native vegetation. However, recent studies suggest that agricultural landscapes support a considerable biodiversity. The state of São Paulo, southeastern Brazil, has extensive grassland areas which is still its primary land use, followed by sugar cane crops and eucalyptus forests. The present study was conducted in Três Lagoas and Arca farms, located in the Upper Paranapanema basin. Concerning data analysis the environments (eucalyptus, abandoned pastures and native vegetation) were considered as independent variables and as dependent variables richness and abundance of trapped amphibians. 23 species were detected in traps, 18 amphibians and five reptiles. Among reptiles, only one snake was sampled by the traps. Surprisingly, native vegetation environment presented lower species richness than plantation and abandoned pasture environments, possibly due to its precarious conservation condition. The relationship between environments was marginally significant for abundance. The temporal distribution of species was heterogeneous, concentrating the encounters during the hot and rainy season. Additionally, the lists of species were supplemented through active search and occasional encounters, totaling 49 species for the study area (31 amphibians and 18 reptiles). The results coupled with the current context of land use change, demonstrate that silvicultural landscapes, whose matrix are eucalyptus forests may have a reasonable conservation value.
\end{abstract}

Keywords: Anura; Reptiles; Eucalyptus; Silvicultural landscape 


\subsection{Introdução}

O desenvolvimento do Estado de São Paulo ocasionou profundas alterações na vegetação original existente, e que atualmente ocupa aproximadamente 14\% de sua área (KRONKA et al., 2002). A agropecuária e a agroindústria são as atividades antrópicas que mais impactaram os ambientes naturais, causando desequilíbrio nos diversos ecossistemas existentes (CHIARELLO, 2000). A modernização da agricultura, aliada ao processo de expansão da fronteira agrícola e da pecuária à Mata Atlântica e Cerrado tiveram como fator característico a efetiva participação do Estado (SILVA, 2000).

Áreas originalmente ocupadas por pecuária extensiva têm sido substituídas por plantações de cana-de-açúcar e eucalipto, mais rentáveis, com este último ocupando principalmente áreas de baixa produtividade da região centro-sul e leste do estado (KRONKA et al., 2003). O estado de São Paulo apresenta uma extensa área de plantios de eucalipto (862.504,52 ha), que corresponde a 12,89\% das unidades de produção agropecuária do estado de São Paulo (SÃO PAULO, 2008) em áreas anteriormente ocupadas por florestas nativas e agropecuária (OLIVEIRA, 2004; PEREIRA-SILVA et al., 2004). No município de Angatuba são cultivados aproximadamente $1,5 \%$ do eucalipto de todo o estado, chegando atualmente a mais de 12 mil hectares (SÃO PAULO, 2008).

A formação de grandes maciços de florestas exóticas no Brasil, com destaque para as áreas plantadas com o gênero Eucalyptus, foi marcadamente influenciada pela prática do incentivo fiscal entre os anos de 1960 e 1980 (SILVA, 1997). As florestas plantadas com Eucalyptus spp representam cerca de $65,4 \%$ dos reflorestamentos brasileiros. É comum que estes plantios estejam em contato direto com remanescentes florestais ou envolvendo fragmentos (OLIVEIRA, 2004). Viana e Pinheiro (1998) concluíram que áreas vizinhas a pastagens estavam sujeitas a um efeito de borda mais intenso e que atividades de reflorestamento e/ou o uso de sistemas agroflorestais são favoráveis para atenuar este efeito.

A riqueza de espécies e os padrões de distribuição e abundância encontrados para outros grupos de vertebrados sugerem que áreas de silvicultura podem suportar uma razoável diversidade. Os esforços devem incluir o combate à monocultura e a preservação de fragmentos florestais nativos entremeados às áreas de plantio de eucalipto, incluindo estudos sobre a minimização do impacto das diversas técnicas de manejo silvicultural (OLIVEIRA, 2004). Em áreas de silvicultura, os estudos são em grande parte relatórios de consultorias ambientais para 
empreendimentos ou documentos acadêmicos (dissertações de mestrado e teses de doutorado; resumos de congresso), de circulação restrita (OLIVEIRA, 2004; MAFFEI et al., 2005; ARAÚJO; CONDEZ; SAWAYA, 2009).

Pouco se sabe sobre os fatores que influenciam a diversidade da herpetofauna de serapilheira das florestas neotropicais. Alguns fatores físicos podem ter influência na densidade, diversidade e/ou biomassa dessa taxocenose (HEINEN, 1992). Os anfíbios são em geral sensíveis a alterações ambientais, em função de uma combinação de atributos morfológicos, fisiológicos e comportamentais, adaptados a certas condições ambientais (HADDAD; PRADO, 2005). Os estudos sobre história natural e ecologia de répteis são escassos e restritos a poucas espécies, sendo importante conhecer informações sobre sua história natural e seu estado de conservação (SAZIMA, 2001). Devido à baixa mobilidade, requerimentos fisiológicos e especificidade de hábitat, os répteis e anfíbios podem ser considerados modelos ideais para estudos sobre os efeitos da fragmentação (SILVANO et al., 2003). Contudo, pesquisas relacionadas à conservação da herpetofauna, são praticamente inexistentes (FRANÇA; ARAÚJO, 2006). Poucos estudos enfocam a distribuição, os padrões ecológicos e a utilização por essas espécies de ambientes alterados por ação antrópica. Avaliar o impacto dessas mudanças em relação a processos de sucessão ecológica e/ou sazonalidade na distribuição e abundância da herpetofauna são relevantes para conhecer as mudanças ocasionadas quando há alterações no uso da terra.

\subsection{Material e Métodos}

\subsection{1 Área de estudo}

O presente estudo foi realizado na Fazenda Três Lagoas e na Fazenda Arca $\left(23^{\circ} 29^{\prime} 23^{\prime \prime} \mathrm{S}\right.$ e 48 24' 46" O), situadas no município de Angatuba, centro-sul do Estado de São Paulo. A área total da primeira é de 3.209,93 ha. A matriz original, predominantemente constituída de 2.590 ha de pastagem exótica (Brachiaria spp.), foi substituída parcialmente por plantações de eucalipto (2.223,9 ha) entre agosto de 2006 e dezembro de 2007, ampliando a Reserva Legal (RL) da fazenda para 586,52 ha e a Área de Preservação Permanente (APP) para 269,23 ha. A área total da segunda é de 1.122,77 ha, sendo 721,9 ha de plantio de eucalipto, 66,6 ha de Área de Preservação Permanente e 293,98 ha de Reserva Legal (Figura 1).

O cerradão é a fitofisionomia predominante, seguida de cerrado sensu stricto e alguns trechos de matas de galeria, em estágios inicial e secundário de regeneração. As plantações de 
eucalipto são constituídas pelas espécies Eucalyptus grandis, E.urophila e seu híbrido E. urograndis. Nestas plantações há presença de árvores esparsas das espécies Copaifera langsdorffii, Pera obovata, Machaerium villosum, Pterogyne nitens, Tabebuia alba e Gochnatia polymorpha, remanescentes da antiga formação florestal que foram mantidas na pastagem após a retirada da floresta na década de 70.

O clima da região é do tipo Cfa, clima temperado úmido com verão quente, de acordo com o sistema de Köppen, com temperatura média nos meses mais quentes superior a $22^{\circ} \mathrm{C}$ e nos meses mais frios aproximadamente de $17^{\circ} \mathrm{C}$. Durante o presente estudo, a temperatura média mensal foi de $20,6^{\circ} \mathrm{C}$, variando de $14,1^{\circ} \mathrm{C}$ em junho de 2008 a $24,3^{\circ} \mathrm{C}$ em março de 2009 . A precipitação mensal acumulada média foi de $115 \mathrm{~mm}$, variando de $0 \mathrm{~mm}$, em julho de 2008, a 313,8 mm, em janeiro de 2009 (Figura 2). Os dados foram fornecidos pela Estação Experimental

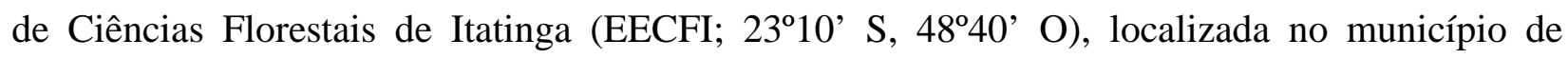
Itatinga, a cerca de 20 quilômetros da área de estudo.

\subsubsection{Delineamento amostral}

O método utilizado no delineamento do estudo é baseado no Programa de Pesquisa em Biodiversidade (PPBio ${ }^{1}$ ) onde as unidades amostrais formam uma grade, distando um quilômetro entre si. Esta metodologia é apropriada para pesquisas ecológicas de longa-duração (PELD), pois permite inventários rápidos para avaliação da complementaridade biótica e planejamento do uso da terra (MAGNUSSON et al., 2005).

Foram delimitadas 30 unidades amostrais na área de estudo, de forma a incluir vegetação nativa e pastos abandonados. Destas, 18 foram implantadas em eucaliptais, sete em vegetação nativa e cinco em pastos abandonados (Figura 3). O ambiente (eucaliptal, pasto abandonado e vegetação nativa) foi considerado variável independente, enquanto que a riqueza e a abundância de anfíbios de serapilheira foram consideradas variáveis dependentes. O período de coleta foi de agosto de 2007 a julho de 2009, sendo as campanhas mensais, excluindo o mês de outubro de 2007, totalizando 23 campanhas. Durante esse período os talhões de eucalipto tinham de zero a dois anos e onze meses de idade.

\footnotetext{
${ }^{1}$ Disponível em: বhttp://ppbio.inpa.gov.brịthtp://ppbio.inpa.gov.br/Port/inventarios/angatubà.
} 


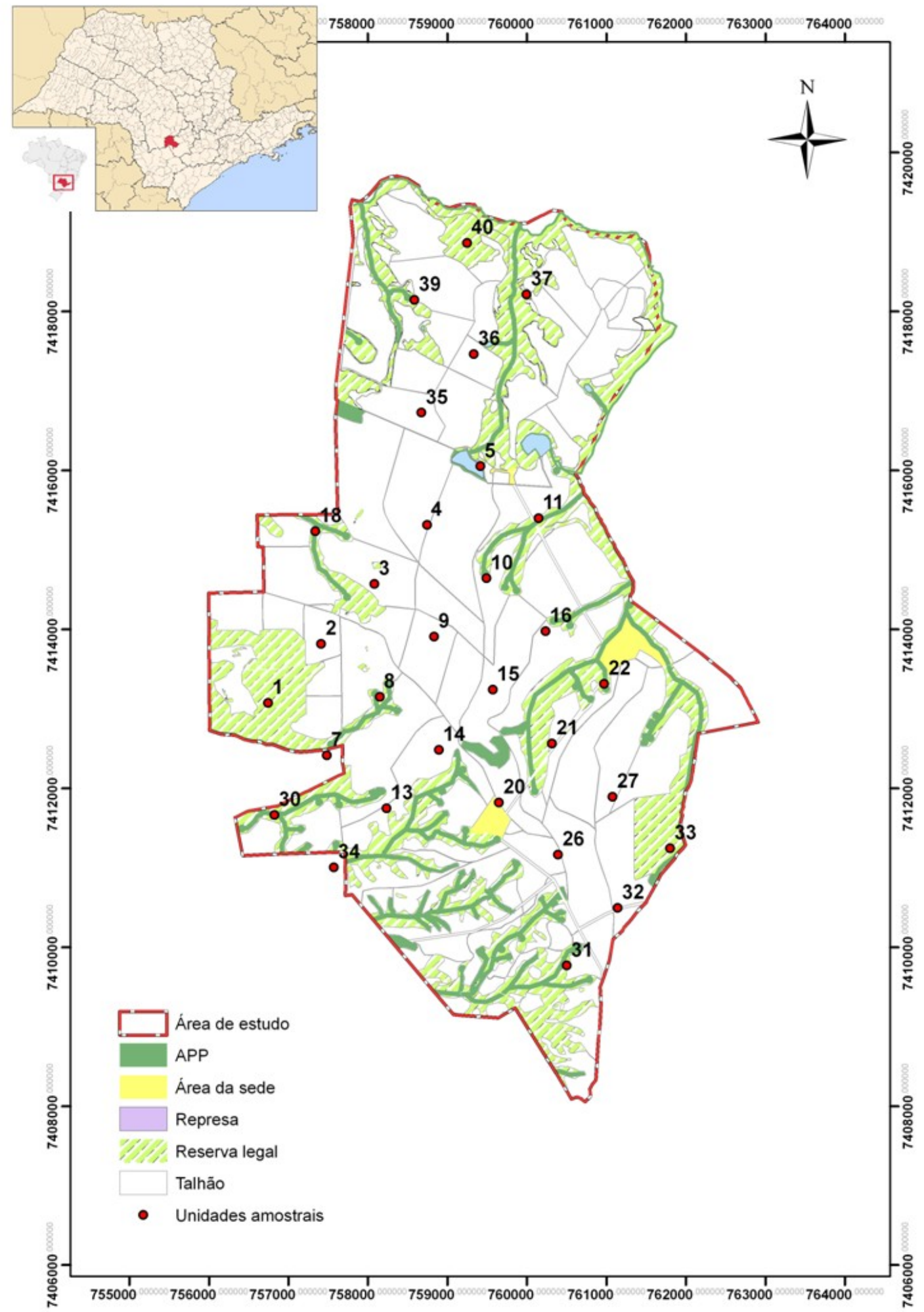

Figura 1 - Área de estudo - Fazenda Três Lagoas e Fazenda Arca, Angatuba, região do Alto Paranapanema, Estado de São Paulo 
$\mathbf{a}$

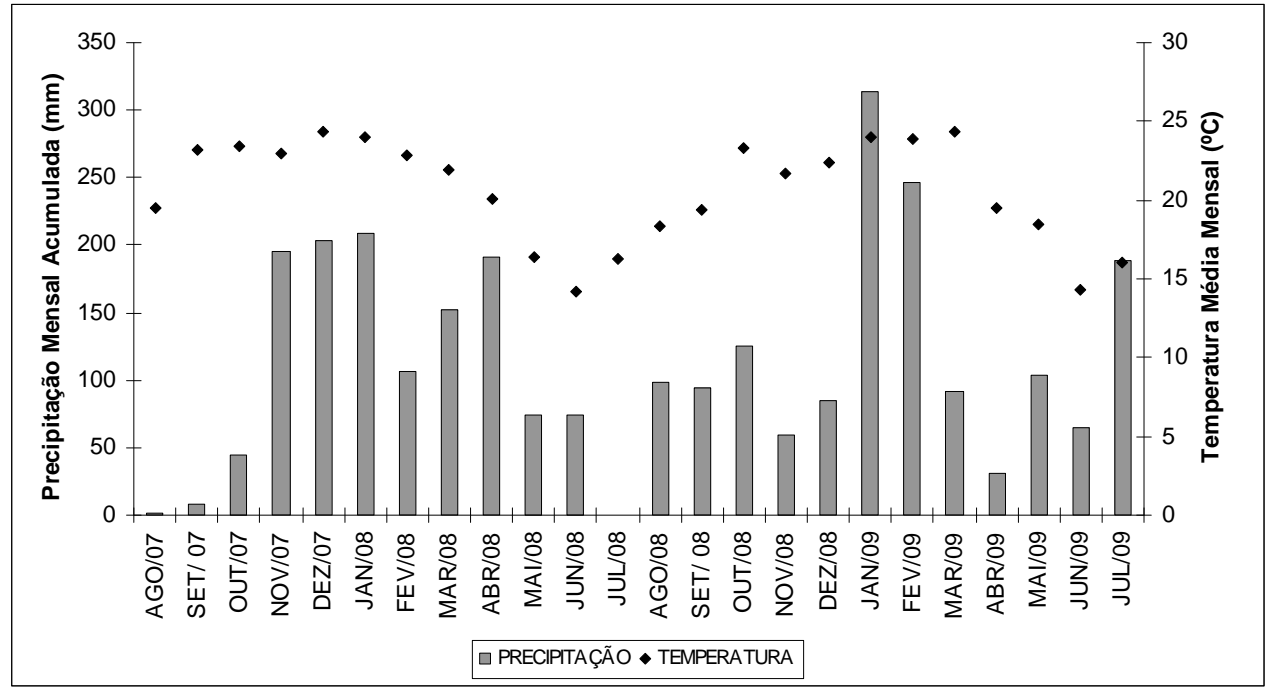

b

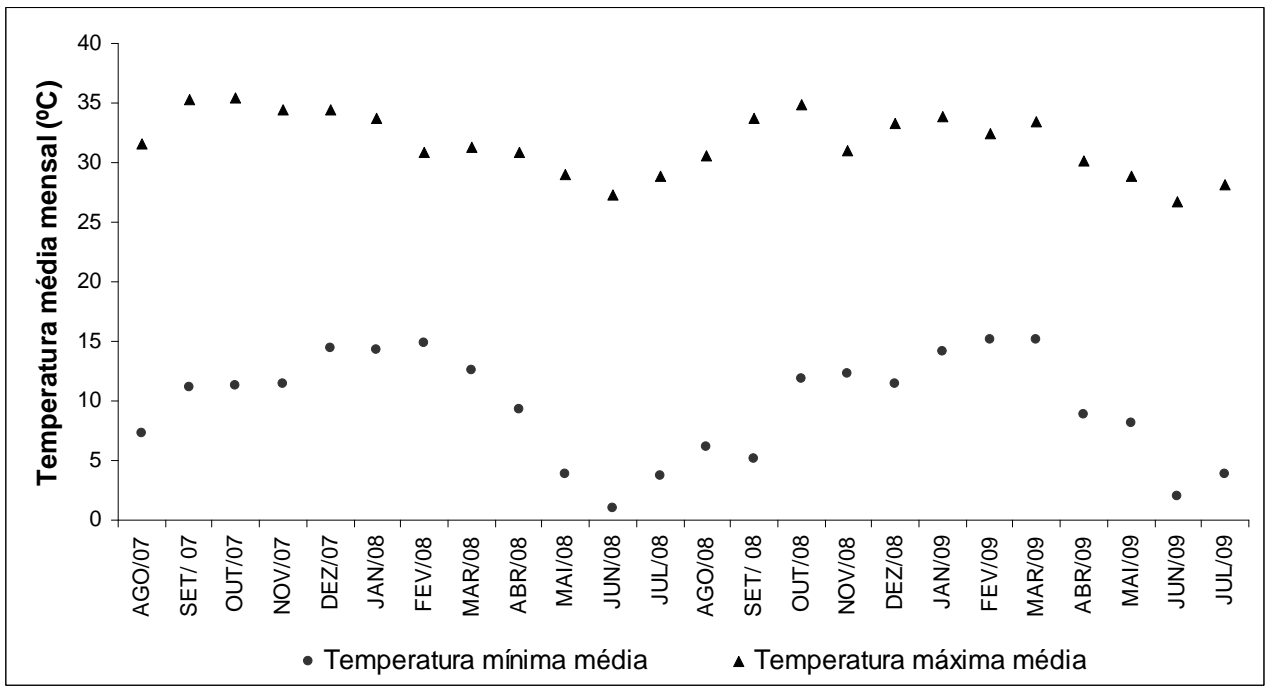

Figura 2 - Dados climáticos: a) Precipitação mensal acumulada (mm), b) Médias das temperaturas míninas e máximas mensais

\subsubsection{Metodologia de coleta}

O levantamento da herpetofauna foi realizado por meio do uso de armadilhas de interceptação e queda com cercas-guia ("pitfall traps with drift fences"; CORN, 1994; BLOCK; MORRISON; SCOTT, 1998; CECHIN; MARTINS, 2000; DIXO; VERDADE, 2006; BERNARDE; MACEDO, 2008). Cada unidade amostral consistiu de quatro baldes plásticos de $100 \mathrm{~L}$ em uma disposição radial, enterrados até a boca, dispostos a cada $15 \mathrm{~m}$ e interligados por cerca-guia, constituída de tela plástica de $80 \mathrm{~cm}$ de altura. Cada braço do Y continha um balde 
em sua porção final, havendo também um balde central. Os baldes possuíam orifícios para a drenagem da água, permanecendo tampados fora dos dias de coleta. No interior de cada balde foi mantido um pequeno recipiente com água e uma pequena placa de isopor para evitar, respectivamente, desidratação ou afogamento dos animais capturados. A cerca guia foi colocada verticalmente em toda a extensão da armadilha, sendo fixada a aproximadamente cada $3 \mathrm{~m} \mathrm{em}$ estacas por meio de grampos metálicos. A tela enterrada cerca de $10 \mathrm{~cm}$ evita que os animais atravessassem-na por baixo. Foram utilizadas 30 unidades amostrais, totalizando 120 baldes e $1.350 \mathrm{~m}$ de cerca guia. Durante as campanas de coleta, os baldes permaneceram abertos por duas noites seguidas, sendo verificados pela manhã $(7: 00-12: 00 h)$, sendo seu interior revolvido levemente com um gancho herpetológico quando havia acúmulo de folhiço ou areia.

Os animais capturados foram identificados, sempre que possível em campo, sendo coletadas as seguintes informações: data, armadilha, espécie, comprimento do corpo e sexo (HADDAD, 1998) e depois liberados. Alguns indivíduos que serviram de espécie-testemunho foram sacrificados com pomada anestésica, fixados em formaldeído $10 \%$ e conservados em álcool 70\%. Os exemplares coletados de anfíbios foram identificados e depositados na Coleção "Célio F. B. Haddad" (CFBH), Instituto de Biociências, Universidade Estadual Paulista - Campus de Rio Claro - SP, e os de répteis no Museu de Zoologia da Universidade de São Paulo (MZUSP), São Paulo - SP (ANEXO B), sob as autorizações de coleta do ICMBIO - IBAMA (licenças n ${ }^{\circ} \mathrm{S} 12623-1$ e 12623-2).

Em adição, foram realizados levantamentos qualitativos de anuros através de vocalizações noturnas em habitats aquáticos por procura ativa em açudes entre outubro de 2008 e março de 2009, época de maior atividade reprodutiva das espécies (BERTOLUCI et al., 2007). 
$\mathbf{a}$

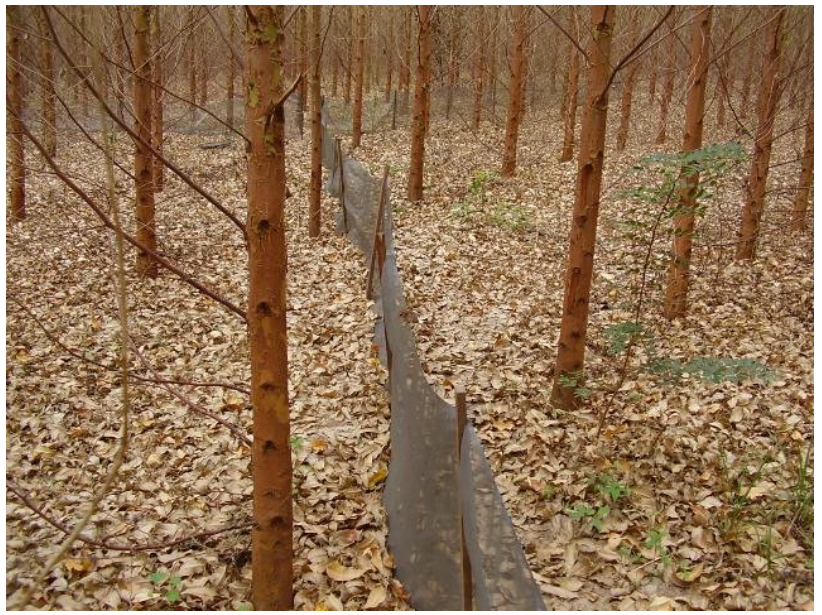

b
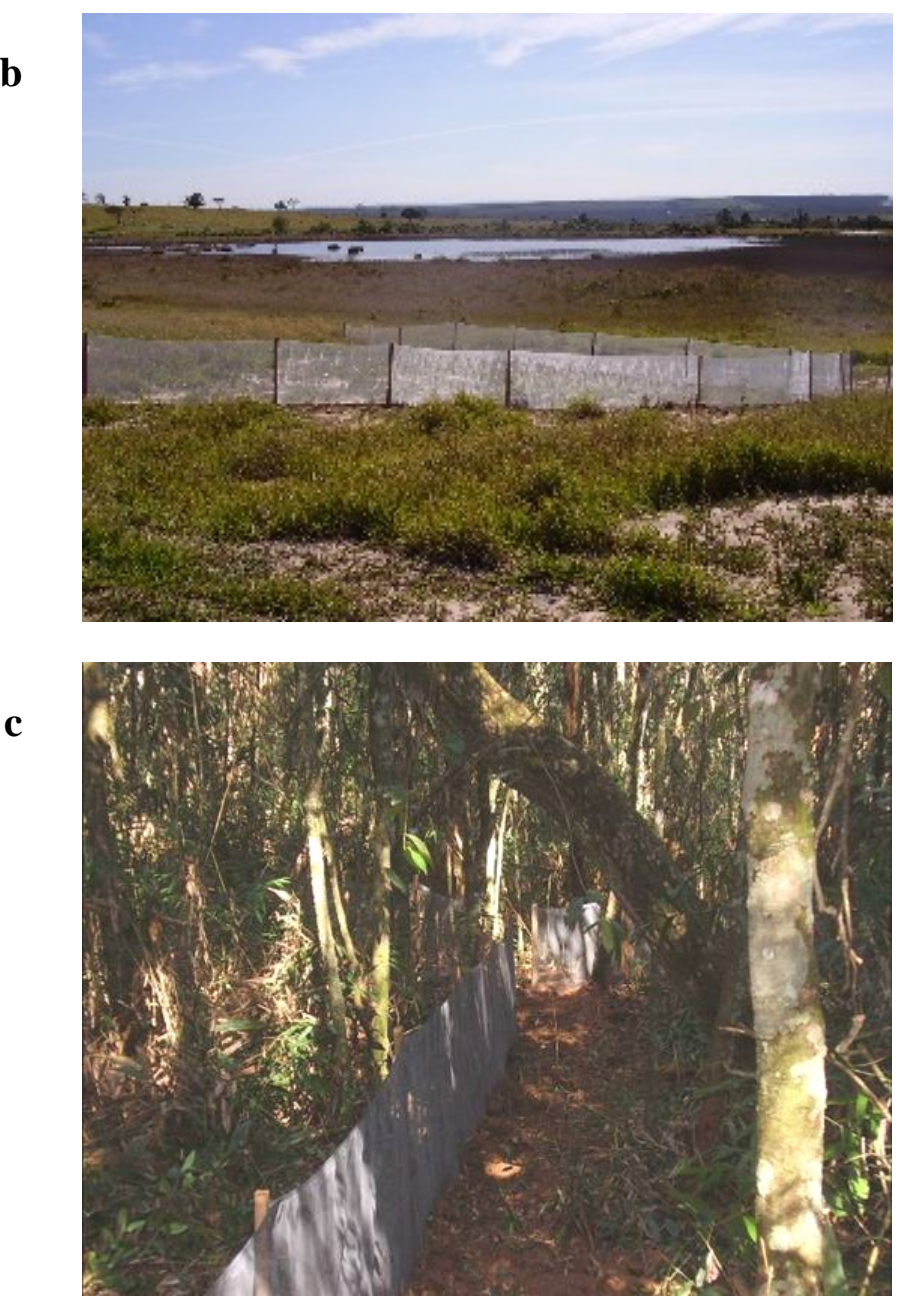

Figura 3 - Séries de armadilhas nos ambientes amostrados: a) eucaliptal; b) pasto abandonado; e, c) vegetação nativa 


\subsubsection{Metodologia analítica}

Para as análises quantitativas foram considerados apenas os anfíbios de serapilheira capturados nas armadilhas. Não foram considerados os anfíbios da família Hylidae, devido à metodologia de captura utilizada e os répteis devido à sua pequena riqueza e abundância na área.

O esforço amostral foi obtido por meio da multiplicação do número de armadilhas por dias de coleta, visto que as mesmas se mantiveram abertas durante todo o período de coleta [23 campanhas x 2 dias de coleta/campanha x 30 unidades amostrais x 4 baldes/unidade amostral]. $\mathrm{O}$ sucesso de captura foi obtido multiplicando o total de capturas por 100 e dividido pelo esforço de captura em armadilhas·dia (STALLINGS, 1989).

Foram estabelecidas curvas de incidência de espécies para cada ambiente e para a área total de estudo, por meio do software EstimateS Win 752 (COLWELL, 2004), utilizando os dados ordenados em amostras (GOTELLI; COLWELL, 2001). Para isso foram realizadas 1000 aleatorizações das amostras por meio do estimador Bootstrap (COLWELL; CODDINGTON, 1994) a fim de gerar um intervalo de confiança.

O tipo de ambiente (eucaliptal, pasto abandonado e vegetação nativa) foi considerado como variável independente enquanto que riqueza e abundância de espécies coletadas nas armadilhas foram consideradas variáveis dependentes. A comparação entre os ambientes foi feita por meio de Análise de Variância (ANOVA) (ZAR, 1996) para riqueza, Teste de Kruskal-Wallis (SIEGEL, 1956) para abundância de indivíduos e Análise de Médias (ANOM) (OTT, 1983) para ambas. Para estas análises foi utilizado o software estatístico Minitab 15 (MINITAB, 2008). O Teste de Kruskal-Wallis (SIEGEL, 1956), uma análise de variância não-paramétrica, foi utilizado para comparar a abundância nos três diferentes ambientes (eucaliptal, pasto abandonado e vegetação nativa).

A variação espaço-temporal foi representada por meio de expressão gráfica gerada no software $R$ 2.9.1 (R PROJECT, 2009), utilizando-se dos dados de abundância relativa, incluindo campanhas e precipitação mensal acumulada.

A avaliação gráfica da composição específica entre os ambientes foi feita por meio de Análise de Correspondência (MANLY, 1994), que se trata de um método multivariado de ordenação. Para esta análise foi utilizado o software estatístico Minitab (MINITAB, 2008).

Para avaliar a variação intra-específica quanto a comprimento rostro-cloacal (CRC) foi feita análise de variância (ANOVA), considerando como variável independente o ambiente, o 
sexo e a interação entre ambos para as espécies que tiveram mais de 20 indivíduos adultos capturados em todos os ambientes.

\subsection{Resultados}

$\mathrm{Na}$ área deste estudo foram encontradas 49 espécies de anfíbios anuros e répteis durante todo o período de coleta, por meio de armadilhas, procura ativa e encontro ocasional. Destas, 31 foram de anfíbios (Tabela 1) e 18 de répteis (Tabela 2). Nas armadilhas de interceptação e queda foram capturados 1.047 indivíduos pertencentes a 18 espécies de anfíbios e 13 indivíduos pertencentes a cinco espécies de répteis, com um esforço amostral de 4.977 armadilhas · dia, realizados de agosto de 2007 a julho de 2009. O sucesso de captura de anfíbios e répteis foi de 21,3\%, sendo 21,04\% de anfíbios e 0,26\% de répteis (lagartos: 0,24\%; serpentes 0,02\%). Adicionando-se os outros métodos de coleta às armadilhas, gerou-se uma lista complementar de

26 espécies, sendo 13 de anfíbios e 13 de répteis diferentes daquelas coletadas nas armadilhas. Essas espécies estão relacionadas na respectiva tabela. Os anfíbios estão distribuídos em seis famílias e oito gêneros, sendo que 614 indivíduos (58\% do total de indivíduos coletados) pertenceram a somente uma espécie (Physalaemus cuvieri) e apenas 13 indivíduos pertenceram às cinco espécies de répteis, sendo quatro lagartos e apenas uma serpente.

As espécies detectadas neste estudo não se encontram ameaçadas ou em risco de extinção de acordo com a lista da IUCN ou IBAMA. A nomenclatura de anfíbios segue o proposto por Frost (2010) e a de répteis por Zaher et al. (2009) e Bérnils (2010). 
Tabela 1 - Espécies de anfíbios e respectivos ambientes de encontro na área de estudo, bacia do Alto Paranapanema, Estado de São Paulo* busca ativa

\begin{tabular}{|c|c|c|c|c|}
\hline Família / Espécie & Eucaliptal & $\begin{array}{c}\text { Vegetação } \\
\text { nativa }\end{array}$ & $\begin{array}{c}\text { Pasto } \\
\text { abandonado }\end{array}$ & Corpo d'água \\
\hline \multicolumn{5}{|l|}{ Bufonidae } \\
\hline Rhinella ornata & $\mathbf{X}$ & $\mathbf{X}$ & & \\
\hline Rhinella schneideri & $\mathbf{X}$ & & & \\
\hline \multicolumn{5}{|l|}{ Craugastoridae } \\
\hline Haddadus binotatus & & $\mathbf{X}$ & $\mathbf{X}$ & \\
\hline \multicolumn{5}{|l|}{ Cycloramphidae } \\
\hline Odontophrynus americanus & $\mathbf{X}$ & $\mathbf{X}$ & & \\
\hline \multicolumn{5}{|l|}{ Hylidae } \\
\hline Aplastodiscus perviridis & $\mathbf{X}$ & & $\mathbf{X}$ & \\
\hline Dendropsophus elianeae & & & & $\mathbf{X}$ \\
\hline Dendropsophus jimi & & & & $\mathbf{X}$ \\
\hline Dendropsophus nanus & & & & $\mathbf{X}$ \\
\hline Dendropsophus minutus & & & & $\mathbf{X}$ \\
\hline Hypsiboas albomarginatus & & & & $\mathbf{X}$ \\
\hline Hypsiboas albopunctatus & & $\mathbf{X}$ & & $\mathbf{X}$ \\
\hline Hypsiboas faber & $\mathbf{X}$ & & & $\mathbf{X}$ \\
\hline Hypsiboas lundii & & & & $\mathbf{X}$ \\
\hline Phyllomedusa tetraploidea & & & & $\mathbf{X}$ \\
\hline Pseudis platensis & & & & $\mathbf{X}$ \\
\hline Scinax fuscomarginatus & & & & $\mathbf{X}$ \\
\hline Scinax fuscovarius & $\mathbf{X}$ & & & $\mathbf{X}$ \\
\hline \multicolumn{5}{|l|}{ Leiuperidae } \\
\hline Eupemphix nattereri & $\mathbf{X}$ & $\mathbf{X}$ & $\mathbf{X}$ & $\mathbf{X}$ \\
\hline Physalaemus centralis & $\mathbf{X}$ & & $\mathbf{X}$ & \\
\hline Physalaemus cuvieri & $\mathbf{X}$ & $\mathbf{X}$ & $\mathbf{X}$ & $\mathbf{X}$ \\
\hline Physalaemus marmoratus & $\mathbf{X}$ & $\mathbf{X}$ & $\mathbf{X}$ & $\mathbf{X}$ \\
\hline Physalaemus olfersii & & $\mathbf{X}$ & & \\
\hline \multicolumn{5}{|l|}{ Leptodactylidae } \\
\hline Leptodactylus cf. furnarius & & $\mathbf{X}$ & & \\
\hline Leptodactylus fuscus & $\mathbf{X}$ & & $\mathbf{X}$ & $\mathbf{X}$ \\
\hline Leptodactylus labyrinthicus & & $\mathbf{X}$ & $\mathbf{X}$ & $\mathbf{X}$ \\
\hline Leptodactylus latrans & $\mathbf{X}$ & & $\mathbf{X}$ & $\mathbf{X}$ \\
\hline Leptodactylus mystaceus & & $\mathbf{X}$ & & \\
\hline Leptodactylus mystacinus & $\mathbf{X}$ & & $\mathbf{X}$ & \\
\hline \multicolumn{5}{|l|}{ Microhylidae } \\
\hline Chiasmocleis albopunctata & $\mathbf{X}$ & & & \\
\hline Elachistocleis $\mathrm{cf}$. bicolor & $\mathbf{X}$ & & $\mathbf{X}$ & \\
\hline Elachistocleis cf. ovalis & $\mathbf{X}$ & & $\mathbf{X}$ & $\mathbf{X}$ \\
\hline
\end{tabular}


Tabela 2 - Espécies de répteis e respectivos ambientes de encontro na área de estudo, bacia do Alto Paranapanema, Estado de São Paulo * encontro ocasional e/ou fora dos dias de coleta

\begin{tabular}{|c|c|c|c|c|}
\hline Família / Espécie & Eucaliptal & $\begin{array}{c}\text { Vegetação } \\
\text { nativa }\end{array}$ & $\begin{array}{c}\text { Pasto } \\
\text { abandonado }\end{array}$ & $\begin{array}{c}\text { Outros } \\
\text { ambientes }\end{array}$ \\
\hline \multicolumn{5}{|l|}{ Amphisbaenidae } \\
\hline Amphisbaena alba & & & & Área sede \\
\hline \multicolumn{5}{|l|}{ Gymnophtalmidae } \\
\hline Cercosaura ocellata & & & $\mathbf{X}^{*}$ & \\
\hline Cercosaura schreibersii & & & $\mathbf{X}^{*}$ & \\
\hline Micrablepharus atticolus & $\mathbf{X}$ & & $\mathbf{X}$ & \\
\hline \multicolumn{5}{|l|}{ Polychrotidae } \\
\hline Enyalius perditus & & $\mathbf{x}$ & & \\
\hline \multicolumn{5}{|l|}{ Scincidae } \\
\hline \multicolumn{4}{|l|}{ Teiidae } & Açude \\
\hline Kentropyx paulensis & & $\mathbf{x}$ & $\mathbf{x}$ & \\
\hline Tupinambis merianae & & $\mathbf{X}^{*}$ & $\mathbf{X}^{*}$ & \\
\hline \multicolumn{5}{|l|}{ Colubridae } \\
\hline Oxyrhopus guibei & $\mathbf{X}$ & & & \\
\hline Oxyrhopus rhombifer & & & & Açude \\
\hline Liophis poecilogyrus & & & & Açude \\
\hline Xenodon merremi & & & & Área sede \\
\hline \multicolumn{5}{|l|}{ Boidae } \\
\hline Boa constrictor & & & & Área sede \\
\hline \multicolumn{5}{|l|}{ Viperidae } \\
\hline Bothropoides jararaca & & $\mathbf{X}^{*}$ & & \\
\hline Bothropoides neuwiedi & & & $\mathbf{X}^{*}$ & \\
\hline Caudisona durissa & $\mathbf{X}^{*}$ & & & Área sede \\
\hline \multicolumn{5}{|l|}{ Chelidae } \\
\hline Mesoclemmys vanderhaegei & & & & Lagoa \\
\hline \multicolumn{5}{|l|}{ Alligatoridae } \\
\hline Caiman latirostris & & & & Lagoa \\
\hline
\end{tabular}

O método de armadilhas de interceptação e queda foi mais eficiente para amostragem de anfíbios pertencentes a famílias de hábitos terrícolas e fossoriais, i.e., de serapilheira, quais sejam, Bufonidae, Cycloramphidae, Craugastoridae, Leiuperidae, Leptodactylidae e Microhylidae. Todas as espécies de anfíbios foram detectadas no plantio de eucalipto, exceto Haddadus binotatus, Leptodactylus labyrinthicus, Leptodactylus mystaceus, Leptodactylus cf. furnarius e Physalaemus olfersii (Figura 4). As espécies de hilídeos registradas nos baldes (Scinax fuscovarius, Aplastodiscus perviridis e Hypsiboas albopunctatus) e H. faber encontrada na serapilheira no eucaliptal não são habitantes freqüentes de chão, sendo seu registro decorrente de capturas acidentais e por isso não foram utilizadas para as análises estatísticas. 
Entre os répteis, foi registrada maior abundância para Mabuya dorsivittata, sendo três indivíduos detectados nos pastos abandonados, dois nos eucaliptais e um na vegetação nativa. Para Micrablepharus atticolus foram detectados dois indivíduos nos eucaliptais e um no pasto abandonado. Para Kentropyx paulensis foram detectados um indivíduo no pasto abandonado e um na vegetação nativa. Para Enyalius perditus, apenas um indivíduo foi detectado na vegetação nativa, e apenas um indivíduo de Oxyrhopus guibei foi detectado nos eucaliptais. Para os répteis, as primeiras campanhas também registraram mais espécies, tendo apenas na décima quinta um acréscimo de duas espécies (Enyalius perditus e Oxyrhopus guibei). Devido às baixas riqueza e abundância encontradas para este grupo, este não foi utilizado para análises estatísticas, sendo apresentadas apenas sua riqueza, sua abundância nas armadilhas e seu ambiente de ocorrência na área de estudo.

Nos eucaliptais foi registrada maior riqueza total de espécies e abundância de indivíduos de anfíbios (13 espécies, 511 indivíduos) em relação às áreas de pastos abandonados e vegetação nativa (11 espécies, 470 indivíduos; 10 espécies, 62 indivíduos, respectivamente; Figura 5). Dessa grande abundância coletada na pastagem, 131 indivíduos de $P$. cuvieri foram coletados em apenas uma campanha (dezembro de 2007) em apenas uma unidade amostral ( $\mathrm{n}^{\circ}$ 5). No entanto, houve um número maior de unidades amostrais em eucaliptais $(n=18)$ que nos pastos abandonados $(n=5)$ e vegetação nativa $(n=7)$.

A espécie mais abundante em todos os ambientes foi Physalaemus cuvieri. Além dela, nos eucaliptais as espécies com alta abundância foram Physalaemus marmoratus e Eupemphix nattereri. Nos outros ambientes nenhuma outra espécie se destacou em relação à abundância encontrada para P. cuvieri. O plantio de eucalipto apresentou maior riqueza em relação aos outros ambientes amostrados, assim como em abundância de indivíduos. As espécies encontradas somente na vegetação nativa apresentaram apenas um indivíduo cada. 


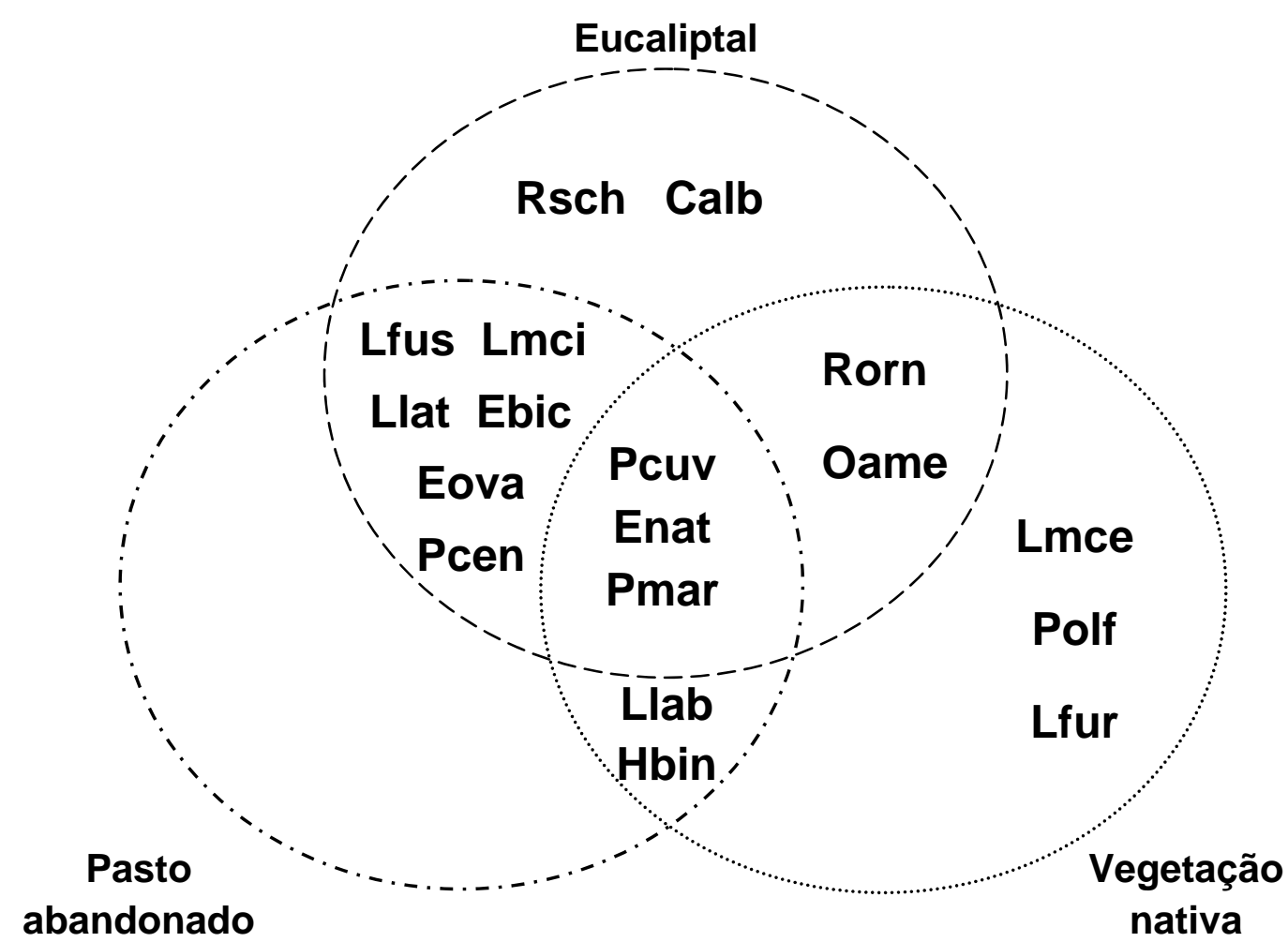

Figura 4 - Composição de espécies de anfíbios por ambiente. As abreviações correspondem às espécies: Calb Chiasmocleis albopunctata, Ebic - Elachistocleis cf. bicolor, Eova - E. cf. ovalis, Enat - Eupemphix nattereri, Hbin - Haddadus binotatus, Lfur - Leptodactylus cf. furnarius, Lfus - Leptodactylus fuscus, Llab - L. labyrinthicus, Llat - L. latrans, Lmci - L. mystacinus, Lmce - L. mystaceus, Oame Odontophrynus americanus, Pcen - Physalaemus centralis, Pcuv - P. cuvieri, Pmar - P. marmoratus, Polf - P. olfersii, Rorn - Rhinella ornata e Rsch - R. schnederi

Nas quatro primeiras campanhas foram registradas 14 espécies de anfíbios, e a partir da décima sétima campanha não houve mais acréscimo de espécies. As curvas de incidência de espécies foram comparadas por meio do estimador não-paramétrico Bootstrap para a área total de estudo e para os três ambientes amostrados (eucaliptais, pastos abandonados e vegetação nativa). Para a área total de estudo o estimador sugere uma riqueza entre 19 e 20 espécies de anfíbios (assíntota de 19,65), tendo sido detectadas 18 espécies. Para os eucaliptais estimavam-se 13,93 espécies, sendo detectadas 13 espécies; para os pastos abandonados estimavam-se 12 espécies, sendo detectadas 11 espécies e para a vegetação nativa, estimavam-se 12,73 espécies, sendo detectadas 10 espécies (Figura 6). 


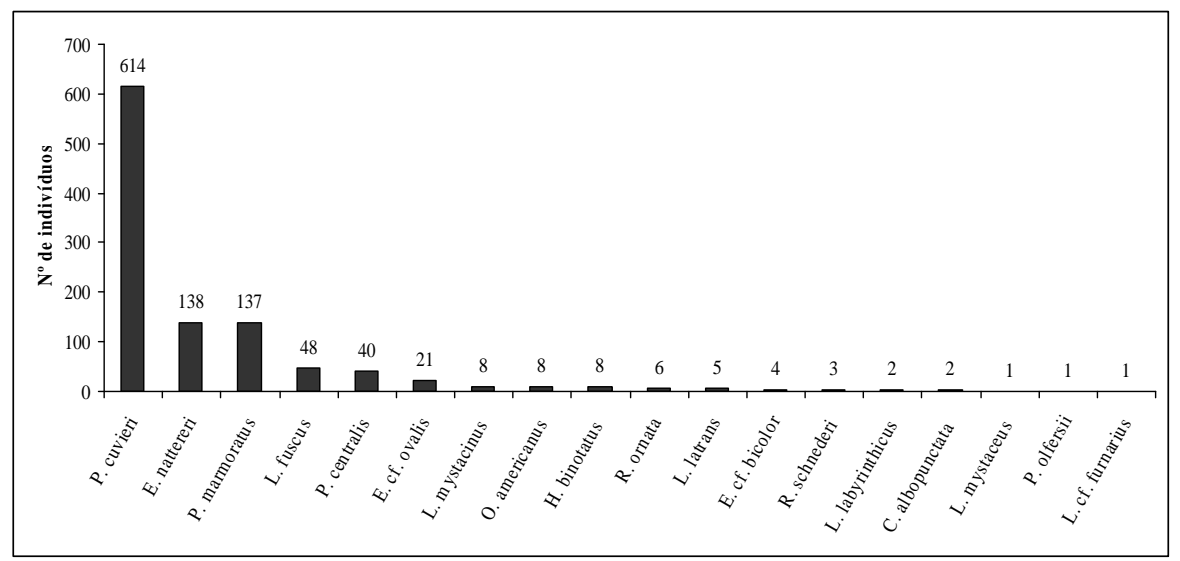

Área de estudo

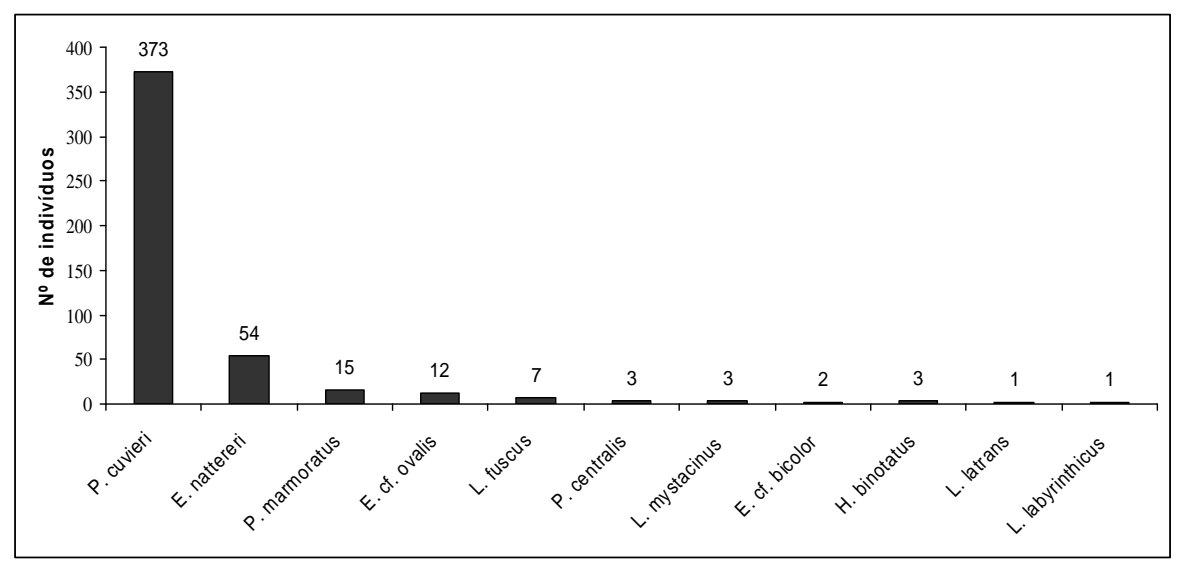

Pasto abandonado

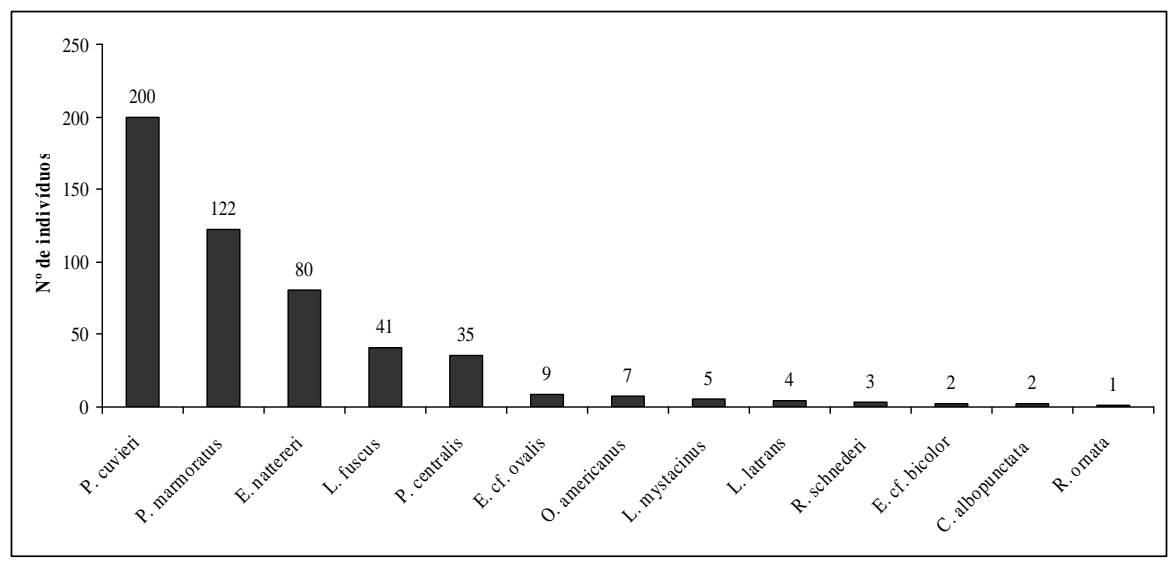

Eucaliptal

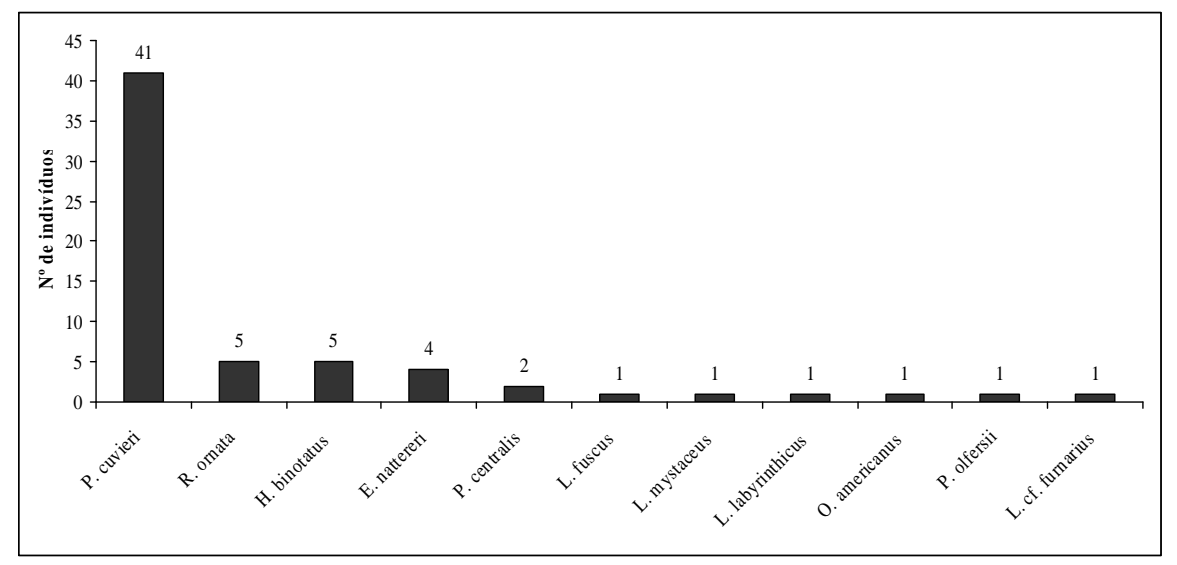

Vegetação nativa

Figura 5 - Curvas de ordenação de espécies em relação ao número de indivíduos para cada ambiente: Área de estudo, Eucaliptal, Pasto abandonado e Vegetação nativa 
$\mathbf{a}$

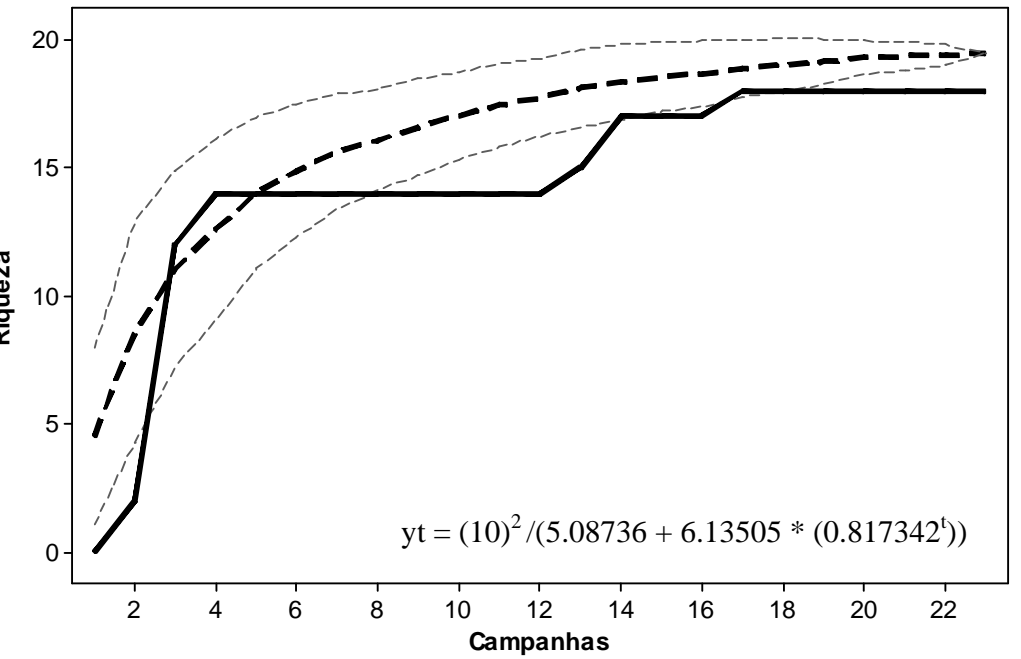

c

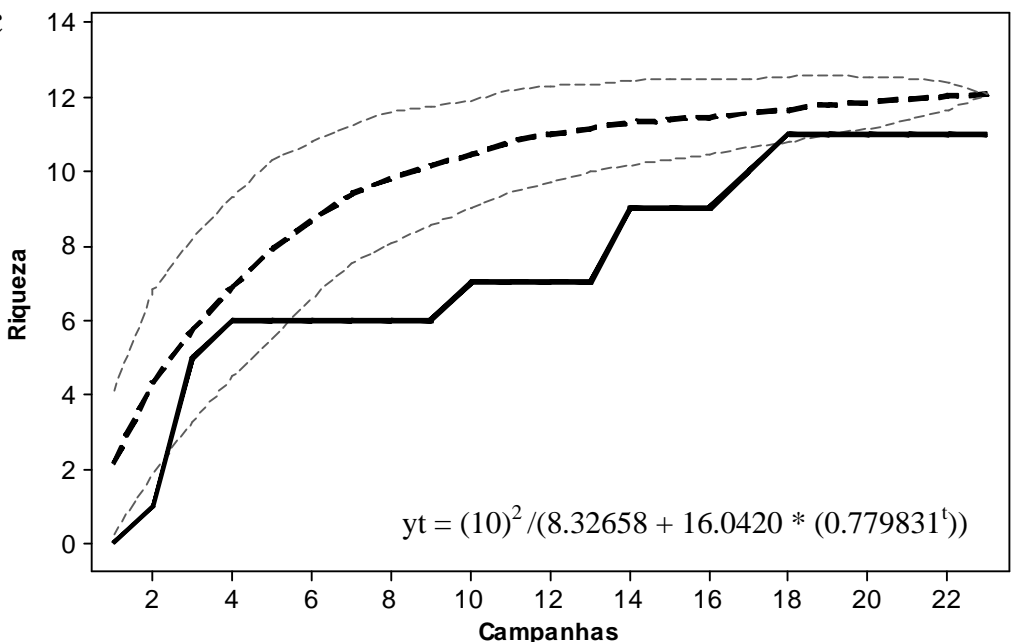

b

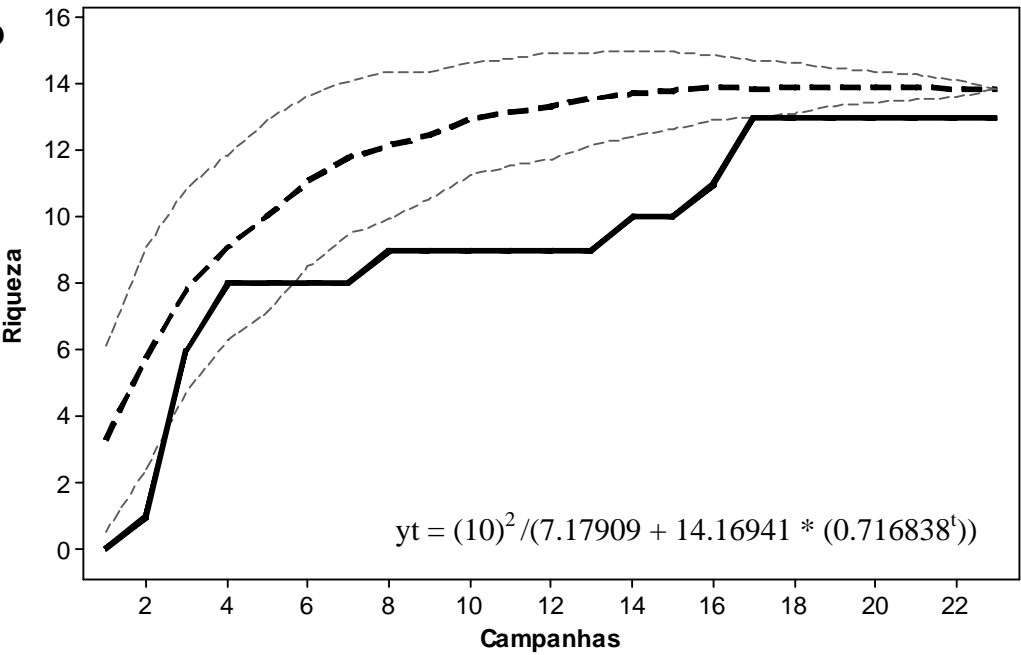

d

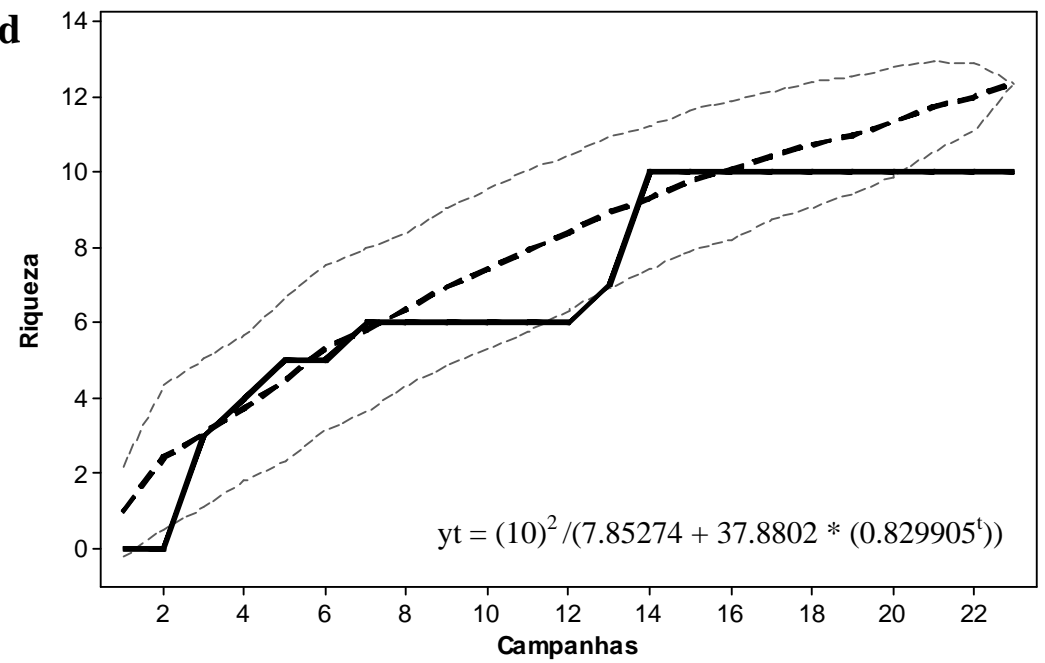

Figura 6 - Curvas de incidência de espécies por campanha: a) Área de estudo; b) Eucaliptais; c) Pastos abandonados; e, d) Vegetação nativa, (y = nº acumulado de espécies, $\mathrm{t}=$ número de campanhas). Linha contínua: riqueza acumulada observada, Linha tracejada em negrito: média do estimador bootstrap. Linhas tracejadas claras: média do estimador mais ou menos o desvio padrão 
Houve diferença significativa quanto à riqueza de espécies entre os ambientes, $(\mathrm{F}=7,38$; g.l. $=29 ; \mathrm{p}=0,003)$, sendo a vegetação nativa com a menor riqueza. O teste de Kruskal-Wallis detectou diferença significativa quanto à abundância de indivíduos entre os ambientes $(\mathrm{H}=12 ; 2$; g.l = 2; p = 0,002) (Figura 7).

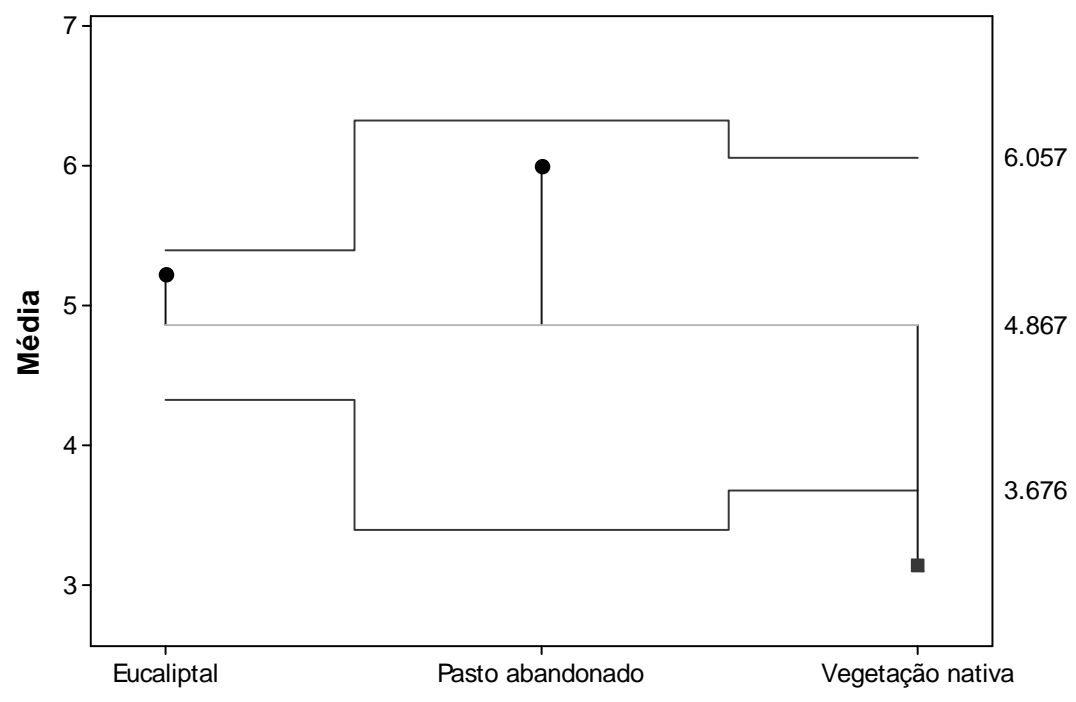

Riqueza

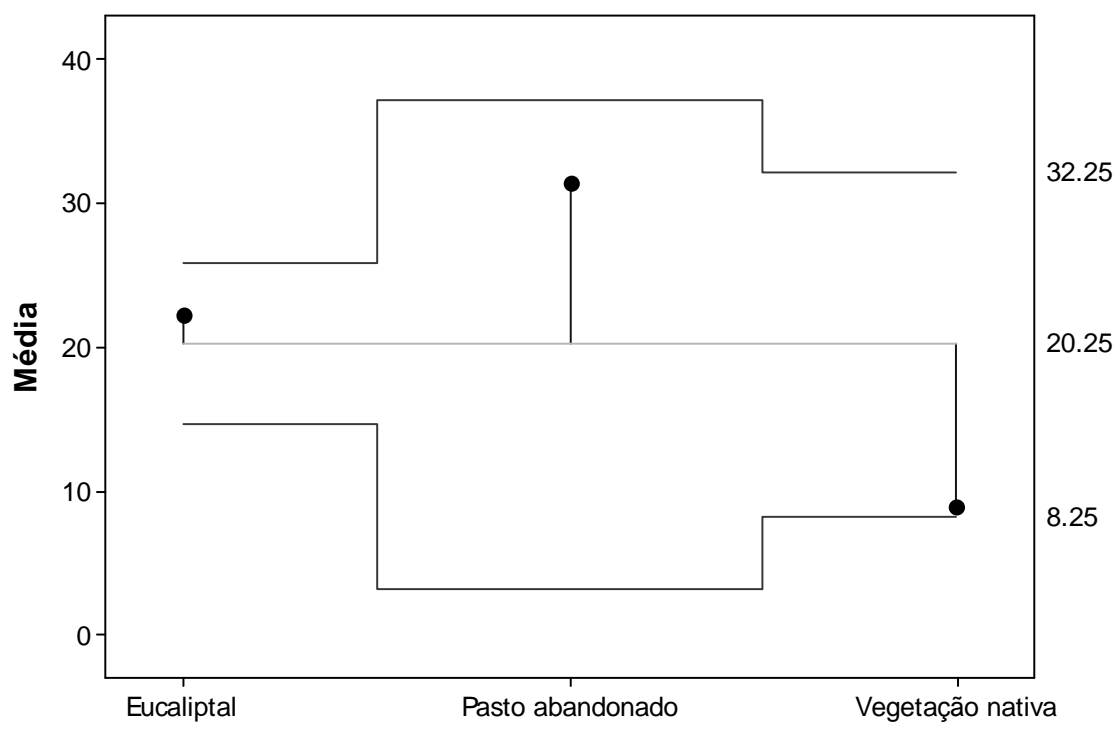

Abundância de indivíduos

Figura 7 - Análise de médias (ANOM) para riqueza e abundância de indivíduos entre os ambientes 
Nos eucaliptais, a riqueza encontrada por parcela variou de três a nove espécies, com uma grande variação, concentrando-se em quatro ou cinco espécies na maioria das unidades amostrais. Nas unidades amostrais de pastos abandonados a riqueza variou de cinco a oito espécies, com uma distribuição mais homogênea, o que também ocorreu nas parcelas de vegetação nativa, estas possuindo uma variação menor, de duas a cinco espécies. (Figura 8).

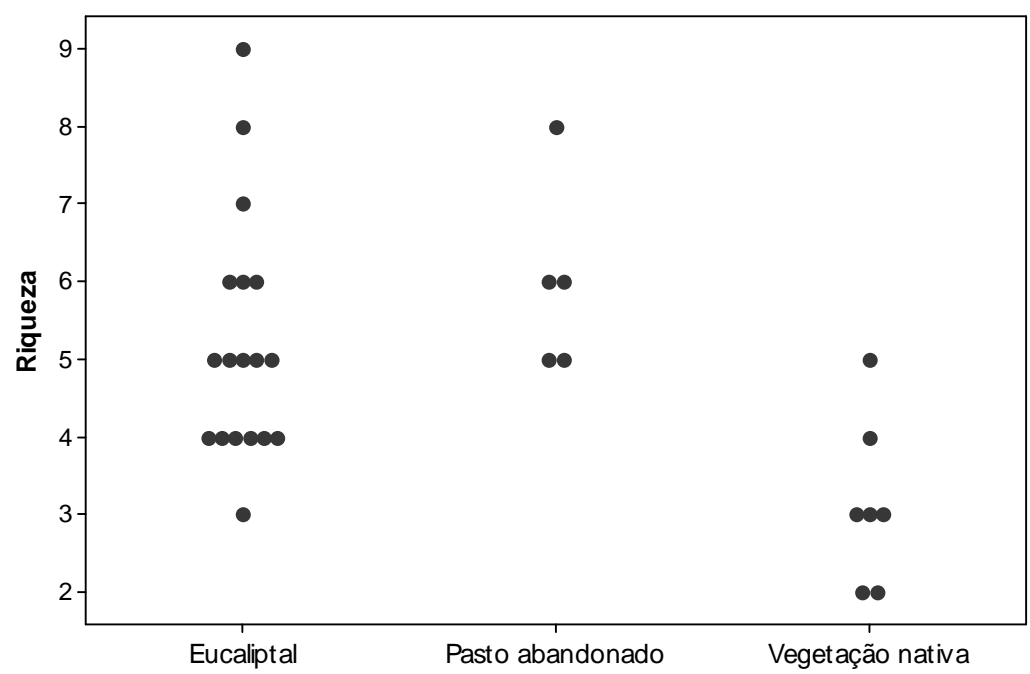

Figura 8 - Riqueza por ambiente em relação a cada unidade amostral

A maioria das unidades amostrais apresentou abundância menor que 20 indivíduos nos três ambientes (Figura 9). Apenas uma unidade amostral apresentou mais de 300 indivíduos durante este estudo.

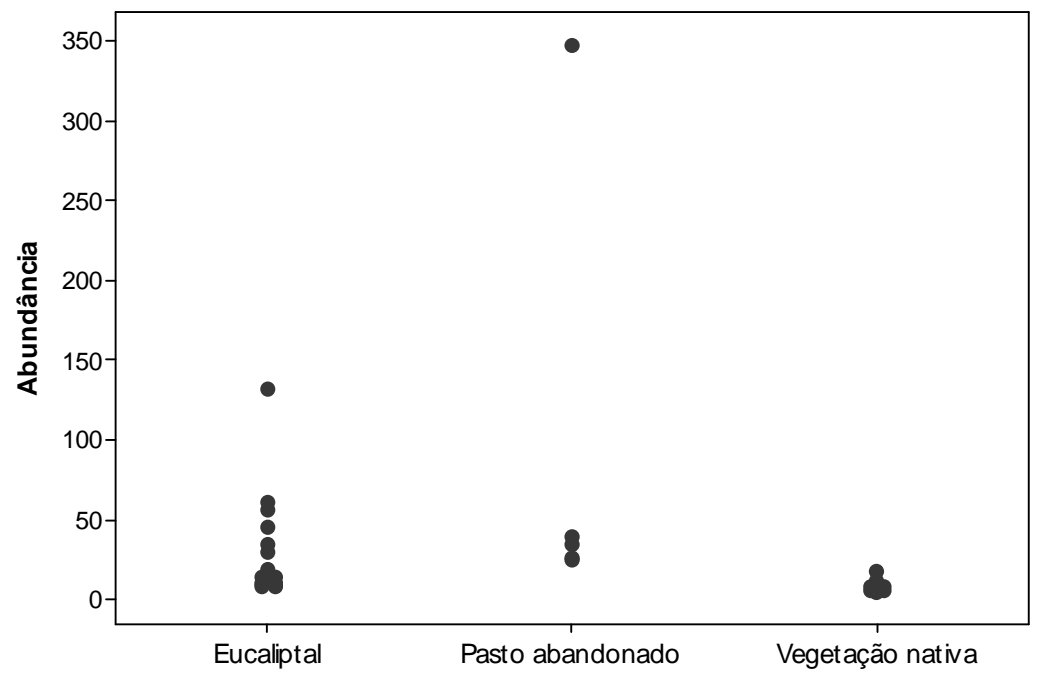

Figura 9 - Abundância por ambiente ( $n^{\circ}$ de indivíduos) em relação à unidade amostral 
A variação temporal das espécies é demonstrada a partir das médias das abundâncias relativas ordenadas por campanha, sendo que estas começaram durante o inverno e duraram até julho de 2009, perfazendo assim uma escala temporal (Figura 10).

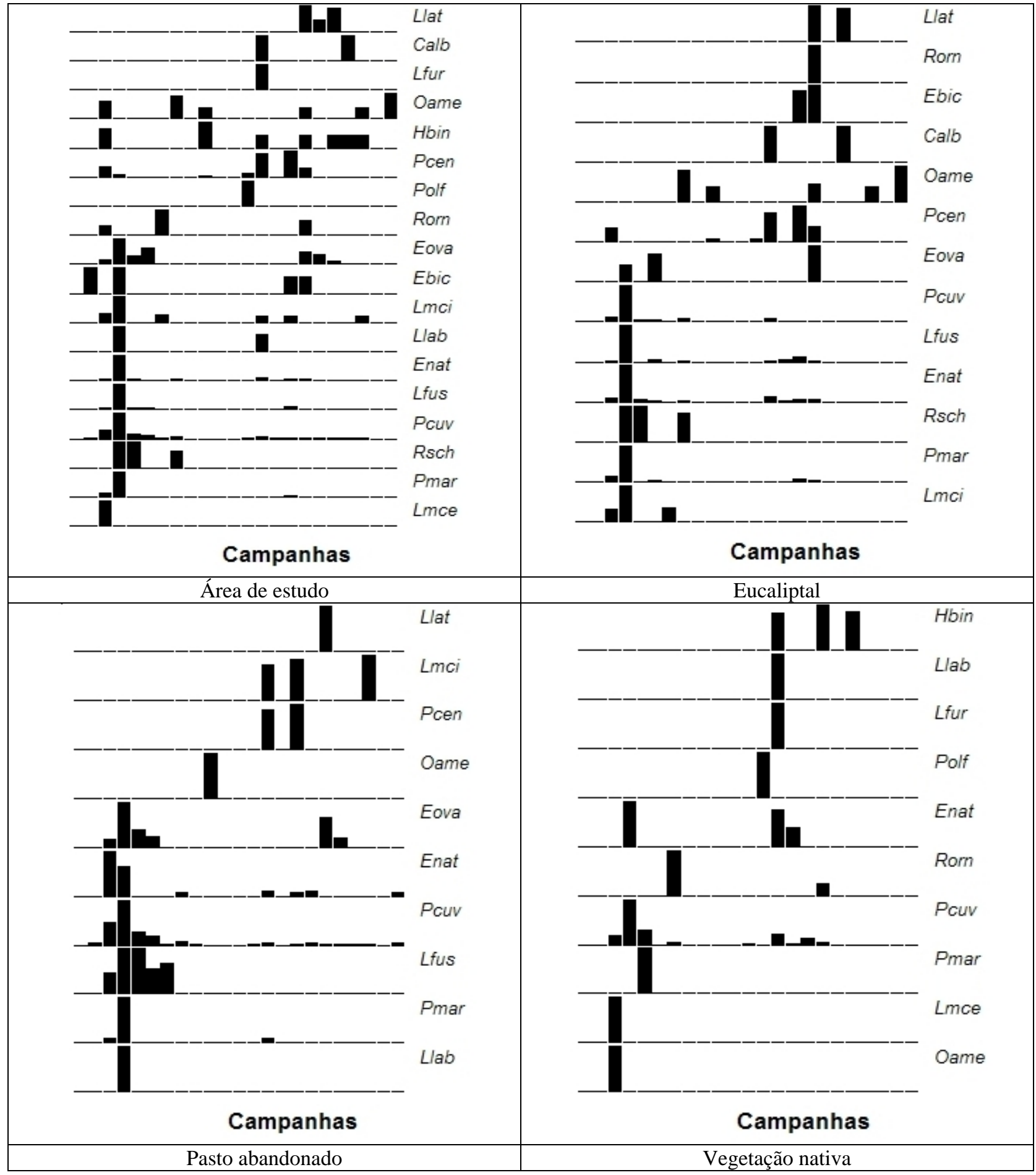

Figura 10 - Variação temporal de espécies registradas nas unidades amostrais distribuídas ao longo das campanhas de coleta (agosto de 2007 a julho de 2009) 
Um dos fatores que mais influencia a atividade dos anfíbios é a precipitação. A maioria das espécies ocorreu com quando a precipitação foi maior (e.g. primavera-verão), demonstrando o período de maior atividade das espécies (Figura 11), quando há maior disponibilidade de recursos.

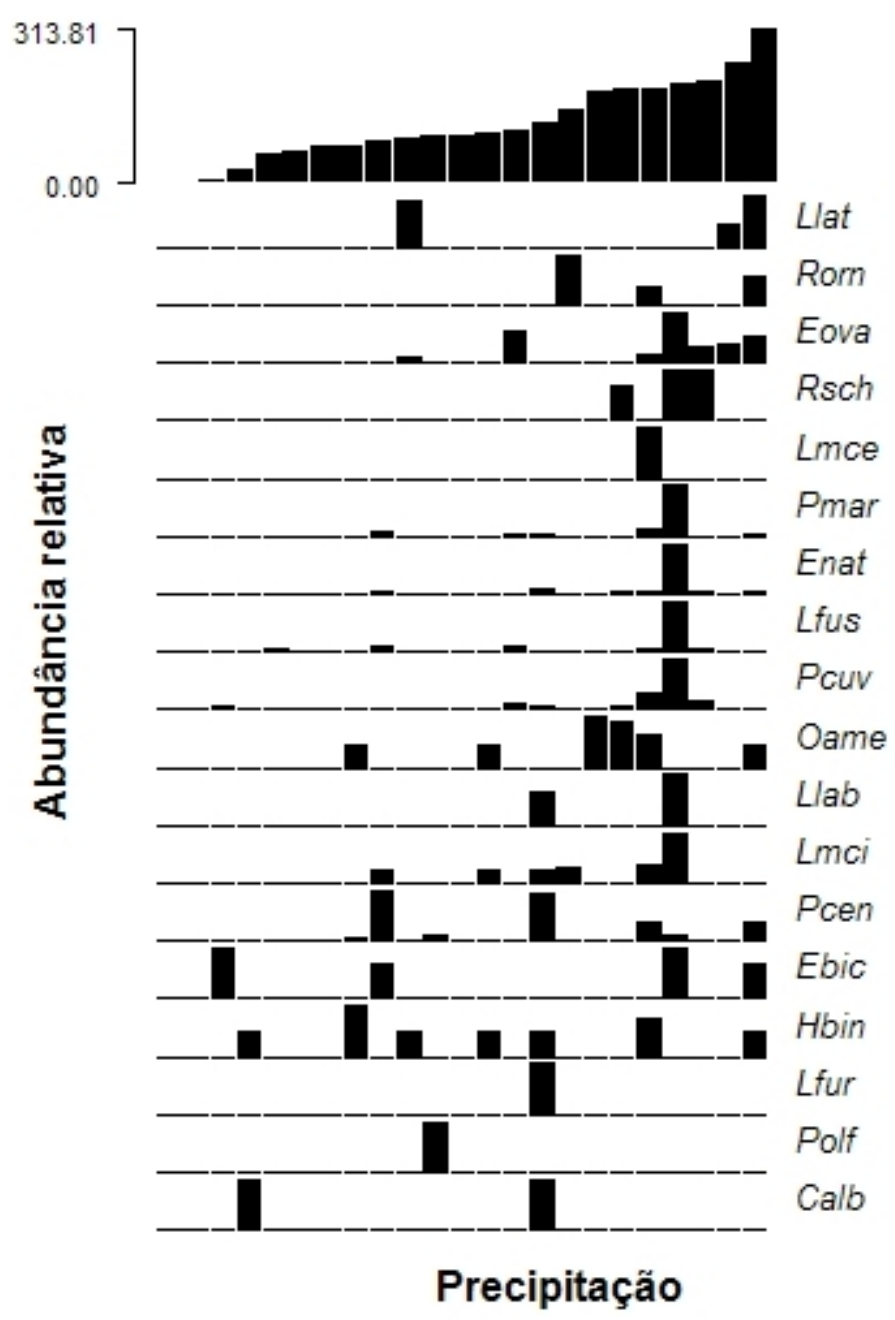

Figura 11 - Distribuição das espécies segundo a precipitação na área de estudo

A Análise de Correspondência (Figura 12) mostra a relação entre as espécies registradas e os três ambientes amostrados. As espécies aparecem próximas aos ambientes onde ocorreram com maior frequência. A análise gerou duas dimensões contendo 38,38\% da variância total, $(24,13 \%$ relativos ao eixo 1 e 14,25\% ao eixo 2). O eixo 2 parece separar ambientes florestais (i.e., vegetação nativa e eucaliptal) de ambiente aberto (i.e., pasto abandonado). O eixo 1 parece 
aproximar o pasto abandonado (cujo processo de revegetação nativa se transforma em capoeira e futuramente em floresta secundária) da vegetação nativa.

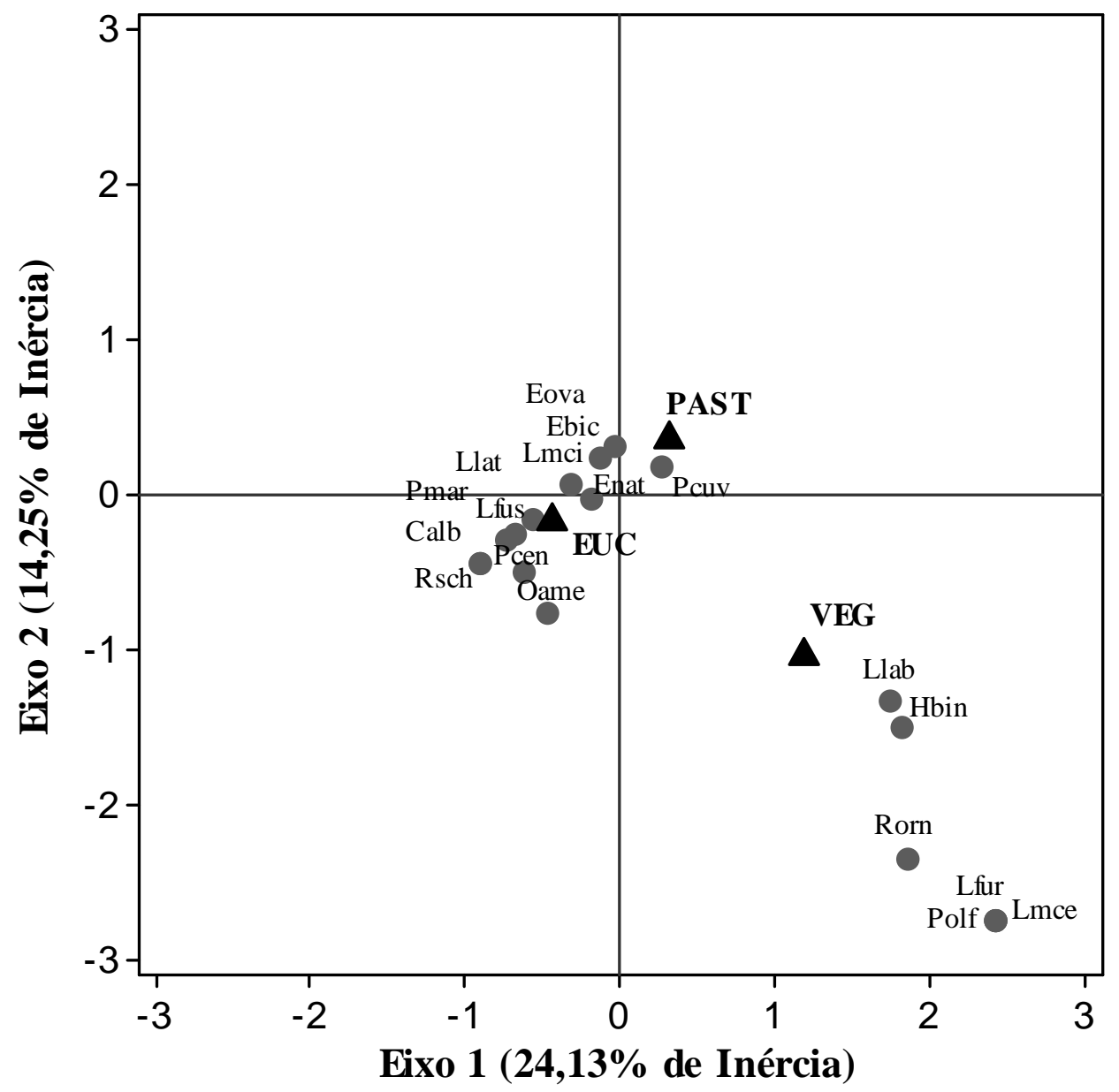

Figura 12 - Análise de correspondência, relacionando as espécies de anfíbios aos ambientes amostrados. EUC: Eucaliptais, PAST: Pasto abandonado e VEG: Vegetação nativa

Não houve variação intra-específica significativa em relação ao comprimento rostrocloacal das espécies (Physalaemus cuvieri, P. marmoratus e Eupemphix nattereri) que foram detectadas em todos os ambientes quanto ao ambiente e sexo. A interação entre sexo e ambiente em tais espécies tampouco foram significativas (ANOVA: $p>0,05$ ).

\subsection{Discussão}

Apesar das significativas alterações ambientais, a diversidade de espécies encontradas na área de estudo é compatível com a de outros estudos realizados em Cerrado (BERTOLUCI et al., 2007), Itirapina (BRASILEIRO et al., 2005; THOMÉ, 2006) e em outras localidades do estado de 
São Paulo (VASCONCELOS; ROSSA-FERES, 2005; MELO; ROSSA-FERES; JIM., 2007; ZINA et al., 2007; TEIXEIRA; ALMEIDA; JIM, 2009) e de Minas Gerais (GIARETTA et al., 2008). Em todos os ambientes houve dominância de apenas uma espécie (Physalaemus cuvieri), com mais de $50 \%$ dos indivíduos amostrados. Esta espécie é comum e abundante em áreas abertas e alteradas (HADDAD, 1998), mas não costuma ser abundante em áreas conservadas (DIXO; VERDADE, 2006). Nos eucaliptais são também relativamente abundantes as seguintes espécies: Physalaemus marmoratus, Eupemphix nattereri, Leptodactylus fuscus e Physalaemus centralis. Nos pastos abandonados apenas E. nattereri destaca-se das demais espécies (exceto $P$. cuvieri) em termos de abundância, assim como em Nova Itapirema (VASCONCELOS; ROSSAFERES, 2005).

Na vegetação nativa a abundância das espécies é similar, com destaque apenas para $P$. cuvieri, como citado anteriormente e para as espécies que só ocorreram nesse ambiente (Physalaemus olfersii, Leptodactylus mystaceus e Leptodactylus cf. furnarius). O padrão encontrado não permite uma divisão clara entre os ambientes. Isto pode ser devido ao pequeno porte das mudas, no início do plantio, que o assemelhe a um ambiente aberto. Algumas espécies como P. cuvieri, P. centralis, P. marmoratus, E. nattereri, L.furnarius e L. fuscus parecem habitar preferencialmente fisionomias campestres (BASTOS et al., 2003). Espécies generalistas e oportunistas são favorecidas, sendo capazes de viver em pequenos fragmentos florestais e tolerar distúrbios do habitat, enquanto espécies especialistas são mais sensíveis e tendem ao declínio (HENLE et al., 2004).

Anuros de áreas mais abertas (originalmente cobertas por cerrados) têm expandido geograficamente seus limites, em detrimento das espécies florestais, isto é, algumas espécies generalistas tendem a ampliar suas distribuições podendo substituir populações nativas mais especializadas (KATS; FERRER, 2003). Com os desmatamentos promovidos pelo homem, espécies ecologicamente mais generalistas de áreas abertas, como Physalaemus cuvieri e Leptodactylus fuscus foram beneficiadas, passando a ocorrer também nas áreas antes cobertas por floresta. De maneira semelhante, algumas espécies que ocorrem em clareiras naturais, se adaptaram às novas condições de ambientes abertos, como é o caso da perereca Hypsiboas faber (HADDAD, 1998). Tocher et al. (1997) observaram um aumento da riqueza nos fragmentos florestais após isolamento, devido a espécies oportunistas associadas à matriz do habitat alterado (como pastos e capoeira) que invadem os fragmentos. 
As curvas de incidência de espécies apresentam tendência à estabilização. No entanto, algum incremento na riqueza de espécies deverá ocorrer com a continuidade do esforço de coleta, principalmente nas áreas de vegetação nativa e nos pastos abandonados em função do processo de revegetação, criando extratos novos no ambiente e aumentando a quantidade de recursos e nichos disponíveis (i.e., complexidade ambiental).

O sucesso de captura deste estudo foi de 21,04\%, considerado baixo comparativamente a estudos realizados em áreas razoavelmente primitivas. No entanto, a riqueza de espécies encontrada é compatível a outros estudos que utilizam armadilhas de interceptação e queda. Dixo (2001), na Reserva Biológica de Una, encontrou 18 espécies de anuros, com o esforço amostral de 2.592 armadilhas dia e sucesso de captura de 94,4\%. Em Pilar do Sul, Oliveira (2004) encontrou 23 espécies com o esforço amostral de 1.728 armadilhas·dia, e um sucesso de captura de $84,4 \%$ em fragmentos de floresta atlântica e plantios de eucalipto.

Para entender os padrões de distribuição espacial e temporal em comunidades animais é necessário conhecer as características do ambiente onde estas se encontram. Cada espécie apresenta tolerância distinta a condições físicas que determinam sua amplitude potencial na ausência de outros organismos ou barreiras geográficas (PEHEK, 1995). Particularmente, os anfíbios apresentam grande sensibilidade a alterações ambientais, pois a qualidade do habitat está intrinsecamente relacionada a seu modo de vida, parcialmente aquática.

Diversas espécies de anuros com modos reprodutivos mais especializados e adaptadas a microhabitats específicos para a reprodução permanecem restritas a áreas de florestas preservadas devido à sua ausência em áreas alteradas (HADDAD, 1998). Os fragmentos florestais podem funcionar como corredores para deslocamento de anuros entre habitats de reprodução e áreas onde realizam outras atividades como alimentação, hibernação e estivação (KNUTSON et al., 1999; WEYRAUCH; GUBB JÚNIOR., 2004). Por outro lado, uma vez que estradas e outros ambientes desfavoráveis podem representar barreiras para o deslocamento dessas espécies (GIBBS, 1998).

A captura de anuros adultos durante a estação seca no presente estudo reforça a importância dos fragmentos florestais como áreas de refúgio. A diminuição no número de capturas parece refletir a menor atividade dos anuros durante este período do ano, em que as condições de umidade e a oferta de alimento são menores (GIBBS, 1998; ALFORD; RICHARDS, 1999; PINHEIRO et al., 2002). 
Espécies que habitam áreas abertas e mais susceptíveis à insolação necessitam de modos mais generalistas de reprodução. Por outro lado, espécies que dependem de microhabitats florestados e úmidos para se reproduzir tendem a desaparecer ou diminuir com a retirada da floresta (HADDAD; PRADO, 2005, UETANABARO et al., 2008). Apesar disso, Peltzer et al. (2003; 2006) verificaram que, mesmo em áreas onde os habitats aquáticos foram severamente alterados, populações de anfíbios tem utilizado plantações ou área em torno para sobrevivência, desenvolvimento e reprodução, substituindo os ambientes naturais que estão desaparecendo (FUJIOKA; LANE, 1997; ELPHICK, 2000).

Ao mesmo tempo em que ações humanas estão reduzindo ou eliminando um grande número de espécies de anuros que dependem de habitats florestados, habitats antrópicos estão se tornando propícios à colonização por algumas espécies mais generalistas (HADDAD, 1998), expandindo assim suas áreas de ocorrência, embora diferentes espécies possam ser afetadas de maneira distinta pelas mudanças na paisagem decorrentes da atividade humana (RUBBO; KIEZECKER, 2005; SWIHART et al., 2003).

A conversão de pastagens em eucaliptais proporciona grandes modificações ao ambiente, como a criação de um extrato arbóreo, aumento de serapilheira, menor compactação do solo e menor incidência direta de luminosidade. Tais fatores podem ser potencialmente benéficos a algumas espécies de anfíbios (ALVES; KOEHLER; MELLO FILHO, 2006). A maior heterogeneidade espacial dos ambientes florestais, mesmo plantados em relação aos ambientes abertos pode suportar uma maior riqueza de espécies por fornecer um maior número de microambientes disponíveis (BERNARDE et al., 1999, SILVANO et al., 2003). Oliveira (2004) sugere que alternativas de manejo nos plantios de eucalipto, como corte seletivo, com manutenção de sub-bosque e manutenção dos talhões com idades diferentes a fim de sempre proporcionar áreas florestadas poderiam favorecer a anurofauna com o aumento da diversidade, evitando a ocupação desse ambiente por espécies generalistas como P. cuvieri.

Nas regiões temperadas, a temperatura é o principal fator na atividade reprodutiva dos anuros, ao passo que nas regiões tropicais e subtropicais a chuva é o principal fator (DUELLMAN; TRUEB, 1994). Nas regiões onde não há sazonalidade acentuada, a maioria das espécies pode se reproduzir ao longo de todo o ano. No entanto, no cerrado a reprodução de grande parte das espécies está restrita à estação chuvosa (BERTOLUCI; RODRIGUES, 2002; PRADO et al., 2005). 
No presente estudo a distribuição temporal das espécies foi compatível com outros estudos, onde a precipitação e/ou a temperatura determinou seu padrão de atividade das espécies (TOLEDO et al., 2003; VASCONCELOS; ROSSA-FERES, 2005; BERTOLUCI et al., 2007, CARMONA, 2007). Tais estudos registraram mudanças nas taxocenoses ao longo dos anos, conforme as alterações climáticas. As mudanças podem ocorrer tanto na composição de espécies quanto no período de reprodução (GASCON, 1991). Isto parece ter ocorrido no presente estudo em que o verão de 2008/2009 foi mais seco que o verão anterior, apresentando menores riqueza e abundância e uma pequena diferença na composição de espécies.

Algumas variáveis ambientais mostraram que algumas espécies podem se tornar mais abundantes em habitats alterados, mas sua composição específica não separa claramente os ambientes. A heterogeneidade espacial da paisagem influencia os padrões naturais de distribuição e diversidade dos animais, uma vez que existem associações entre a fauna e as fitofisionomias (TEWS et al., 2004).

\subsection{Considerações finais}

Os resultados encontrados neste trabalho ressaltam a importância das paisagens silviculturais na conservação de anfíbios. Este estudo detectou uma razoável diversidade de espécies nessas paisagens. A riqueza não parece estar ligada à simplificação da estrutura da vegetação. Quando comparadas a ambientes florestais (i.e., vegetação nativa e eucaliptais) podese observar que ambientes mais conservados contém espécies de hábitos mais restritivos. Isto é importante ressaltar, já que indica a importância da reserva legal e da área de preservação permanente em paisagens silviculturais (assim como agrícolas), o que muitas vezes não ocorre com a pecuária, principalmente quando o gado invade os fragmentos de vegetação nativa, prejudicando a dinâmica da floresta.

A silvicultura de eucalipto é a única entre os grandes setores agroindustriais que respeita razoavelmente a legislação ambiental, promovendo a permanência de áreas de preservação permanente. Essas áreas podem estar minimizando o efeito de borda nos fragmentos de vegetação nativa e funcionando como uma matriz permeável que poderia ser utilizada como habitat e ambiente de deslocamento por algumas espécies entre os fragmentos de vegetação nativa e corpos d'água, promovendo um considerável aumento no valor conservacionista da paisagem (i.e., promovendo a manutenção da diversidade biológica local). 
Os possíveis impactos da silvicultura, principalmente em relação ao uso de agroquímicos e adubos devem ser avaliados a fim de auxiliar no manejo da cultura. Para mitigar os impactos dessa cultura ao ambiente, poderiam ser utilizados métodos menos invasivos de corte dos eucaliptos, em que as plantas do sub-bosque fossem menos danificadas. Outra possibilidade seria a manutenção de talhões em idades diferentes, onde a anurofauna não seria exposta repentinamente a uma alteração brusca de extensas áreas abertas. A formação de corredores com espécies nativas unindo os fragmentos de vegetação nativa poderiam melhorar as condições para a conservação da fauna como um todo.

É importante ressaltar que os resultados obtidos neste estudo devem ser aplicados apenas localmente, visto as circunstâncias em que os eucaliptais estão inseridos, substituindo uma matriz de pastagem exótica após cerca de 30 anos de pecuária extensiva na área de estudo. Este estudo amostrou apenas os dois anos iniciais do plantio, sendo que seu ciclo é de sete anos. A dimensão temporal influencia a distribuição das espécies, principalmente quando associadas a uma grande heterogeneidade espaço-temporal, como é o caso da dinâmica de grandes culturas agrícolas no estado de São Paulo.

Estudos de curta duração não conseguem explicar os processos ecológicos que ocorrem no ambiente, tendo apenas resultados imediatos que, consequentemente, podem se tornar equivocados e devem por isso ser utilizados com cautela. Somente estudos contínuos e de longa duração podem diferenciar impactos antrópicos de flutuações naturais de populações. Por meio de estudos padronizados entre áreas que recebem impactos humanos diferentes, poder-se-á ajustar a resposta ecológica do ecossistema tropical a um gradiente de ação antropogênica. Esses estudos são necessários para o processo de tomada de decisões ligados à políticas públicas de conservação biológica. 


\section{Referências}

ALFORD, R.A; RICHARDS, S.J. Global amphibian declines: a problem in applied ecology. Annual Review of Ecology and Systematics, Palo Alto, v. 30, p. 133-165, Nov. 1999.

ALVES, M.V.G.; KOEHLER, H.S.; MELLO FILHO, B. Tendências e perspectivas para o setor florestal brasileiro. 2006. Disponível em: 〈http://WwW_iufro.org/ uploads/media/t1-alves-marcosdiag-for-br.pdf. Acesso em: 09 mar.2007.

ARAÚJO, C.O.; CONDEZ, T.H.; R.J.S. SAWAYA. Anfíbios Anuros do Parque Estadual das Furnas do Bom Jesus, sudeste do Brasil, e suas relações com outras taxocenoses no Brasil. Biota Neotropica, São Paulo, v. 9, n. 2. 2009. Disponível em: Shttp://www.biotaneotropica.org.br/ v9n2/pt/abstract? article+bn01309022009>. Acesso em: 05 maio 2009.

BASTOS, R.P., MOTTA, J.A.O., LIMA, L.P.; GUIMARÃES, L.D. Anfíbios da Floresta Nacional de Silvânia, estado de Goiás. Goiânia: R.P. Bastos, 2003. 82p.

BERNARDE, P.S.; MACEDO, L.C. Impacto do desmatamento e formação de pastagens sobre a anurofauna de serapilheira em Rondônia. Iheringia, Série Zoologia, Porto Alegre, v. 98, n. 4, p. 454-459, dez. 2008.

BERNARDE, P.S.; KOKUBUM, M.C.N.; MACHADO, R.A.; ANJOS, L. Uso de habitats naturais e antrópicos pelos anuros em uma localidade no Estado de Rondônia, Brasil (Amphibia:Anura). Acta Amazônica, Manaus, v. 29, n. 4, p. 555-562, 1999.

BÉRNILS, R.S. (org.). 2010. Brazilian reptiles - List of species. Disponível em: ל'ttp://Www.sbherpetologia.org.bry. Sociedade Brasileira de Herpetologia. Acesso em: 31 maio 2010 .

BERTOLUCI, J.; RODRIGUES, M.T. Seasonal patterns of breeding activity of Atlantic Rainforest anurans at Boracéia, Southeastern Brazil. Amphibia-Reptilia, Leiden, v. 23, p. 161167, 2002.

BERTOLUCI, J.; BRASSALOTI, R.A.; RIBEIRO JÚNIOR, J.W.; VILELA, V.M.F.N.;

SAWAKUCHI, H.O. Species composition and similarities among anuran assemblages of Forest sites in Southeastern Brazil. Scientia Agricola, Piracicaba, v. 64, n. 4, p. 364-374, Jul-Aug 2007. 
BLOCK, M.B.; MORRISON M.L.; SCOTT, P.E. Development and evaluation of habitat models for herpetofauna and small mammals. Forest Science, Bethesda, v. 44, n. 3, p. 430-437, Aug. 1998.

BRASILEIRO, C.A.; SAWAYA, R.J.; KIEFER, M.C.; MARTINS, M. Amphibians of an open Cerrado fragment in southeastern Brazil. Biota Neotropica, São Paulo, v. 5, n. 2. 2005. Disponível em: 〈http://www.biotaneotropica.org.br/v5n2/pt/abstract?article+BN00405022005 Acesso em: 12 mar. 2007.

CARMONA, R.U. Estudo da comunidade de anfíbios e répteis em um fragmento de Mata Atlântica e em áreas perturbadas no Estado de São Paulo: subsídios para conservação e manejo de áreas protegidas. 90p. 2007. Dissertação (Mestrado em Sistemas Florestais) - Escola Superior de Agricultura “Luiz de Queiroz”, Universidade de São Paulo, Piracicaba. 2007.

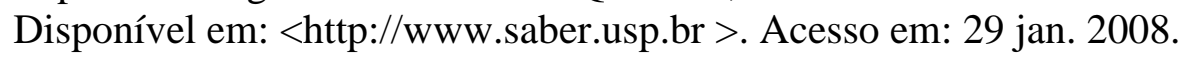

CECHIN, S.Z.; MARTINS, M. 2000. Eficiência de armadilhas de queda (pitfall traps) em amostragens de anfíbios e répteis no Brasil. Revista Brasileira de Zoologia, Curitiba, v. 17, n. 3, p. 729-740, set. 2000 .

CHIARELLO, A.G. Conservation value of a native forest fragment in a region of extensive agriculture. Brazilian Journal of Biology, São Carlos, v. 60, n. 2, p. 237-247, maio 2000.

COLWELL, R.K. EstimateS: statistical estimation of species richness and shared species from samples, versão 7.0. U.S.A. 2004.

COLWELL, R.K.; CODDINGTON, J.A. Estimating terrestrial biodiversity through extrapolation. Philosophical Transaction of the Royal Society of London, London, v. 345, p. 101-118, 1994.

CORN, P.S. Straight-line drift fences and pitfall traps. In: HEYER, W.R.; DONNELY, M.A.; MCDIARMID, R.W.; HAYEK, L.C.; FOSTER, M.S. (Ed.). Measuring and monitoring biological diversity. Standard methods for amphibians. Washington and London: Smithsonian Institution Press, 1994. p. 109-117.

DIXO, M.B.O. Efeito da fragmentação da floresta sobre a comunidade de sapos e lagartos de serapilheira no sul da Bahia. 2001. 77 p. Dissertação (Mestrado em Ciências - Ecologia) Instituto de Biociências, Universidade de São Paulo, 2001. 
DIXO, M.B.O.; VERDADE, V.K. Herpetofauna de serrapilheira da Reserva Florestal de Morro Grande, Cotia (SP). Biota Neotropica, São Paulo, v. 6, n. 2, p. 1-20, Maio-Agosto 2006.

Disponível em: 〈http://Www.biotaneotropica.org.br/v6n2/2pt/abstract?article+1' bn00706022006>. Acesso em: 12 abril 2007.

DUELLMAN, W.; TRUEB, L. Biology of amphibians. New York: McGraw-Hill Book, 1994. 670p.

ELPHICK, C.S. Functional equivalency between rice fields and seminatural wetland habitats. Conservation Biology, Cambridge, v. 14, n. 1, p. 181-191, Feb. 2000.

FRANÇA, F.G.R.; ARAÚJO, A.F.B. The conservation status of snakes in central Brazil. South American Journal of Herpetology, São Paulo, v. 1, n.1, p. 25-36, Apr. 2006.

FROST, D.R. Amphibian Species of the World: an online reference. Versão 5.2, Database Eletrônica. Disponível em: 〈http://research.amnh.org/herpetology/amphibia/index.php̀. American Museum of Natural History, New York, USA. Acesso em: 30 abril 2010.

FUJIOKA, M.; LANE, S.J. The impact of changing irrigation practices in rice fields on frog populations of the Kanto Plain, central Japan. Ecological Research, Berlin, v. 12, p. 101-108, 1997.

GASCON, C. Population-and community-level analyses of species occurrences of Central Amazonian Rainforest tadpoles. Ecology, Brooklyn, v. 72, n. 5, p.1731-1746, 1991.

GIARETTA, A.A., MENIN, M., FACURE, K.G., KOKUBUM, M.N.C.; OLIVEIRA FILHO, J.C. Species richness, relative abundance, and habitat of reproduction of terrestrial frogs in the Triângulo Mineiro region, Cerrado biome, southeastern Brazil. Iheringia, Série Zoologia, Porto Alegre, v. 98, n. 2, p. 181-188, 2008.

GIBBS, J.P. Amphibian movements in response to forest edges, roads, and streambeds in Southern New England. Journal of Wildlife Management, Lawrence, v. 62, n. 2, p. 584-589, 1998.

GOTELLI, N.J.; COLWELL, R.K. Quantifying biodiversity: procedures and pitfalls in the measurement and comparison of species richness. Ecology Letters, Oxford, v. 4, p. 379-391, 2001. 
HADDAD, C.F.B. Biodiversidade dos anfíbios no estado de São Paulo. In: Biodiversidade do Estado de São Paulo, Brasil. Síntese do conhecimento ao final do século XX. CASTRO, R. (Ed.). São Paulo: FAPESP, 1998. p. 17-26: 6. Vertebrados.

HADDAD, C.F.B.; PRADO, C.P.A. Reproductive modes in frogs and their unexpected diversity in the Atlantic forest of Brazil. BioScience, Washington, v. 55, n. 3, p. 207-217, Mar. 2005.

HEINEN, J.T. Comparisons of the leaf litter herpetofauna in abandoned cacao plantations and primary rain forest in Costa Rica: some implications for faunal restoration. Biotropica, Lawrence, v. 24, n. 3, p. 431-439, Sept. 1992.

HENLE, K.; DAVIES, K.F.; KLEYER, M.; MARGULES, C.; SETTELE, J. Predictors of species sensitivity to fragmentation. Biodiversity and Conservation, London, v. 13, n. 1, p. 207-251, 2004.

KATS, L.B.; FERRER, R.P. Alien predator and amphibian declines: review of two decades of science and transition to conservation. Diversity and Distributions, Oxford, v. 9, n. 2, p. 99-110, 2003.

KNUTSON, M.G., SAUER, J.R., OLSEN, D.A., MOSSMAN, M.J., HEMESATH, L.M.; LANNOO, M.J. Effects of landscape composition and wetland fragmentation on frog and toad abundance and species richness in Iowa and Wisconsin, U.S.A. Conservation Biology, Cambridge, v. 13, n. 6, p. 1437-1446, Dec. 1999.

KRONKA, F.J.N.; NALON; M.A.; MATSUKUMA, C.K.; PAVÃO, M.; KANASHIRO, M.M.; YWANE, M.S.S.; LIMA, L.M.P.R.; GUILLAUMON, J.R.; BAITELLO, J.B.; MONTEIRO, C.H.B. Inventário florestal das áreas reflorestadas do Estado de São Paulo. São Paulo: Pancron, 2002. v.1. 183 p.

KRONKA, F.J.N.; NALON, M.A.; MATSUKUMA, C.K.; KANASHIRO, M.M.; YWANE, M.S.S.; LIMA, L.M.P.R.; GUILLAUMON, J.R.; BARRADAS, A.M.F.; PAVÃO, M.; MANETTI, L.A.; BORGO, S.C. Mapeamento e quantificação do reflorestamento no Estado de São Paulo. Disponível em: 〈http://Www.sp.br.emb-japan.go.jp/portugues/img/, simp_kronka.pdf>. Acesso em: 05 maio 2006.

MAFFEI, F.; MAIA, J.L.S.; HEUBEL, M.T.C.D.; COELHO, A.R. 2005. Levantamento da anurofauna em área de reflorestamento de eucalipto, Angatuba, SP. In: CONGRESSO BRASILEIRO DE HERPETOLOGIA, 2., 2005. Belo Horizonte. Resumos... Belo Horizonte, 2005. 1 CD-ROM. 
MAGNUSSON, W.E.; LIMA, A.P.; LUIZÃO, R.; LUIZÃO, F.; COSTA, F.R.C.; CASTILHO, C.V.; KINUPP, V.F. RAPELD: a modification of the Gentry method for biodiversity surveys in long term ecological research sites. Biota Neotropica, São Paulo, v. 5, n. 2. jul.-dez. 2009.

Disponível em: $\langle$ http://Www.biotaneotropica.org.br/v5n2/pt/abstract?point-of-view+bun 01005022005>. Acesso em: 04 set. 2006.

MANLY, B.F.J. Multivariate statistical methods: a primer. 1994. 215p.

MELO, G.V.; ROSSA-FERES, D.C.; JIM, J. Variação temporal no sítio de vocalização em uma comunidade de anuros de Botucatu, Estado de São Paulo, Brasil. Biota Neotropica, São Paulo, v. 7, n. 2, p. 93-102, abr-jun, 2007.

MINITAB INC. 2008. Minitab 15. U.S.A.

OLIVEIRA, S.H. Diversidade de anuros de serapilheira em fragmentos de Floresta Atlântica e plantios de Eucaliptus saligna no Município de Pilar do Sul, SP. 2004. 60p. Dissertação (Mestrado em Ecologia Aplicada) - Escola Superior de Agricultura "Luiz de Queiroz", Universidade de São Paulo, Piracicaba, 2004. Disponível em:

〈http://Www.saber.usp.bù >. Acesso em: 29 maio 2007.

OTT, E.R. Analysis of means: a graphical procedure. Journal of Quality Technology, Milwaukee, v. 15, p. 10-18, 1983.

PEHEK, E.L. Competition, pH, and the ecology of larval Hyla andersonii. Ecology, Washington, v. 76, p. 1786-1793, Sept. 1995.

PELTZER, P.M.; LAJMANOVICH, R.C.; BELTZER, A.H. The effects of habitat fragmentation on amphibian species richness in the floodplain of the middle Parana River. Herpetological Journal, Angus, v. 13, n. 2, p. 95-98, 2003.

PELTZER, P.M.; LAJMANOVICH, R.C.; ATTADEMO, A.M.; BELTZER, A.H. Anuran diversity across agricultural pond in Argentina. Biodiversity and Conservation, London, v. 15, p. 3499-3513, 2006. 
PEREIRA-SILVA, E.F.L.; SANTOS, J.E.; KAGEYAMA, P.Y.; HARDT, E. Florística e fitossociologia dos estratos arbustivo e arbóreo de um remanescente de Cerradão em uma Unidade de Conservação do Estado de São Paulo. Revista Brasileira de Botânica, São Paulo, v. 27, n. 3, p. 533-544, jul-set. 2004.

PINHEIRO, F.; DINIZ, I.R.; COELHO, D.; BANDEIRA, M.P.S. Seasonal pattern of insect abundance in the Brazilian cerrado. Austral Ecology, Adelaide, v. 27, n. 2, p. 132-136, 2002.

PRADO, C.P.A., UETANABARO, M.; HADDAD, C.F.B. Breding activity patterns, reproductive modes, and habitat use by anurans (Amphibia) in a seasonal environment in the Pantanal, Brasil. Amphibia-Reptilia, Leiden, v. 26, n. 1, p. 1-11, 2005.

SÃO PAULO (Estado). Secretaria de Agricultura e Abastecimento. Coordenadoria de Assistência Técnica Integral. Instituto de Economia Agrícola. Levantamento censitário de unidades de produção agrícola do Estado de São Paulo - LUPA 2007/2008. São Paulo: SAA/CATI/IEA, 2008. Disponível em: 〈http://WWW.cati.sp.gov.br/projetolupà . Acesso em: 12 ago. 2009.

R PROJECT. Programa R. 2009. Disponível em: 〈http://WwW.r-project.org خ. Acesso em: 04 ago.2009.

RUBBO, M.J.; KIEZECKER, J.M. Amphibian breeding distribution in an urbanized landscape. Conservation Biology, Cambridge, v. 19, p. 504-511, 2005.

SAZIMA, I. Répteis. In: LEONEL, C. (Ed.) Intervales. São Paulo: Fundação para a conservação e a produção florestal do Estado de São Paulo: Secretaria de Estado do Meio Ambiente, 2001. p. 146-157.

SIEGEL, S. Nonparametric statistics for the behavioral sciences. New York: McGraw Hill, 1956. $312 \mathrm{p}$.

SILVA, E. Impactos de eucaliptais sobre vertebrados silvestres. In: CONFERÊNCIA IUFRO SOBRE SILVICULTURA E MELHORAMENTO DE EUCALIPTOS, 1997. Salvador. Anais... Salvador: IUFRO, 1997. v. 1, p. 150-153.

SILVA, L.L. O papel do Estado no processo de ocupação das áreas de cerrado entre as décadas de 60 e 80. Caminhos de Geografia, Uberlândia, v. 2, n. 2, p. 24-36, fev. 2001. 
SILVANO, D.L.; COLLI, G.R.; DIXO, M.B.O.; PIMENTA, B.V.S.; WIEDERHECKER, H.C. Anfíbios e Répteis. In: RAMBALDI, D.M.; OLIVEIRA, D.A.S. (Ed.). Fragmentação de Ecossistemas: Causas, efeitos sobre a biodiversidade e recomendações de políticas públicas. Brasília: Ministério do Meio Ambiente/Secretaria de Biodiversidade e Florestas, 2003. p. $183-200$.

STALLINGS, J.R. Small mammals inventories in an Eastern Brazilian Park. Bulletim Florida State Museum, Biological Science, Florida, v. 34, n. 4, p. 153-200, 1989.

SWIHART, R.K.; GEHRING, T.M.; KOLOZSVARY, M.B.; NUPP, T.E. Responses of "resistant" vertebrates to habitat loss and fragmentation: the importance of niche breadth and range boundaries. Diversity and Distributions, Oxford, v. 9, p. 1-18, 2003.

TEIXEIRA, M.G.; ALMEIDA, S.C.; JIM, J. Distribuição espacial e temporal de anfíbios anuros de remanescente de Mata Atlântica no município de Botucatu, São Paulo, Brasil. In: CONGRESSO LATINO AMERICANO DE ECOLOGIA, 3., 2009. São Lourenço-MG. Anais... São Lourenço, 2009. 1 CD-ROM

TEWS, J.; BORSE, U.; GRIMM, V.; TIELBORGER, K.; WICHMANN, M.C.; SCHWAGER, M.; JELTSCH, F. Animal species diversity driven by habitat heterogenity/diversity: the importance of key stones structures. Journal of Biogeography, Oxford, v. 31, p. 79-92, 2004.

THOMÉ, M.T.C. Diversidade de anuros e lagartos em fisionomias de Cerrado na região de Itirapina, Sudeste do Brasil. 59 p. 2006. Dissertação (Mestrado em Ciências - Ecologia) Instituto de Biociências - Universidade de São Paulo, São Paulo. Disponível em: לhttp://WwW.saber.usp.br > Acesso em: 29 maio 2008.

TOCHER, M.D.; GASCON, C.; ZIMMERMAN, B.L. Fragmentation effects on a central Amazonian frog community: a ten-year study. In: LAURENCE, W.F.; BIERREGAARD Jr., R.O. Tropical Forest Remnants: Ecology, management and conservation of fragmented communities. Chicago: The University of Chicago Press, 1997. p. 124-137.

TOLEDO, L.F., ZINA, J.; HADDAD, C.F.B. Distribuição espacial e temporal de uma comunidade de anfíbios anuros do município de Rio Claro, São Paulo, Brasil. Holos Environment, Rio Claro, v. 3, n. 2, p. 136-149, 2003.

UETANABARO, M; PRADO, C.P.A.; RODRIGUES, D.J.; GORDO, M.; CAMPOS, Z. Guia de campo dos anuros do pantanal sul e planaltos de entorno. Cuiabá: Editora UFM e UFMT, 2008. 196p. 
VASCONCELOS, T.S.; ROSSA-FERES, D.C. Diversidade, distribuição espacial e temporal de anfíbios anuros (Amphibia, Anura) na região noroeste do Estado de São Paulo, Brasil. Biota Neotropica, São Paulo, v. 5, n. 2, p. 1-14, abr-jun 2005.

VIANA, V.M.; PINHEIRO, L.A.F.V. Conservação da biodiversidade em fragmentos florestais. Série Técnica IPEF, Piracicaba, v. 12, n. 32, p. 25-42, Dec. 1998.

WEYRAUCH, S.L.; GRUBB JÚNIOR, T.C. Patch and landscape characteristics associated with the distribution of woodland amphibians in an agricultural fragmented landscape: an informationtheorectic approach. Biological Conservation, Oxford, v. 115, p. 443-450, Feb. 2004.

ZAHER, H.; GRAZZIOTIN, F.G.; CADLE, J.E.; MURPHY, R.W.; MOURA-LEITE, J.C.; BONATTO, S.L. Molecular phylogeny of advanced snakes (Serpentes, Caenophidia) with an emphasis on South American Xenodontines: a revised classification and descriptions of new taxa. Papéis Avulsos de Zoologia, São Paulo, v. 49, n. 11, p. 115-153, 2009.

ZAR, J.H. Biostatistical analysis. Upper Saddle River. Prentice Hall, 1996. 662p.

ZINA, J.; ENNSER, J.; PINHEIRO, S.C.P.; HADDAD, C.F.B.; TOLEDO, L.F. Anurans of a semidecidual forest in the interior of the São Paulo state and comparisons with other assemblages of the state, southeastern Brazil. Biota Neotropica, São Paulo, v. 7, n. 2, p. 49-57, Apr-Jun, 2007. 


\section{PADRÃO ESPAÇO-TEMPORAL DE DISTRIBUIÇÃO E ABUNDÂNCIA DE ANFÍBIOS NEOTROPICAIS EM PLANTAÇÕES DE EUCALIPTO (Eucalyptus spp.)}

\section{Resumo}

A maioria dos estudos sobre biodiversidade realizados no Brasil é desenvolvida em remanescentes de vegetação nativa. Entretanto, estudos recentes sugerem que paisagens agrícolas suportam uma considerável biodiversidade. Este estudo foi desenvolvido na Fazenda Três Lagoas, localizada na região do Alto Paranapanema. A área de 3.209 ha inicialmente possuía uma matriz de pastagem (Brachiaria spp.), que foi substituída por plantações de eucalipto durante o período de agosto de 2006 a novembro de 2007. Neste estudo foram levantados anfíbios anuros de serapilheira de eucaliptais em 14 unidades amostrais formadas por armadilhas de interceptação e queda dispostas em forma de grade, com uma distância de um quilômetro um das outras, com um esforço amostral total de 2.542 armadilhas.dia. Foram detectadas 12 espécies, sendo a maioria de anuros de áreas abertas. Possivelmente por serem espécies generalistas, não houve relação entre a distância da vegetação nativa e do corpo d'água mais próximos no seu padrão de distribuição e abundância no interior dos eucaliptais. No entanto, estudos futuros sobre o possível uso de áreas de vegetação nativa por tais espécies em algum momento de seu ciclo (e.g., reprodução) poderão ser priorizados.

Palavras-chave: Anura; Vegetação nativa; Corpo d'água; Eucalipto 


\title{
SPACIAL-TEMPORAL PATTERN OF DISTRIBUTION AND ABUNDANCE OF NEOTROPICAL AMPHIBIANS IN EUCALYPTUS PLANTATIONS
}

\begin{abstract}
Most studies on biodiversity conducted in Brazil are accomplished in remnants of native vegetation. However, recent studies suggest that agricultural landscapes support a considerable biodiversity. The present study was conducted in Três Lagoas farm, located in the Upper Paranapanema basin. The area of 3,209 ha initially had a pasture matrix (Brachiaria spp.), which was replaced by eucalyptus plantations from August 2006 to November 2007. During the present study amphibians from eucalyptus litter were surveyed in 14 sampling units containing pitfall traps arranged in a grid one kilometer apart from each other, with a total sampling effort of 2.542 trap-days. 12 species were detected, most of them are anurans of open areas. Possibly because they are generalists, there was no relationship between the distance of native vegetation and of the closest water bodies on their distribution pattern and abundance within the eucalyptus forests. However, future studies on the possible use of native vegetation by these species at some point in their cycle (e.g., reproduction) may be prioritized.
\end{abstract}

Keywords: Anura; Natural forest; Waterbody; Eucalyptus 


\subsection{Introdução}

A heterogeneidade espacial da paisagem influencia os padrões naturais de distribuição e diversidade das espécies, uma vez que existem associações entre a fauna e as diversas fitofisionomias (TEWS et al., 2004). Os padrões naturais de distribuição de espécies são um dos aspectos mais relevantes na elaboração de estratégias de conservação da fauna e flora silvestres. A ação antrópica causa modificações na estrutura das comunidades, devido não somente às alterações na fisionomia dos ambientes, mas também aos distúrbios em relações de predação, competição e partilha temporal dos recursos entre as espécies (ETEROVICK; SAZIMA, 2000; SILVANO et al., 2003). Tais processos podem comprometer o fluxo gênico e a dispersão dos indivíduos, resultando em declínio populacional (FEDER; BURGGREN, 1992; YOUNG et al., 2000).

Os anfíbios constituem um grupo adequado para estudos em escala de paisagem, pois dependem em geral de dois ambientes distintos: aquático (corpos d'água ou simples umidade do ar) para reprodução, e terrestre para forrageio, estivação, migração e dispersão (STEBBINS; COHEN, 1995; ZUG; VITT; CALDWELL, 2001). Os anfíbios apresentam por isso forte sensibilidade a alterações de parâmetros físicos e químicos da água (UETANABARO et al., 2008). Muitas espécies também são sensíveis a alterações na estrutura da vegetação próxima aos corpos d'água (JIM, 1980; WATSON; DAVIES; TYLER, 1995; VALAN, 2002; PARRIS, 2004; RENKEN et al., 2004). Além disso, seus padrões de dispersão e as distâncias entre sítios de alimentação estão intrinsecamente relacionados com a qualidade do habitat (DUELLMAN; TRUEB, 1994; PELTZER; LAJMANOVICH; BELTZER, 2003).

A fragmentação de habitats, os desmatamentos para a expansão da agricultura e a contaminação das águas pelo uso de agrotóxicos e fertilizantes são tidos como principais causas da perda de diversidade e extinção local de espécies de anuros em todo o mundo (GRAY et al., 2004; YOUNG et al., 2004). Os plantios de eucalipto utilizam principalmente em seu início de plantio, agroquímicos, visando aumento em sua produtividade.

O constante crescimento populacional humano e a consequente degradação ambiental decorrente de tal processo podem proporcionar a ocupação de agroecossistemas por parte de diversas espécies silvestres (HOLE et al., 2005; PEH et al., 2005), incluindo os anuros (BABBITT; TANNER, 2000; PELTZER et al., 2003; 2006; 2008). Neste contexto, as plantações 
podem exercer um papel significativo como habitat, substituindo os ambientes naturais em declínio (FUJIOKA; LANE 1997; ELPHICK, 2000).

Os fragmentos florestais podem funcionar como corredores para deslocamento de anuros entre habitats de reprodução e áreas onde realizam outras atividades como alimentação, hibernação e estivação (KNUTSON et al., 1999; MARSH; TRENHAM, 2001; WEYRAUCH; GUBB JÚNIOR, 2004; HADDAD; PRADO, 2005), uma vez que estradas e outros ambientes menos favoráveis devem provavelmente constituir barreiras para seu deslocamento (GIBBS, 1998). A temperatura elevada e a baixa umidade encontrada em áreas de pasto devem ser limitantes para os anfíbios, que apresentam perda de água por transpiração e relativamente baixa capacidade de dispersão (ROTHERMEL; SEMLITSCH, 2002). No entanto, os anfíbios em áreas florestais, parecem não responder ao tamanho e a complexidade do ambiente, mas à diversidade e quantidade de habitats de reprodução (ZIMMERMAM; BIERRERGAARD, 1986).

Apesar de muitos autores sugerirem que fragmentos florestais são importantes para anuros de áreas abertas, a taxa e o modo de utilização desses fragmentos ainda são pouco conhecidos. Este estudo tem como objetivo verificar os padrões de distribuição e abundância de anfíbios anuros em eucaliptais em fase inicial de plantio (i.e., 0 a 3 anos), a fim de inferir sobre a possível relação entre a distribuição das espécies em tal ambiente e a distância em relação a corpos d'água e fragmentos de vegetação nativa.

\subsection{Material e Métodos}

\subsection{1 Área de Estudo}

O presente estudo foi realizado na Fazenda Três Lagoas ( $23^{\circ} 29^{\prime} 23^{\prime \prime} \mathrm{S}$ e $48^{\circ} 24^{\prime} 46^{\prime \prime} \mathrm{O}$ ), situada no município de Angatuba, centro-sul do Estado de São Paulo. Sua área total é de 3.209,93 ha. A matriz original, constituída de 2.590 ha de pastagem exótica (Brachiaria spp.), foi substituída parcialmente por plantações de eucalipto (2.223,9 ha) entre agosto de 2006 e novembro de 2007, ampliando a Reserva Legal (RL) da fazenda para 586,52 ha e a Área de Preservação Permanente (APP) para 269,23 ha (Figura 1).

A vegetação nativa encontra-se em estágios inicial e secundário de regeneração. $\mathrm{O}$ cerradão é a fitofisionomia predominante, seguida de cerrado sensu stricto e alguns trechos de matas de galeria. Os corpos d'água são representados por riachos, lagoas e açudes. 
As plantações de eucalipto contém Eucalyptus grandis, E. urophila e seu híbrido E. urograndis. Nestas plantações há a presença de árvores esparsas, remanescentes de cobertura vegetal prévia a retirada da floresta. A região possui clima temperado úmido com verão quente (Cfa) de acordo com o sistema de Köppen, com precipitação variando de 0 a $300 \mathrm{~mm}$ e acúmulo anual de aproximadamente $1300 \mathrm{~mm}$, no inverno com valores menores de $100 \mathrm{~mm}$ ano mês e no verão maior que $150 \mathrm{~mm}$ ao mês. Temperatura média em torno de $20^{\circ} \mathrm{C}$, variando de temperaturas muito baixas no inverno $\left(4^{\circ} \mathrm{C}\right)$ e quentes no verão $\left(35^{\circ} \mathrm{C}\right)$.

\subsubsection{Delineamento amostral}

O delineamento amostral deste estudo é adaptado a partir do Programa de Pesquisa em Biodiversidade (PPBio), onde as unidades amostrais estão distantes um quilômetro uma das outras, dispostas em forma de grade (MAGNUSSON et al., 2005). Cada unidade amostral foi composta de quatro baldes de 100L dispostos em forma de Y com 15m entre si, sendo um no centro e um em cada extremidade, todos conectados por meio de uma rede plástica com $80 \mathrm{~cm}$ de altura, e 10 cm enterrada do solo (armadilhas de interceptação e queda; CORN, 1994; BLOCK MORRISON; SCOTT, 1998; CECHIN; MARTINS, 2000; DIXO; VERDADE, 2006, BERNARDE; MACEDO, 2008).

No presente estudo, foram usadas 14 unidades amostrais situadas no interior de eucaliptais da Fazenda Três Lagoas. O esforço amostral total foi de 2.542 armadilhas.dia [23 campanhas x 2 dias de coleta/campanha x 14 parcelas x 4 armadilhas (baldes)/parcela], distribuídos entre as 14 parcelas supracitadas. O período de coleta foi de agosto de 2007 a julho de 2009, com 23 campanhas mensais (Licenças ICMBIO - IBAMA n ${ }^{\text {os }} 12623-1$ e 12623-2).

Os animais capturados foram identificados, sendo coletadas as seguintes informações: espécie, data e unidade amostral. Alguns indivíduos foram sacrificados, fixados em formaldeído 10\%, conservados em álcool 70\% e depositados na Coleção "Célio F. B. Haddad" (CFBH), do Instituto de Biociências da Universidade Estadual Paulista - Rio Claro. 


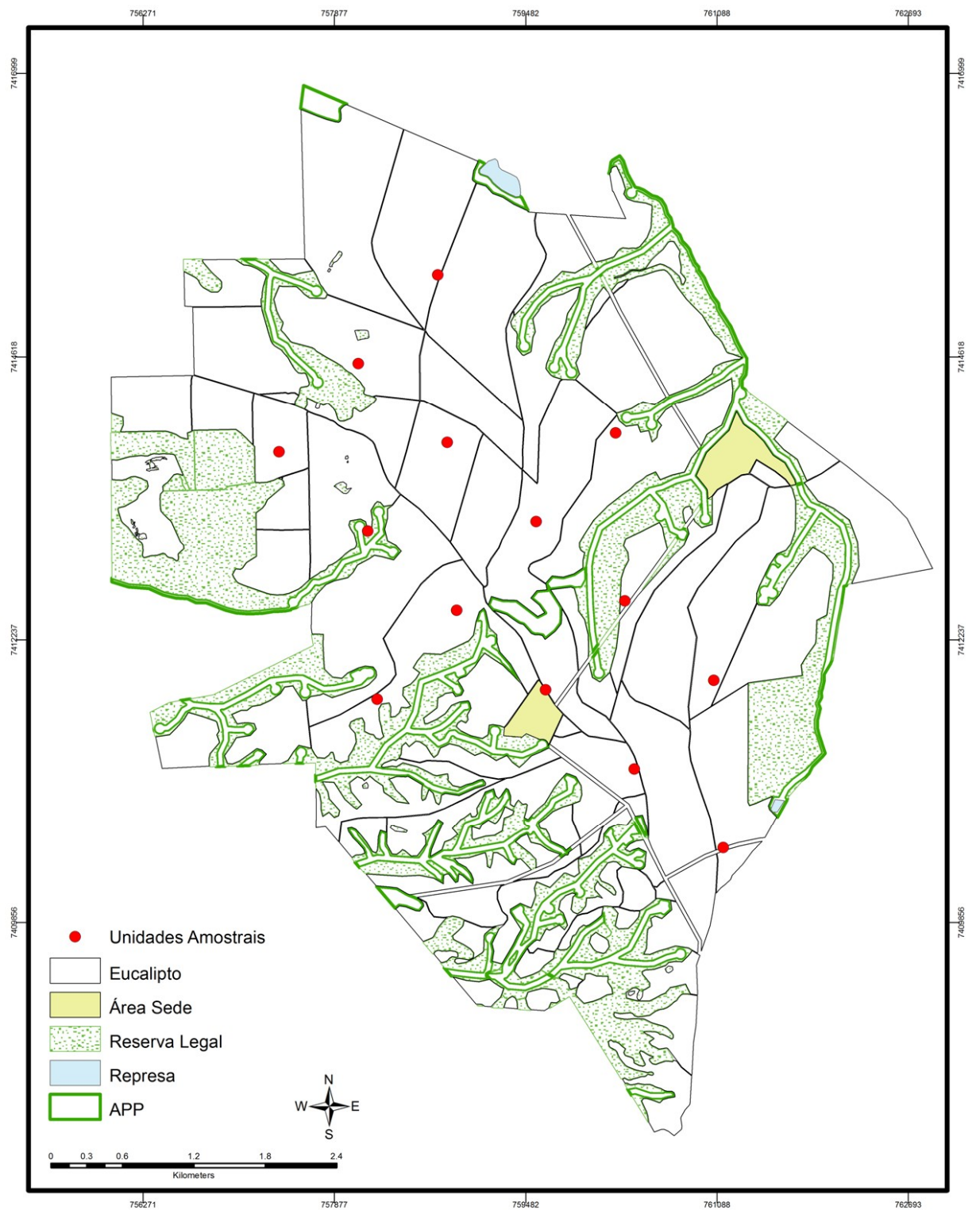

Figura 1 - Fazenda Três Lagoas, região do Alto Paranapanema, estado de São Paulo, apresentando a unidades amostrais de eucalipto

Para análise dos dados foram consideradas como variável independente a distância das unidades amostrais em relação ao corpo d'água e a vegetação nativa mais próxima (Tabela 1) e como variáveis dependentes a riqueza e abundância dos anfíbios coletados nas armadilhas. Foi estabelecida a curva de incidência de espécies por meio de Bootstrap (COLWELL; CODDINGTON, 1994), baseado em 1.000 aleatorizações, com auxílio do software EstimateS (COLWELL, 2004) e do pacote estatístico Minitab (MINITAB, 2008). Para a variação das espécies foi utilizado o software R (R PROJECT, 2009). 
Tabela 1 - Distância mínima entre cada unidade amostral e um fragmento de vegetação nativa ou um corpo d'água, obtida com o auxílio do software ArcView 3.2 (ESRI, 1996)

\begin{tabular}{ccc}
\hline Unidade amostral & Distância da vegetação nativa $(\mathbf{m})$ & Distância de corpo d'água (m) \\
\hline 1 & 900 & 1130 \\
2 & 894 & 707 \\
3 & 883 & 972 \\
4 & 619 & 460 \\
5 & 535 & 673 \\
6 & 450 & 553 \\
7 & 380 & 661 \\
8 & 376 & 369 \\
9 & 335 & 330 \\
10 & 300 & 785 \\
11 & 223 & 438 \\
12 & 200 & 291 \\
13 & 173 & 240 \\
14 & 66 & 60 \\
\hline
\end{tabular}

\subsection{Resultados}

Foram detectadas 12 espécies de anfíbios de serapilheira, pertencentes às famílias Leiuperidae (quatro espécies), Leptodactylidae e Microhylidae, (três espécies cada), Bufonidae e Cycloramphidae (uma espécie cada) (Tabela 2). Foram capturados 468 indivíduos com um sucesso de captura de 0,18 indivíduos $\cdot \operatorname{armadilha}^{-1} \cdot \operatorname{dia}^{-1}$. As espécies mais abundantes foram Physalaemus cuvieri e P. marmoratus.

Tabela 2 - Lista de espécies amostradas no eucalipto, com respectivas abundâncias

\begin{tabular}{lc}
\hline \multicolumn{1}{c}{ Espécie } & $\mathbf{N}^{\mathbf{0}}$ de indivíduos capturados \\
\hline Rhinella schneideri & 2 \\
Leptodactylus fuscus & 38 \\
Leptodactylus latrans & 5 \\
Leptodactylus mystacinus & 4 \\
Odontophrynus americanus & 7 \\
Eupemphix nattereri & 74 \\
Physalaemus centralis & 26 \\
Physalaemus cuvieri & 181 \\
Physalaemus marmoratus & 113 \\
Chiasmocleis albopunctata & 2 \\
Elachistocleis cf. bicolor & 2 \\
Elachistocleis cf. ovalis & 8 \\
\hline
\end{tabular}


A curva de incidência de espécies comparadas por meio do estimador não-paramétrico Bootstrap estima uma riqueza de 12,72 espécies, tendo sido encontradas 12 espécies neste estudo (Figura 2).

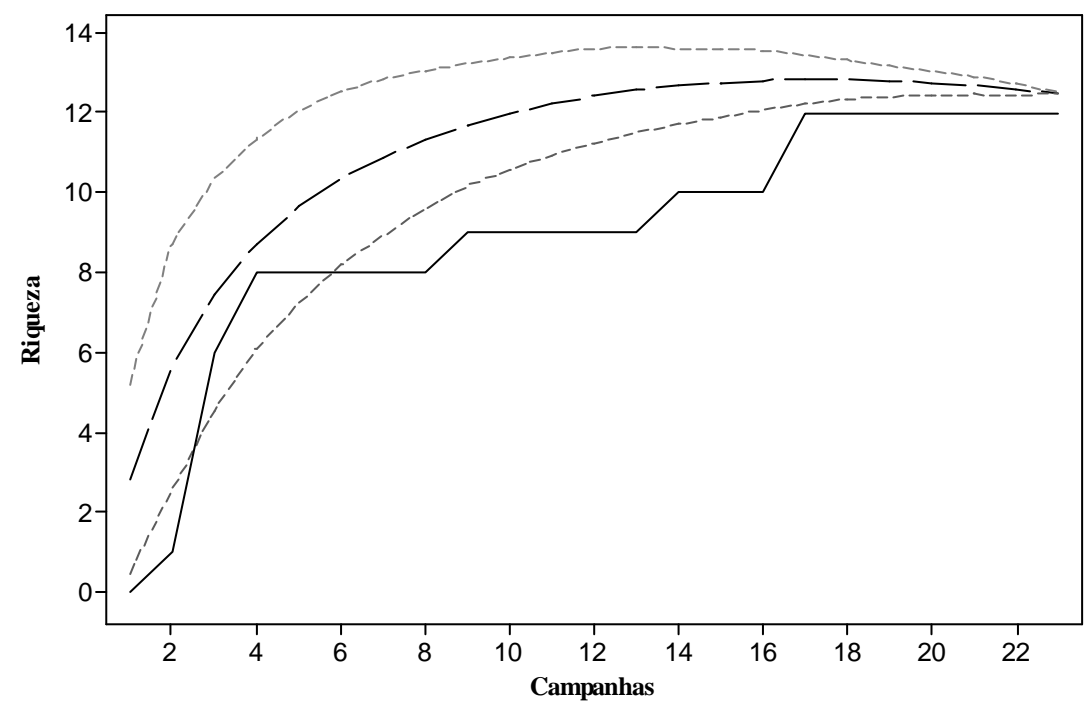

Figura 2 - Curva de incidência de espécies. Linha contínua: riqueza acumulada observada. Linhas tracejadas: média do estimador bootstrap, mais ou menos o desvio padrão

A abundância de anfíbios encontrados nas plantações de eucalipto variou ao longo de toda amostragem, se concentrando nas épocas mais quentes e chuvosas de cada ano (Figura 3).

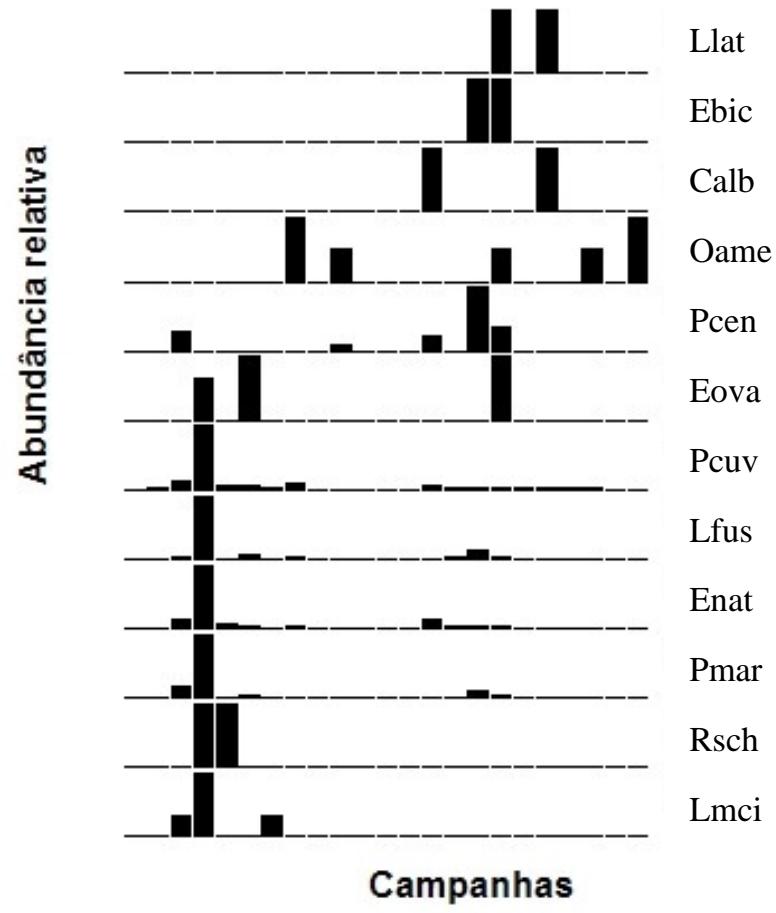

Figura 3 - Variação temporal de espécies nos eucaliptais ao longo das campanhas de coleta (ago 2007 - jul 2009) 
Não há relação entre riqueza ou abundância de anfíbios e distância dos corpos d'água (Figura 4) e vegetação nativa (Figura 5) dos eucaliptais. Os resultados não foram significativos para ambas $(\mathrm{p}>0,05)$ análises de regressão realizadas, não demonstrando haver padrão de deslocamento.

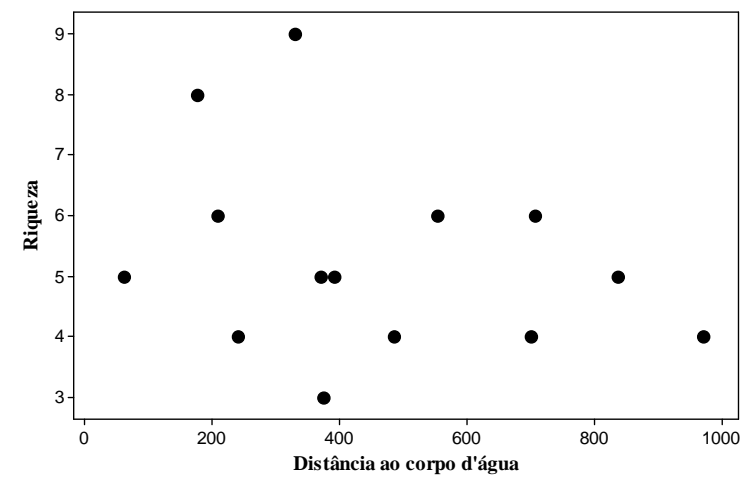

$r=6,01-0,00132 \cdot$ distância_água

$$
\text { g.l.=13 p }=0,309
$$

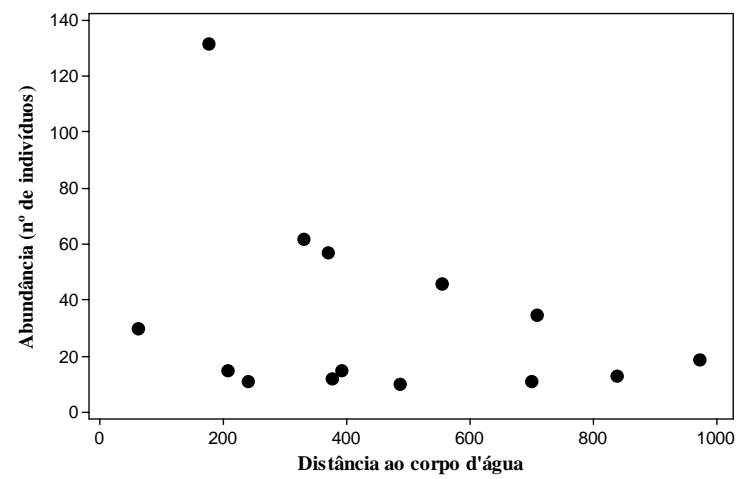

$\mathrm{N}=0,266-0,000152 \cdot$ distância_água

$$
\text { g.l.= } 13 \quad \mathrm{p}=0,236
$$

Figura 4 - Relação entre riqueza e abundância à distância do corpo d'água mais próxima para cada parcela na Fazenda Três Lagoas, Angatuba, estado de São Paulo

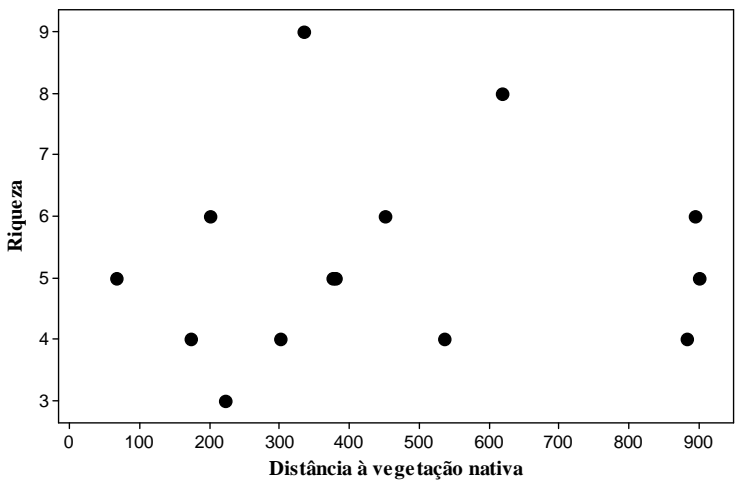

$\mathrm{r}=5,02+0,00059 \cdot$ distância_veg

$$
\text { g.l.=13 } \quad \mathrm{p}=0,791
$$

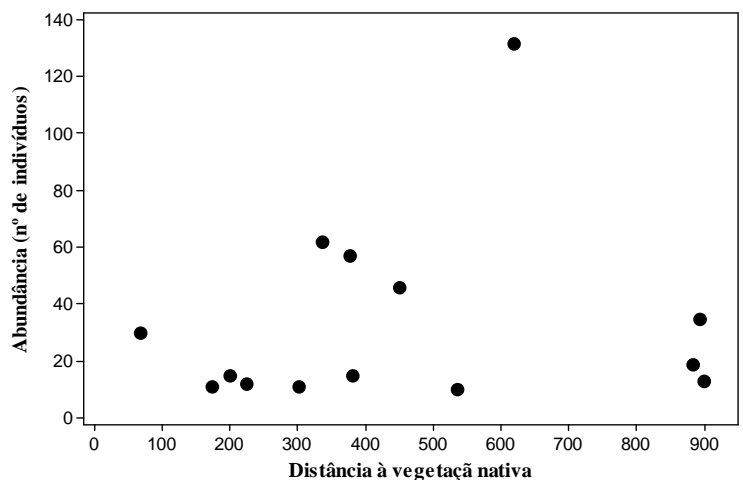

$\mathrm{N}=0,143+0,000089 \cdot$ distância_veg g.l.=13 p $=0,642$

Figura 5 - Relação entre riqueza e abundância à distância do fragmento de vegetação nativa mais próxima para cada parcela na Fazenda Três Lagoas, Angatuba, Estado de São Paulo 


\subsection{Discussão}

As espécies encontradas nos eucaliptais são típicas de áreas abertas e, geralmente são abundantes em sua área de ocorrência (VASCONCELOS; ROSSA-FERES, 2005). Silva et al. (2009) estudaram outros agroecossistemas (soja, milho e seringueira), onde os ambientes naturais eram similares ao deste estudo (cerrado e matas de galeria) no noroeste do estado de São Paulo, e encontrou espécies semelhantes às deste estudo.

Segundo Knutson et al. (1999) e Hazell et al. (2001), a ocorrência de algumas espécies de áreas abertas está associada com a presença de fragmentos florestais próximos a corpos d'água para reprodução. Para essas espécies, os tipos de habitat disponíveis em uma escala regional são de grande importância (PRIMACK; RODRIGUES, 2001). Os fragmentos florestais podem funcionar como corredores para deslocamento de anuros entre habitats de reprodução e áreas onde realizam outras atividades como alimentação, hibernação e estivação (KNUTSON et al., 1999), o que reforça a presença das áreas de preservação permanente e reserva legal nos locais de plantio de eucalipto, assim como enfatiza sua utilização em outras culturas agrícolas.

Dixo (2001) não encontrou diferença entre riqueza e abundância entre fragmentos e matas contínuas, mostrando que provavelmente a simples presença de serapilheira e a manutenção de uma fisionomia florestal nas cabrucas e capoeiras parecem funcionar como extensões de floresta e sejam suficientes para a manutenção da diversidade mesmo nos habitats perturbados. Avaliar se a presença e a manutenção de sub-bosque nos eucaliptais influenciam a distribuição e abundância das espécies pode ser importantes em estudos relacionados à manutenção da diversidade nesses plantios.

Em áreas onde os habitats aquáticos foram severamente alterados, populações de anfíbios têm utilizado plantações ou áreas em torno para sobrevivência, desenvolvimento e reprodução, substituindo os ambientes naturais que estão desaparecendo (FUJIOKA; LANE, 1997; ELPHICK, 2000; PELTZER et al. 2003, 2006). Alguns estudos têm detectado relação positiva entre abundância e riqueza de espécies de anfíbios com os corpos d'água e fragmentos florestais (LAAN; VERBOOM, 1990; FINDLAY; HOULABAN, 1997) e com a área de cobertura florestal nativa (HECNAR; MCLOSKEY, 199; VALAN, 2000; GUERRY; HUNTER, 2002), o que não ocorreu neste estudo. Grande parte das espécies também se relaciona fortemente com a vegetação próxima aos corpos d'água, sendo extremamente suscetível a quaisquer alterações que a estrutura deste tipo de vegetação venha a sofrer, o que pode representar a destruição de substratos 
específicos (RENKEN et al., 2004). A manutenção das áreas de preservação permanente em torno dos riachos e perto dos açudes e lagoas são importantes para proporcionar ambientes favoráveis ao modo reprodutivo de cada espécie.

$\mathrm{Na}$ área de estudo, a presença de açudes e de locais propícios ao acúmulo de água nos talhões de eucalipto possibilitam seu uso por algumas espécies de anuros durante seu período reprodutivo (obs. pessoal). Como consequência destas observações, pode-se sugerir que, em amplas áreas de plantio de eucalipto, as empresas adotem este tipo de manejo para garantir ou auxiliar nos processos ecológicos, garantindo a perpetuação das espécies em tais áreas, além da manutenção da diversidade regional.

A substituição da matriz de pastagem existente na área de estudo pelas plantações de eucalipto parece ter favorecido a dispersão das espécies em um primeiro momento (i.e., início do plantio), o que enfatiza a importância de estudos de longa duração para a compreensão de processos ecológicos mais amplos em função do ciclo longo da produção de eucalipto.

\subsection{Considerações finais}

Este estudo não encontrou relação entre as distâncias da vegetação nativa ou corpos d'água e os eucaliptais. No entanto, estudos em diferentes agroecossistemas podem auxiliar no entendimento de como as espécies passam a ocupar os ambientes, assim como o plantio de eucalipto.

Estudos utilizando outras métricas da paisagem podem ser relevantes para avaliar a permeabilidade dos ambientes originados por ação antrópica. A técnica de marcação e recaptura pode auxiliar no encontro de uma relação existente entre diferentes habitats e a composição de espécies que conseguem ocupar estes ambientes quando há mudança brusca de formação ambiental.

O papel das áreas de fragmentos florestais nativos (APP e reserva legal) por exemplo, na reprodução das espécies locais de anfíbios deverá ser priorizado em estudos futuros. Estudos de longa duração são importantes para auxiliar na compreensão de processos ecológicos em função das mudanças ocasionadas no ambiente. 


\section{Referências}

BABBITT, K.J.; TANNER, G.W. Use of temporary wetlands by anurans in a hydrologically modified landscape. Wetlands, Dordrecht, v. 20, p. 313-322, 2000.

BERNARDE, P.S.; MACEDO, L.C. Impacto do desmatamento e formação de pastagens sobre a anurofauna de serapilheira em Rondônia. Iheringia, Série Zoologia, Porto Alegre, v. 98, n. 4, p. 454-459, dez. 2008.

BLOCK, M.B.; MORRISON M.L.; SCOTT, P.E. Development and evaluation of habitat models for herpetofauna and small mammals. Forest Science, Lawrence, v. 44, n. 3, p. 430-437, 1998.

CECHIN, S.Z.; MARTINS, M. Eficiência de armadilhas de queda (pitfall traps) em amostragens de anfíbios e répteis no Brasil. Revista Brasileira de Zoologia, Curitiba, v. 17, n. 3, p. 729-740, 2000 .

COLWELL, R.K. EstimateS, Versão 7: Statistical estimation of species richness and shared species from samples. 2004.

COLWELL, R.K.; CODDINGTON, J.A. Estimating terrestrial biodiversity through extrapolation. Philosophical Transaction of the Royal Society of London, London, v. 345, p. 101-118, 1994.

CORN, P.S. Straight-line drift fences and pitfall traps. In: HEYER, W.R.; DONNELY, M.A.; MCDIARMID, R.W.; HAYEK, L.C., FOSTER, M.S. (Ed.) Measuring and Monitoring Biological Diversity. Standard Methods for Amphibians. Washington and London: Smithsonian Institution Press, 1994. p. 109-117.

DIXO, M.; VERDADE, V.K. Herpetofauna de serrapilheira da Reserva Florestal de Morro Grande, Cotia (SP). Biota Neotropica, São Paulo, v. 6, n.2, p. 1-20, 2006.

DIXO, M.B.O. Efeito da fragmentação da floresta sobre a comunidade de sapos e lagartos de serapilheira no sul da Bahia. 2001. 77p. Dissertação (Mestrado em Ciências - Ecologia) Instituto de Biociências - Universidade de São Paulo, São Paulo, 2001.

DUELLMAN, W.E.; TRUEB, L. Biology of Amphibians. New York.:McGraw-Hill Publ, 1994. $670 \mathrm{p}$. 
ELPHICK, C.S. Functional equivalency between rice fields and seminatural wetland habitats. Conservation Biology, Cambridge, v. 14, n. 1, p.181-191, 2000.

ESRI. Enviromental Systems Research Institute. ArcView GIS. ESRI (USA). 1996.

ETEROVICK, P.C.; SAZIMA, I. Structure of an anuran community in a montane meadow in southeastern Brazil: effects of seasonality, habitat, and predation. Amphibia-Reptilia, Leiden, v. 21, p. 439-461, 2000.

FEDER, M.E.; BURGGREN, W.W. Environmental Physiology of the Amphibians. Chicago: The University of Chicago Press, 1992. 646 p.

FINDLAY, C. S.; HOULAHAN, J. Anthropogenic correlates of species richness in Southeastern Ontario Wetlands. Conservation Biology, Cambridge, v.11, n. 4, p. 1000-1009, 1997.

FUJIOKA, M.; LANE, S.J. The impact of changing irrigation practices in rice fields on frog populations of the Kanto Plain, central Japan. Ecological Research, Tokyo, v. 12, p. 101-108, 1997.

GIBBS, J.P. Amphibian movements in response to forest edges, roads, and streambeds in Southern New England. Journal of Wildlife Management, Menasha, v. 62, n. 2, p. 584-589, 1998.

GRAY, M.J.; SMITH, L.M.; BRENES, R. Effects of agricultural cultivation on demographics of southern high plains amphibians. Conservation Biology, Cambridge, v.18, n. 5, p. 1368-1377, 2004.

GUERRY, A.D.; HUNTER JÚNIOR, M.L. Amphibian distributions in a landscape of forest and agriculture: an examination of landscape composition and configuration. Conservation Biology, Cambridge, v.16, n. 3, p. 745-754, 2002.

HADDAD, C.F.B.; PRADO, C.P.A. Reproductive modes in frogs and their unexpected diversity in the Atlantic forest of Brazil. BioScience, Uberlândia, v. 55, n. 3, p. 207-217, 2005.

HAZELL, D.; CUNNINGHAM, D.L.; MACKEY, B.; OSBORNE, W. Use of farm dams as frog habitat in an Australian agricultural landscape: factors affecting species richness and distribution. Biological Conservation, Barking, v. 102, p. 155-169, 2001. 
HECNAR, S.J.; M'CLOSKEY, R.T. The effects of predatory fish on amphibian species richness and distribution. Biological Conservation, Barking, v. 79, p. 123-131, 1997.

HOLE, D.G.; PERKINS, A.J.; WILSON, J.D.; ALEXANDER, I.H.; GRICE, P.V.; EVANS, A.D. Does organic farming benefit biodiversity? Biological Conservation, Barking, v. 122, p. 113-130, 2005.

JIM, J. Aspectos ecológicos dos anfíbios registrados na região de Botucatu, São Paulo (Amphibia, Anura). 1980. 332p. Tese (Doutorado em Zoologia) - Universidade de São Paulo, São Paulo, 1980.

KNUTSON, M.G.; SAUER, J.R.; OLSEN, D.A.; MOSSMAN, M.J.; HEMESATH, L.M.; LANNOO, M.J. Effects of landscape composition and wetland fragmentation on frog and toad abundance and species richness in Iowa and Wisconsin, U.S.A. Conservation Biology, Cambridge, v. 13, n. 6, p. 1437-1446, 1999.

LAAN, R.; VERBOOM, B. Effects of pool size and isolation on amphibian communities. Biological Conservation, Barking, v. 54, p. 251-262, 1990.

MAGNUSSON, W.E.; LIMA, A.P.; LUIZÃO, R.; LUIZÃO, F.; COSTA, F.R.C.; CASTILHO, C.V.; KINUPP, V.F. RAPELD: a modification of the Gentry method for biodiversity surveys in long term ecological research sites. Biota Neotropica, v. 5, n. 2. 2005. Disponível em: 〈'tttp://www.biotaneotropica.org.br/v $5 \mathrm{n} 2 / \mathrm{pt} / \mathrm{ab}$ stract?point-of-view+bn 01005022005>. Acesso em: 20 mar. 2007.

MARSH, D.M.; TRENHAM, P.C. Metapopulation dynamics and amphibian conservation. Conservation Biology, Cambridge, v. 15, n.1, p. 40-49, 2001.

MINITAB INC. 2008. Minitab 15. U.S.A.

PARRIS, K.M. Environmental and spatial variables influence the composition of frog assemblages in sub-tropical eastern Australia. Ecography, Copenhagen, v. 27, p. 392-400, 2004.

PEH, K.S.H.; DE JONG, J.; SODHI, N.S.; LIM, S.L.H.; YAP, C.A.M. Lowland rainforest avifauna and human disturbance: persistence of primary forest birds in selectively logged forests and mixed-rural habitats of southern Peninsular Malaysia. Biological Conservation, Barking, v. 123, p. 489-505, 2005. 
PELTZER, P.M.; LAJMANOVICH, R.C.; BELTZER, A.H. The effects of habitat fragmentation on amphibian species richness in the floodplain of the middle Parana River. Herpetological Journal, London, v. 13, n. 2, p. 95-98, 2003.

PELTZER, P.M.; LAJMANOVICH, R.C.; ATTADEMO, A.M.; BELTZER, A.H. Anuran diversity across agricultural pond in Argentina. Biodiversity and Conservation, London, v. 15, p. 3499-3513, 2006.

PELTZER, P.M.; LAJMANOVICH, R.C.; SÁNCHEZ-HERNANDEZ, J.C.; CABAGNA, M.C.; ATTADEMO, A.M.; BASSÓ, A. Effects of agricultural pond eutrophication on survival and health status of Scinax nasicus tadpoles. Ecotoxicology and Environmental, New York, v. 70, p. 185-197, may 2008.

PRIMACK, R.B.; RODRIGUES, E. Biologia da conservação. Londrina: Gráfica e editora Midiograf, 2001. 327p.

R PROJECT. Programa R. 2009. Disponível em: 〈http://WwW.r-project.org

RENKEN, R.B.; WENDY, K.G.; DEBRA, K.F.; STEPHEN, C.R.; TIMOTHY, J.M.; KEVIN, B.R.; BRADLEY, R.; WANG, X. Effects of forest management on amphibians and reptiles in Missouri Ozark Forests. Conservation Biology, Cambridge, v. 18, p. 174-188, 2004.

ROTHERMEL, B.B.; SEMLITSCH, R.D. An experimental investigation of landscape resistance of forest versus old-field habitats to emigrating juvenile amphibians. Conservation Biology, Cambridge, v. 16, p. 1324-1332, 2002.

SILVA, F.R., SANTOS, R.S., NUNES, M.A.; ROSSA-FERES, D.C. Anuros capturados em armadilhas de queda em três agrossistemas no noroeste paulista, Brasil. Biota Neotropica, São Paulo, v. 9, n. 4, 2009. Disponível em: 〈http://Www.biotaneotropica.org.br/v9n4/en/abstract? short-communication+bn01109042009>. Acesso em: 14 mar. 2010.

SILVANO, D.L.; COLLI, G.R.; DIXO, M.B.O.; PIMENTA, B.V.S.; WIEDERHECKER, H.C. Anfíbios e Répteis. In: RAMBALDI, D.M.; OLIVEIRA, D.A.S. (Ed.). Fragmentação de Ecossistemas: Causas, efeitos sobre a biodiversidade e recomendações de políticas públicas. Brasília: Ministério do Meio Ambiente/Secretaria de Biodiversidade e Florestas, 2003. p. $183-200$.

STEBBINS, R.C.; COHEN, N.W. A Natural History of Amphibians. New Jersey: Princeton University Press, 1995. 316p. 
TEWS, J.; BORSE, U.; GRIMM, V.; TIELBORGER, K.; WICHMANN, M.C.; SCHWAGER, M.; JELTSCH, F. Animal species diversity driven by habitat heterogenity/diversity: the importance of key stones structures. Journal of Biogeography, Oxford, v. 31, p. 79-92, 2004.

UETANABARO, M; PRADO, C.P.A.; RODRIGUES, D.J.; GORDO, M.; CAMPOS, Z. Guia de Campo dos Anuros do Pantanal Sul e Planaltos de Entorno. Editora UFM e UFMT, 2008. 192p.

VALAN, D. Effects of anthropogenic environmental changes on amphibian diversity in the rain forests of Eastern Madagascar. Journal of Tropical Ecology, Cambridge, v. 18, p. 725-742, 2002.

VASCONCELOS, T.S.; ROSSA-FERES, D.C. Diversidade, distribuição espacial e temporal de anfíbios anuros (Amphibia, Anura) na região noroeste do Estado de São Paulo, Brasil. Biota Neotropica, São Paulo, v. 5, n. 2, p. 1-14, abr-jun 2005.

WATSON, G.F.; DAVIES, M.; TYLER, M.J. Observations on temporary water in northwestern Australia. Hydrobiologia, Dordrecht, v. 299, p. 53-73, 1995.

WEYRAUCH, S.L.; GUBB JÚNIOR, T.C. Patch and landscape characteristics associated with the distribution of woodland amphibians in an agricultural fragmented landscape: an informationtheorectic approach. Biological Conservation, Barking, v. 115, p. 443-450, 2004.

YOUNG, B E.; LIPS, K.R.; REASER, J K.; IBÁÑES, R.; SALAS, A.W.; CEDEÑO, J.R.; COLOMA, L.A.; RON, S.; MARCA, E.; MEYER, J. R.; MUÑOZ, A.; BOLAÑOS, F.; CHAVES, G.; ROMO, D. Population declines and priorities for amphibian conservation in Latin America. Conservation Biology, Cambridge, v. 15, n. 5, p. 1213-1223, 2000.

YOUNG, B.E.; STUART, S.N.; CHANSON, J.S.; COX, N.A.; BOUCHER, T.M. Joyas que estan desapareciendo: El estado de los anfibios en el Nuevo Mundo. Arlington, Virginia. NatureServe, 2004. 53p.

ZIMMERMAN, B.L.; BIERREGAARD, R.O. Relevance of the equilibrium theory of island biogeography and species-area relations to conservation with a case from Amazonia. Journal of Biogeography, Oxford, v. 13, p. 133-143, 1986.

ZUG, G.R.; VITT, L.J.; CALDWELL, J.P. Herpetology: an introductory biology of amphibians and reptiles. San Diego: Academic Press, 2001. 
ANEXOS 
NEXO A

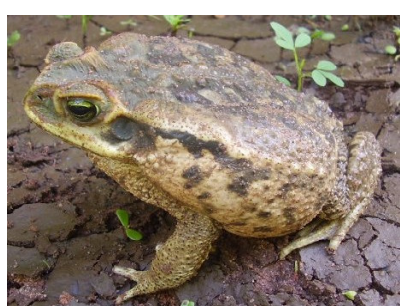

Rhinella schneideri

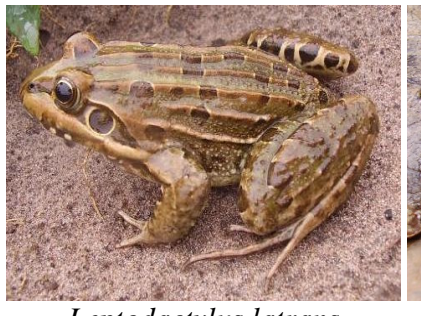

Leptodactylus latrans

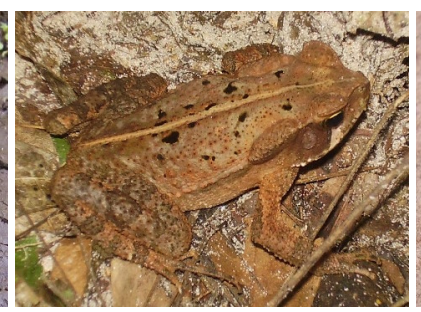

Rhinella ornata

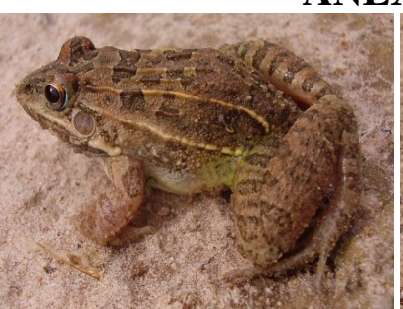

Leptodactylus fuscus

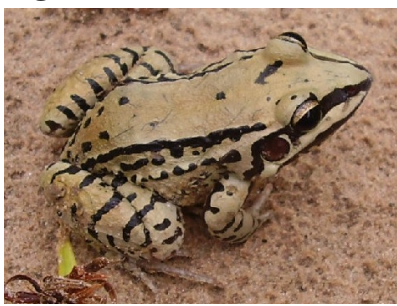

Leptodactylus mystacinus

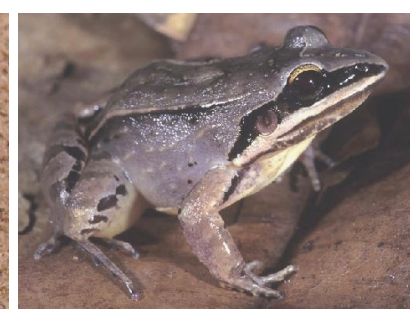

Leptodactylus mystaceus

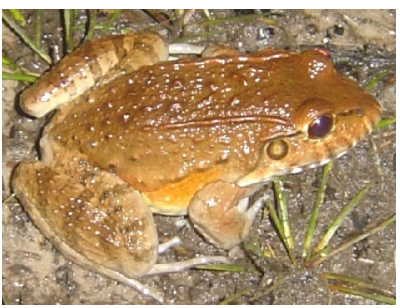

Leptodactylus labyrinthicus
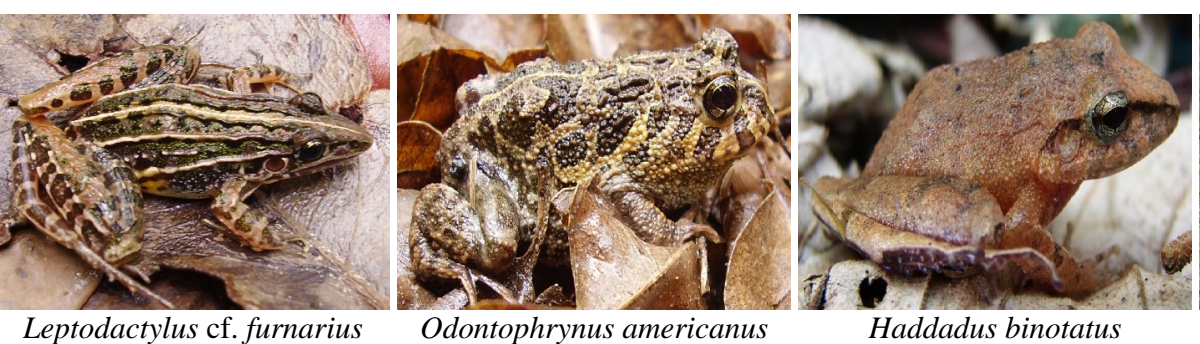

Haddadus binotatus

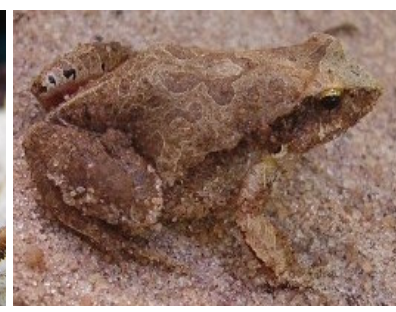

Physalaemus cuvieri

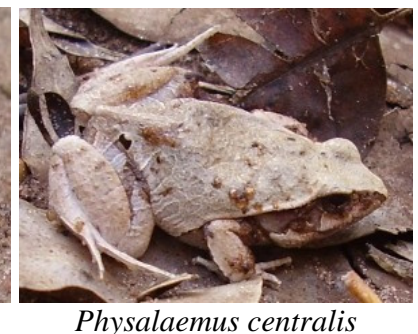

Physalaemus centralis

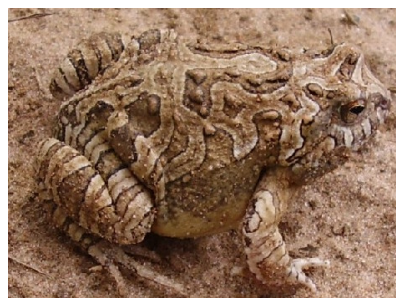

Physalaemus marmoratus

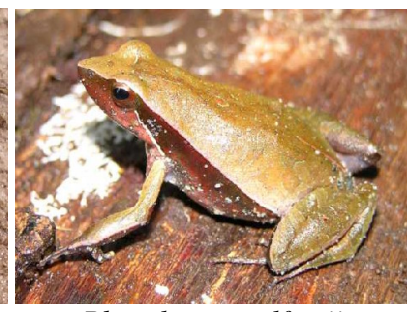

Physalaemus olfersi

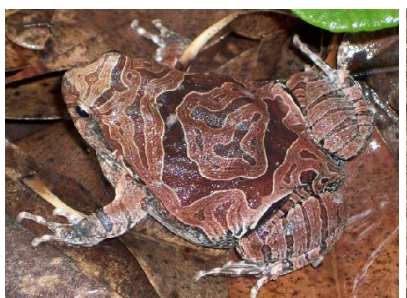

Eupemphix nattereri

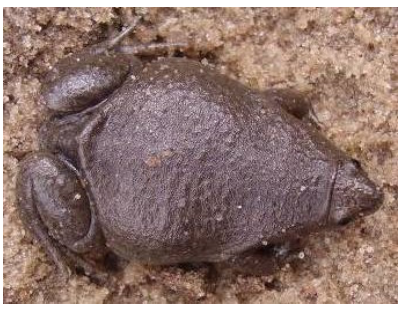

Elachistocleis cf. ovalis

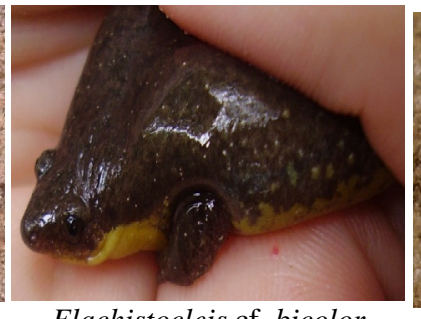

Elachistocleis cf. bicolor

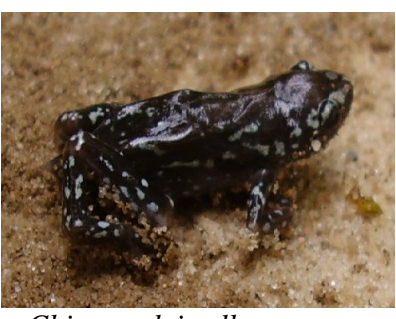

Chiasmocleis albopunctata

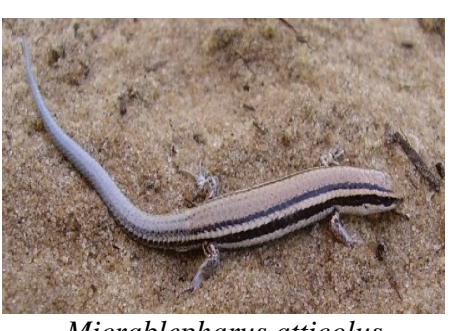

Micrablepharus atticolus

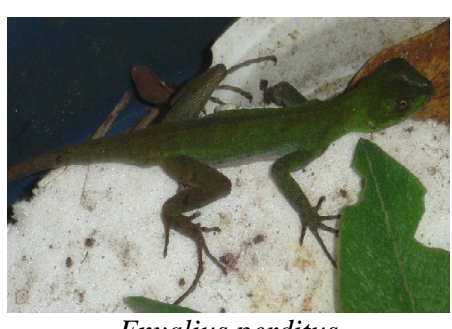

Enyalius perditus

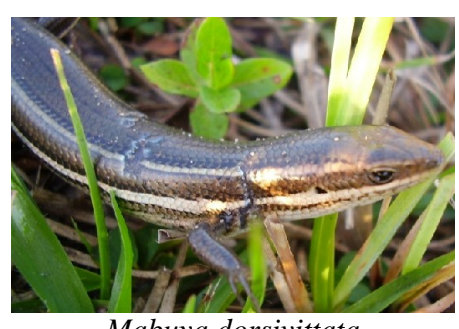

Mabuya dorsivittata

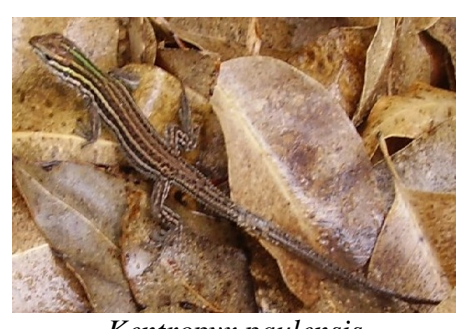

Kentropyx paulensis

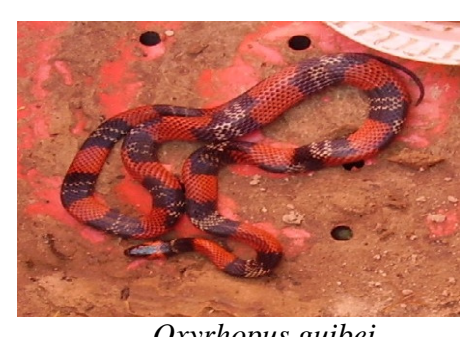

Oxyrhopus guibei

Figura 1 - Espécies de anfíbios e répteis encontradas nas armadilhas de interceptação e queda. Fotos da autora, exceto L. mystaceus (wwww. - 


\begin{abstract}
ANEXO B
Exemplares depositados:

\section{Coleção CFBH - UNESP, Rio Claro}

Anfíbios: Aplastodiscus perviridis: CFBH 23151; Chiasmocleis albopunctata: CFBH 23154; Dendropsophus jimi: CFBH 23164; Elachistocleis cf. bicolor: CFBH 23163; Elachistocleis cf. ovalis: CFBH 23136; Eupemphix nattereri: CFBH 23133, 23134; Haddadus binotatus: CFBH 23147, 23156; Hypsiboas albopunctatus: CFBH 23161; Leptodactylus fuscus: CFBH 23142, 23150; Leptodactylus labyrinthicus: CFBH 23157; Leptodactylus latrans: CFBH 23140, 23141, 23152; Leptodactylus mystaceus: CFBH 23146; Leptodactylus mystacinus: CFBH 23137; Odontophrinus americanus: CFBH 23143, 23155; Phyllomedusa tetraploidea: CFBH 23158; Physalaemus centralis CFBH 23118, 23138, 23149; Physalaemus cuvieri: CFBH 23119, 23120, 23121, 23122, 23123, 23124, 23126, 23127, 23128, 23129, 23130, 23135, 23148; Physalaemus marmoratus: CFBH 23131, 23132, 23139; Physalaemus olfersii: CFBH 23162; Pseudis platensis: CFBH 23159, 23160; Rhinella ornata: CFBH 23144, 23145; Scinax fuscovarius: CFBH 23125, 23153.
\end{abstract}

\title{
Museu de Zoologia da Universidade de São Paulo (MZUSP)
}

Répteis: Cercosaura schreibersii: MZUSP 99397, 99398; 99400; Cercosaura ocellata: MZUSP 99404, 99405; Enyalius perditus: MZUSP 99401; Kentropyx paulensis: MZUSP 99402, 99403; Micrablepharus atticolus: MZUSP 99399. 
This document was created with Win2PDF available at http://www.win2pdf.com.

The unregistered version of Win2PDF is for evaluation or non-commercial use only.

This page will not be added after purchasing Win2PDF. 